\title{
Eosen yaşlı Kışlaköy volkanitlerinin petrografisi, mineral kimyası ve kristallenme koşulları, Erzurum, KD Türkiye
}

\author{
Petrography, mineral chemistry and cristallization conditions of eocene aged Kışlaköy \\ volcanics, Erzurum, NE Turkey
}

\author{
Emre AYDINÇAKIR ${ }^{* 1, a}$, Hande GÜNGÖR ${ }^{1, b}$, Cem YÜCEL $^{2, \mathrm{c}}$, Özgür BİLİCi் ${ }^{3, \mathrm{~d}}$, Emel ABDİOĞLU \\ YAZAR ${ }^{4, e}$ \\ ${ }^{1}$ Gümüşhane Üniversitesi, Mühendislik ve Doğa Bilimleri Fakültesi, Jeoloji Mühendisliği Bölümü, 29100, Gümüşhane \\ ${ }^{2}$ Gümüşhane Üniversitesi, Mühendislik ve Doğa Bilimleri Fakültesi, Maden Mühendisliği Bölümü, 29100, Gümüşhane \\ ${ }^{3}$ Atatürk Üniversitesi, Mühendislik Fakültesi, İnşaat Mühendisliği Bölümü, 25030, Erzurum \\ ${ }^{4}$ Karadeniz Teknik Üniversitesi, Mühendislik Fakültesi, Jeoloji Mühendisliği Bölümü, 61080, Trabzon
}

• Geliş tarihi / Received: 26.03.2021 • Düzeltilerek geliş tarihi / Received in revised form: 20.05.2021 • Kabul tarihi / Accepted: 03.06.2021

\section{Öz}

Bu çalışmada Eosen yaşlı Kışlaköy (Narman/Erzurum) volkanik kayaçlarının minerolojik, petrografik ve mineral kimyası analizleri incelenmiştir. Elde edilen veriler doğrultusunda magmaların kristallenme esnasında etkili olan sıcaklık, basınç gibi fizikokimyasal özellikleri ile fizikokimyasal verileri jeolojik verilerle birleştirerek bu kayaçları oluşturan magmaların kabuktaki gelişimleri irdelenmiştir. Çalışma alanındaki başlıca birimler Eosen yaşlı Kışlaköy Volkaniti, Oligo-Miyosen yaşlı Oltu Formasyonu, Oligo-Miyosen yaşlı Alabalık Formasyonu ve Alüvyonlardan oluşmaktadır. Kışlaköy volkanik kayaçları volkanik fasiyes özelliklerine göre piroklastitler, dayklar ve lavlar olmak üzere üç başlıkta incelenmiş, genellikle bazalt bileşiminde ve başlıca plajiyoklaz ( $\mathrm{An}_{49-85}$ ), klinopiroksen ( $\left.\mathrm{Wo}_{40-46} \mathrm{En}_{41-50} \mathrm{Fs}_{5-18}\right)$, olivin $\left(\mathrm{Fo}_{68-75}\right)$ ve $\mathrm{Fe}$-Ti oksit minerallerden oluşmaktadır. Bu kayaçlar genel olarak hyalo-mikrolitik porfirik, glomeroporfirik, glomerofirik, mikrolitik porfirik, poikilitik, intersertal doku sergilemektedirler. İncelenen volkanitler; plajiyoklaz fenokirstallerinde halkalı zonlanma, elek dokusu ve kemirilme; klinopiroksenlerdeki yenme, kemirilme ve kalıntı merkezler gibi dengesizlik dokuları gözlenmiştir. Termobarometre hesaplamalara göre volkaniklerin kristallenme sıcaklığı $489-1247{ }^{\circ} \mathrm{C}$ arasında, basınç 0.5-4.7 kbar arasında değişmekte olup, bütün bu verilere bakılarak incelenen volkanik kayaçların orta-sı̆ kıtasal kabuk $(\sim 4-12 \mathrm{~km})$ içerisinde yerleştiği söylenebilir.

Anahtar kelimeler: Jeotermobarometre, Kışlaköy volkaniti, Mineral kimyası, Narman, Petrografi

\begin{abstract}
This study was examined minerological, petrographic and mineral chemistry analyzes of Eocene aged Klşlaköy volcanic rocks (Narman / Erzurum). The data obtained suggest that the physicochemical properties of the magmas such as temperature, pressure, which are effective during crystallization, and physicochemical data were combined with geological data, and the development of the magmas forming these rocks in the crust was examined. The main units in the study area are Eocene aged Klşlaköy Volcanite, Oligo-Miocene aged Oltu Formation, Oligo-Miocene Trout Formation and Alluviums. Klşlaköy volcanic rocks have been examined under three headings as pyroclastics, dykes and lavas according to their volcanic facies characteristics, have compositionally basalt and mainly consist of plagioclase (An49-85), clinopyroxene (Wo40-46 En ${ }_{41-50} \mathrm{Fs}_{5-18}$ ), olivine (Fo68-75) and Fe-Ti oxide. These minerals generally exhibit hyalomicrolytic porphyritic, glomera porphyritic, cumulative porphyritic, microlitic porphyritic, poikilitic, intersertal textures. The studied volcanics rocks, disequilibrium texture are observed such as oscillatory zoning, sieve texture and corrosion in plagioclase phenocrysts, zoning, resorbed cores and mantles, rounded crytals, and embayed rims in clinopyroxenes. According to thermobarometric calculations, volcanics have crystallization temperature and pressure values ranging from 489 to $1247{ }^{\circ} \mathrm{C}, 0.5$ to $4.7 \mathrm{kbar}$ respectively. It can be concluded that the studied volcanics were emplaced at mid to shallow crustal depths $(\sim 4-12 \mathrm{~km})$.
\end{abstract}

Keywords: Geothermobarometry, Kışlaköy volcanite, Mineral chemistry, Narman, Petrography

\footnotetext{
${ }^{*}$ a Emre AYDINÇAKIR; aydincakir61@gmail.com, Tel: (0462) 233 10 00, orcid.org/0000-0001-8704-8485

${ }^{b}$ orcid.org/0000-0003-4531-2019 $\quad{ }^{c}$ orcid.org/0000-0001-7220-9397 $\quad{ }^{\mathrm{c}}$ orcid.org/0000-0002-8810-9662

${ }^{\mathrm{c}}$ orcid.org/0000-0001-5196-8060
} 


\section{Giriş}

Alpin-Himalaya orojenik kuşağında yer alan Doğu Pontidler (KD Türkiye), volkanik ve plütonik kayaçların yaygın olarak gözlendiği önemli alanlardan biridir. Doğu Pontidler, Jura, Kretase ve Eosen olmak üzere başlıca üç farklı zaman periyodunda gelişen volkanik kayaçlar tarafından temsil edilmektedir (Arslan vd., 1997; Şen, 2007; Aydın vd., 2008; Kaygusuz vd., 2011; Arslan vd., 2013; Aydınçakır ve Şen, 2013; Yücel vd., 2017; Dokuz vd., 2019; Aydın vd., 2020; Aydınçakır vd., 2020). Çalışma alanın da içerisinde yer aldığı Doğu Pontid Orojenik Kuşağı (KD Türkiye), Türkiye'nin jeolojik olarak şekillenmesinde önemli bir rol oynayan Alp-Himalaya orojenezinin etkisi ile oluşmuş olup farklı türde magmatik kayaçları içermesi bakımından önemli bir alan konumundadır. Karadeniz havzasının güneydoğu kıyısı boyunca yaklaşık $500 \mathrm{~km}$ uzunluğunda ve $100 \mathrm{~km}$ genişliğinde bir orojenik kuşağ 1 meydana getiren bu bölge, Geç Mesozoyik sırasında kuzeye yiten okyanusal litosfer üzerinde gelişmiş ve iyi korunmuş bir ada yayı olarak bilinmektedir (Şengör ve Y1lmaz, 1981).

Çalışma alanı ve çevresinde yapılan önceki çalışmalarda detay genel jeoloji, tüm kayaç jeokimyası ile sınırlı sayıda izotopik çalışmalar yapılmıştır (Bayrakturan, 1994; Keskin, 1994; Keskin vd., 1998; Konak, 2001). Ancak, volkanik kayaçların mineraloji ve mineral kimyası kullanarak irdeleyen çalışmalar jeotermobarometrik hesaplamalar magmatik kayaç oluşturan ergiyiğin jeokimyasal özellikleri ile evrimleşme süreç ve koşulları, kayacı oluşturan mineral toplulukları ve minerallerin kimyasal içerikleri ile yakından ilgilidir (Abbott, 1985).

Bu çalışmada, Doğu Anadolu Bölgesinde yer alan Kışlaköy (Narman-Erzurum) çevresinde yüzeyleme veren ve önceki çalışmalarda yaşı Eosen kabul edilen Kışlaköy volkanik kayaçların mineralojik, petrografik ve mineral kimyası analizleri incelenmiştir. Bu çalışma ile Kışlaköy (Narman) yöresinde gözlenen volkanik kayaçların detaylı petrografisi ve mineral kimyası analizleri sonuçlarına göre, volkanik kayaçları oluşturan magmanın kristallenme koşulları, bölgesel jeoloji ile beraber yorumlanarak kayaçları oluşturan magmaların kabuktaki gelişim süreçlerinin araştırılması amaçlanmıştır. Çalışma alanı 1/25.000 ölçekli Erzurum-H47-b3 H48-a4 pafta sınırları içerisinde bulunmaktadır. Bunun yanında volkanitlerin yerleşim koşullarına yönelik bir çalışmanın yapılmaması bu çalışmanın önceki çalışmalardan en önemli farkıdır.

\section{Bölgesel jeoloji}

Doğu Anadolu Bölgesi, çarpışmayla ilişkili volkanizmanın dünyada en iyi görüldüğü alanlardan biri olması ve bölgenin kuzeydoğusunda yer alan Erzurum-Kars platosu çarpışma kökenli volkanik aktivitenin yaygın gözlendiği alan olması nedeniyle birçok araştırmacının dikkatini çekmiştir.

Bölgede genel jeoloji, tektonik ve volkanizma konularında pek çok çalışma yapılmıştır (Lambert vd., 1974; Innocenti vd., 1976, 1982; Gülen, 1980a, b; Şengör, 1980; Şaroğlu ve Güner, 1981; Y1lmaz vd., 1987; Pearce vd., 1990; Ercan vd., 1990; Keskin, 1994, 2003, 2007; Keskin vd., 1998, 2006, 2008; Şengör vd. 2003; Özdemir vd., 2006, 2011, 2014; Oyan vd., 2016). Anadolu ve Arap levhaları arasında meydana gelen çarpışma Kuzey ve Doğu Anadolu Fayları ile Anadolu bloğunun yanal olarak magmatizma üretmesine sebep olmuştur. Çarpışma sonucu oluşan volkanizma ürünleri bazalttan riyolite kadar farklı bileşimde kayaçların oluşumuna imkân sağlamıştır. Bununla birlikte bu çarpışma sonucunda doğu ve güneydoğu Türkiye de kalk-alkali ve alkali volkanizma gelişmiştir (Şengör ve Yılmaz, 1981; Innocenti vd., 1982; Dewey vd., 1986; Pearce vd., 1990; Buket ve Temel, 1998; Güleç, 1991; Keskin vd., 1998, 2006; Karsl1 vd., 2008; Kürüm vd., 2008; Kaygusuz, 2009; Keskin vd., 2006; 2012; Aydınçakır ve Şen, 2013; Sipahi ve Sadıklar, 2014; Sipahi vd., 2014; Özdemir ve Güleç, 2014; Lebedev vd., 2016a, 2016b; Yücel vd., 2017; Kaygusuz vd., 2018). Bölgedeki volkanikler üzerine yapılan çalışmalarda (Ercan vd., 1990; Pearce vd., 1990; Keskin, 1994, 2007; Notsu vd., 1995; Keskin vd., 2006; Lustrino vd., 2012; Lebedev vd., 2013; Özdemir ve Güleç, 2014) yaygın volkanizmanın Anadolu ve Arap levhaları arasında meydana gelen bir çarpışma ile oluştuğu düşünülmektedir (Şengör vd., 2003) (Şekil 1A). Doğu Anadolu Platosu coğrafik olarak, Orta Anadolu ile Orta İran arasında yerleşmiş ve kuzey de Doğu Pontid Yayı ve güneyde de Arap Platformu arasinda uzanmaktadır. Doğu Anadolu da yer alan bölge, dört ana tektonik bloğa ayrılmıştır (Şengör vd., 2003) (Şekil 1B). (1) Doğu Pontid yay magmatik kayaçları ve onlarla ilişkili sedimanter kayaçlar tarafindan temsil edilen Pontid temel kayaçları (Okay ve Şahintürk, 1997; Aydın vd., 2008; Kaygusuz ve Aydınçakır, 2009, 2011; Aslan, 2010; Dilek vd., 2010; Arslan vd., 2013; Aydınçakır ve Şen, 2013; Aslan vd., 2014; Aydınçakır, 2014; Şengör ve Yılmaz, 1981; Aydınçakır, 2016; Yücel vd., 2017; Sipahi vd. 2018; Kaygusuz vd., 2021); (2) Doğu Anadolu Yığışım Karmaşığı (Üst Kretase 
yada daha genç yaşlı ofiyolitik melanj ve filişik kayaçlar, Şengör vd., 2003), (3) Anadolu temeli (yüksek-orta dereceli kabuksal metamorfik kayaçlar, Şengör vd., 2003), (4) Doğu Anadolu yığışım kompleksi ve Anadolu temeline ait olan Neojen yaşlı sedimanter ve volkanik kayaçlar (Şekil 1A, B). Arap ve Anadolu kıtaları arasındaki çarpışmanın yaşı hakkında hala bir görüşbirliği yoktur. Çarpışma, bölgede yoğun sisimik aktiviteye, doğrultu atımlı faylara (Doğu ve Kuzey Doğu Anadolu Fay Zonları) ve yaygın bir volkanizmaya sebep olmuştur (Özdemir ve Güleç, 2014). Çarpışmanın yaşı, Geç Kretase den (Hall, 1976), Geç Eosen-Oligosen (35-25 My; Jolivet ve Faccenna, 2000; Agard vd., 2005; Allen ve Armstrong, 2008), ve Miyosen'e kadardır (Şengör vd., 2008; Dewey vd., 1986; Y1lmaz, 1993; Robertson vd., 2007). Son zamanlarda, Okay vd. (2010), Bitlis-Zagros Sütür Zonu'ndaki Eosen yaşlı kumtaşları ve metamorfik kayaçlardan yapılan apatit fusion track yaşlarına dayanarak
Arap ve Avrupa plakalarının arasındaki son okyanusal litosferin Erken Miyosende ( 20 My) tükendiğini savunmuşlardır. Doğu Anadolu Platosu, Geç Kretase - Erken Tersiyer döneminde birçok mikro-kıtaların birbirine eklenmesi sonucu oluşmuştur (Şengör, 1990). Bu mikro-kıtalar ofiyolit kuşakları ve yı̆̆ışım karmaşık komplekleri tarafından ayırılabilirler. Temel kayaçlar, Geç Senozoyik çarpışma ile ilişkili volkanik kayaçlar ve Oligosen-Miyosen yaşlı sığ denizel sedimanlar tarafından uyumsuz olarak örtülmektedirler. Çarpışma sonrası volkanizma ürünleri, kuzeyde Erzurum-Kars Platosu, güneyde ise Arap kıtasina büyük kalkan volkanları (Tendürek, Karacadağ) ve strato-volkanlar (Ağrı, Nemrut, Süphan, Etrüks) şeklinde yayılır (Yılmaz vd., 1987, 1998; Pearce vd., 1990; Notsu vd., 1995; Keskin vd., 1998; Keskin, 2003, 2007; Karaoğlu vd., 2005; Özdemir vd., 2006, 2011; Özdemir ve Güleç, 2014; Oyan vd., 2016; Lustrino vd., 2012; Lebedev vd., 2016a,b).

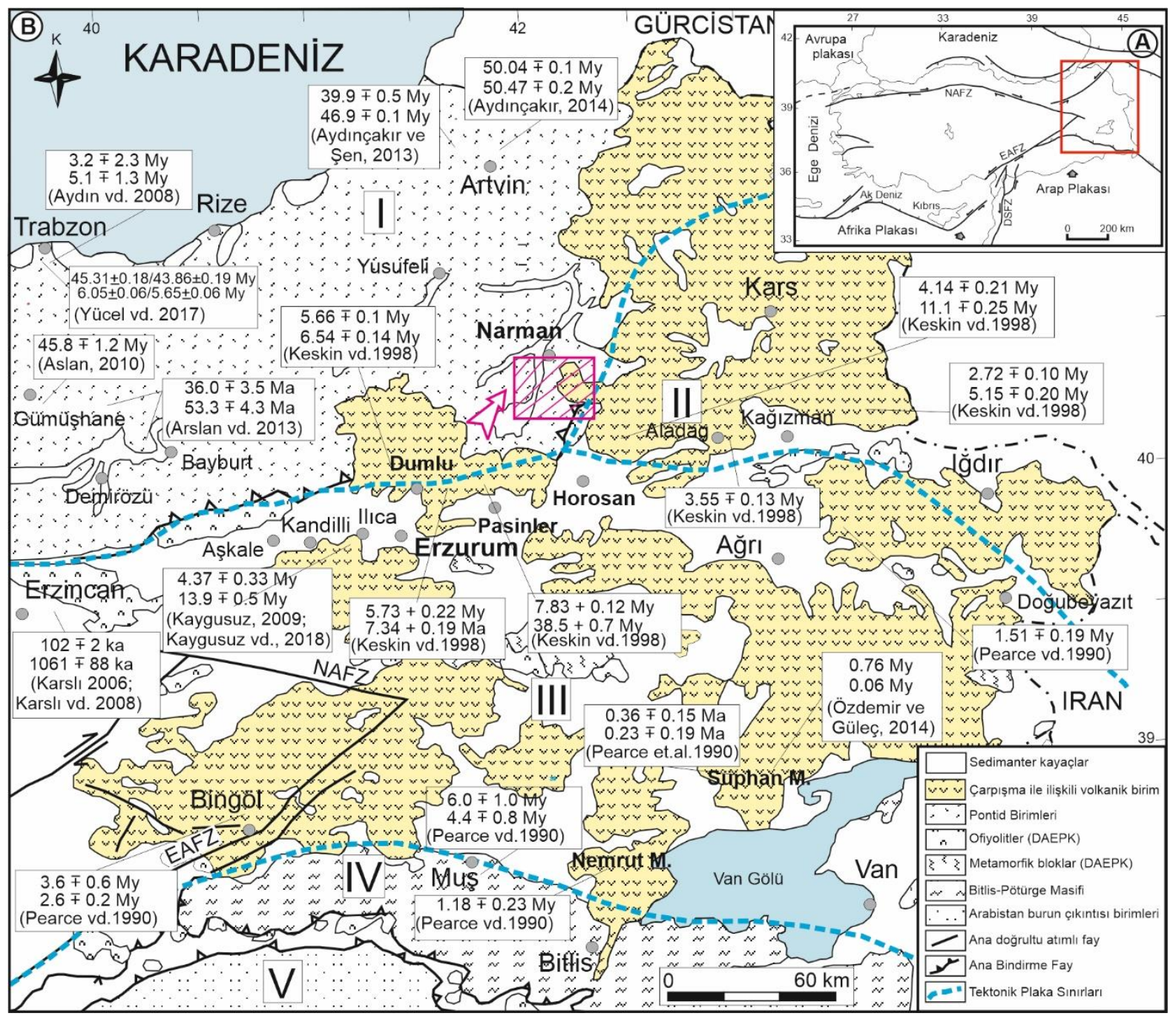

Şekil 1. A) Türkiye ve çevresinin tektonik haritası (Şengör vd. 2003), B) Doğu Anadolu Bölgesinde çarpışma ile ilişkili volkanik kayaçların ayrımı. I: Rodop-Pontid parçası, II: Kuzeybatı İran parçası, III: Doğu Anadolu Yığıısım Karmaşığı, IV: Bitlis-Pötürge Masifi, V: Arabistan burnu. 
$\mathrm{Bu}$ çalışma ile Eosen yaşlı Kışlaköy Volkanitlerinin ilk defa detaylı petrografik ve mineral kimyası verileri irdelenerek; 1) magma (lar)ın kristallenme sirasında etkili olan sicaklık ve basınç gibi fizikokimyasal özellikleri, 2) fizikokimyasal verileri jeolojik veriler ile birleştirerek bu kayaçları oluşturan magma (lar) in kabuktaki gelişimlerinin irdelenmesi amaçlanmıştır.

\section{Materyal ve yöntem}

Arazi çalışması Erzurum İli, Narman İlçesi, Kışlaköy ve civarındaki Kilimli, Serinsu ve Pınaryolu köylerini kapsamaktadır. Saha çalışmaları sırasında, inceleme alanındaki çalışma konusunu oluşturan volkanik kayaçlardan ve bu kayaçlarla ilişkili olan çevre kayaçlar dan GPS aleti kullanılarak tam lokasyon ile sistematik kayaç örnekleri alınmış ve önemli görülen yüzlekler fotoğraflanarak belgelenmiştir. Yapılan tüm bu arazi çalışmalardan elde edilen veriler 1şığında bölgenin 1/25000 ölçekli jeoloji haritası hazırlanmıştır (Şekil 2). Çalışma alanından alınan volkanik kayaç örneklerinin mineralojik ve petrografik özelliklerinin tespit edilmesi için ince kesitleri hazırlanmıştır. İnceleme için kayaçlardan alınan $0.5 \times 2 \times 4 \mathrm{~cm}$ boyutunda plakaciklar, bir yüzeylerinin pürüzlülüğü giderildikten sonra $1 \mathrm{~mm}$ kalınlığındaki $2.5 \times 5 \mathrm{~cm}$ boyundaki cam üzerine kanada balzamı kullanılarak yapıştırılmıştır. Cam üzerine yapışmış olan kayaç, aşındırıcılar yardımıyla $0,025 \mathrm{~mm}$ kalınlığına kadar inceltilerek petrografik incelemek için hazır hale getirilmiştir. İnce kesit örnekleri Gümüşhane Üniversitesi Mühendislik ve Doğa Bilimleri Fakültesi Jeoloji Mühendisliği Bölümü ince kesit laboratuvarında yapılmıştır.

Kışlaköy volkanik kayaçlarına ait olan 4 adet kayaç örneğinin mineral kimyası analizleri plajiyoklaz, klinopiroksen, olivin ve opak minerallerden yapılmıştır. Mikroprob analizleri, Universite de Bretagne Occidentale (Brest, Fransa) Geoscience Marines (IFREMER) Elektron Mikroprob Laboratuvarı'nda yapılmıştır. Karbon kaplı parlak kesitler üzerindeki mineral kimyası çalışmaları, CAMECA-SX-100 WDS marka bir elektron mikroprob aleti ile gerçekleştirilmiştir. Aletin çalışma şartları $15 \mathrm{kV}$ voltaj ve $20 \mathrm{nA}$ 'dır. Analizler $10 \mu \mathrm{m}$ 'lik bir 1şın çapında yapılmış ve Si, $\mathrm{Al}, \mathrm{Ti}, \mathrm{Fe}, \mathrm{Mn}, \mathrm{Mg}, \mathrm{Ca}, \mathrm{Na}$ ve $\mathrm{K}$ elementleri için sayılma zamanı 10 sn olarak belirlenmiş̧ir. 1 $\mu \mathrm{m}$ 'lik bir nokta ışını piroksen, hornblend ve Fe-Ti oksit analizleri için kullanılmıştır. Feldispat ve mika analizlerinde sodyum buharlaşması nedeniyle oluşacak kayıpları önlemek için çok hafif defokuslamış $\left(\begin{array}{lll}10 & \mu \mathrm{m}) & \text { 1şın kullanılmıştır. }\end{array}\right.$ Analizlerdeki doğal mineral standartları forsterit, diyopsit, ortoklas, albit, anortit, biyotit, apatit, vollastonit ve magnetittir. Analitik hata ana elementler için \%1'den ve iz elementler için ise 200 ppm den daha azdır.

Volkanik kayaçlara ait 4 adet örneğin ana ve iz element analizleri ACME analitik laboratuvarında (Kanada) yapılmıştır. Ana oksit ve iz elementler ICP, nadir toprak elementler ise ICP-MS ile analiz yöntemi ile incelenmiş olup, toz örneklerden $0.2 \mathrm{~g}$ alınarak $1.5 \mathrm{~g} \mathrm{LiBO}_{2}$ ile karıştırılmış, $\% 5 \mathrm{HNO}_{3}$ içeren bir sıvı içinde çözündürülmüştür. Toz örneklerden $0.250 \mathrm{~g}$ dört farklı asit içinde çözündürülmüş ve ppm olarak nadir toprak element analizleri gerçekleştirilmiştir. Ana elementler \% ağırlık, iz elementler ppm olarak ölçülmüş olup veriler uygun bir şekilde düzenlenmiştir.

\section{Bulgular}

\subsection{Stratigrafi}

Doğu Anadolu Bölgesinde, Kışlaköy (Narman, Erzurum) yöresinde yer alan çalışma sahasındaki birimlerin temelini bazalt, andezit ve piroklastitlerden oluşan Eosen yaşlı Kışlaköy Volkanitleri (Konak vd., 2001) oluşturur (Şekil 2). Bu birim, Oligo-Miyosen yaşlı beyaz renkli jips ve kireçtaşı ara katmanları ile kömür damarları içeren, sarı-kırmızı-yeşil renkli, çakııttaşı, kumtaşı ve çamurtaşlarından oluşan Oltu Formasyonu (Konak vd., 2001) tarafindan uyumsuz olarak üzerlenmektedir. Oltu Formasyonu üzerine uyumlu olarak yine aynı yaşlı lav, aglomera, sarı-yeşil renkli tüf ve epiklastik seviyelerden oluşan Alabalık Formasyonu (Konak vd., 2001) gelmektedir (Şekil 2). Kuvaterner yaşlı alüvyonlar en genç birimdir.

İlk kez Konak vd. (2001) tarafindan tanımlanan Kışlaköy Volkanitinin inceleme alanı başlıca, Narman ilçesinin doğusunda Kışlaköy ve çevresinde, Pınaryolu köyünün batısında, Mahmutçavuş köyü ile Haşut dağının doğusunda ve Güvenlik köyünün güneyinde, Kilimli ve Taşburun köylerini de kapsayan bir alanda yüzeyleme vermektedir (Şekil 2). Keskin vd., (1998) tarafından birimin yaşının K/Ar yöntemi ile Eosen $(38.5 \pm 0.7 \mathrm{My})$ olarak verilmiştir. 


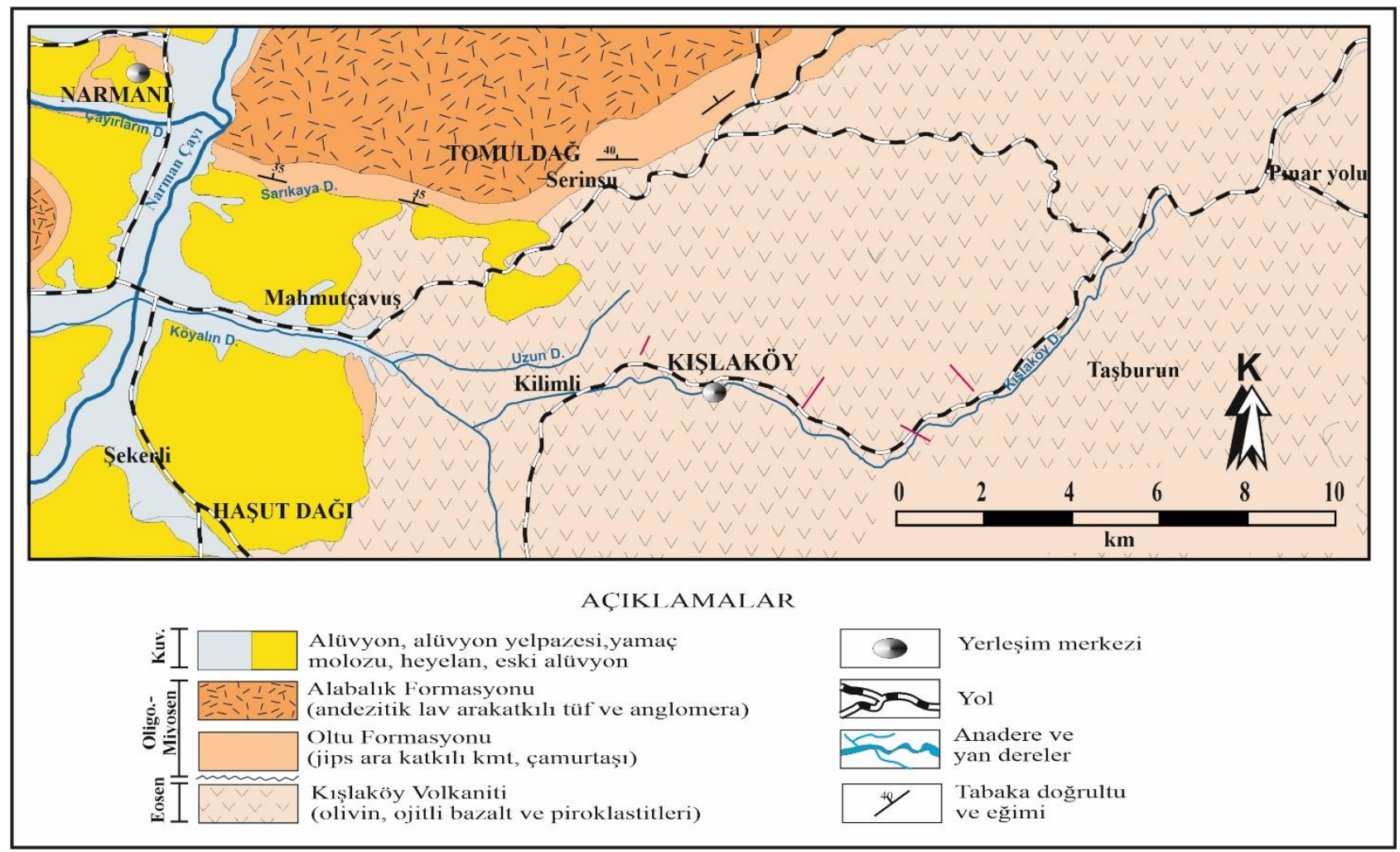

Şekil 2. Çalışma alanının jeoloji haritası.

\subsection{Petrografi}

Kışlaköy Volkaniti olarak tanımlanan birim içerisinde yüzeyleme veren volkanik kayaçlar volkanik fasiyes özelliklerine göre, 1) Piroklastitler, 2) Bazaltik Dayklar ve 3) Bazaltlar olmak üzere üç başlıkta incelenmiştir.

\subsubsection{Piroklastitler}

Piroklastik kayaçların büyük çoğunluğu piroklastik breş olmakla beraber yer yer küçük lokasyonlarda aglomeralar da gözlenmektedir. Çapları, $2 \mathrm{~cm}$ 'den blok boyutuna kadar değişen köşeli kayaç parçalarından oluşmaktadır. Kayaç içerisindeki breş çakıllarının bağlayıcısı genelde tüf olup, breş çakıllarının oranı yaklaşık olarak \% 70'e kadar ulaşmaktadır (Şekil 3a, b). Taze kırık yüzeyi koyu gri-siyah renktedir. Bol miktarda mafik mineral fenokristalleri içermektedirler.

Bazaltik Volkanik Breşler; genellikle hyalomikrolitik porfirik, glomeroporfirik doku göstermektedirler. Petrografik bileşimi pl + kpir + ol + opak mineral şeklindedir (Şekil 3c, d). Plajiyoklazlar, genellikle özşekilli fenokristaller halinde ve hamurda mikro taneler halinde görülür. Tek nikolde renksiz, polarizan rengi gri olup albit ikizi sunmaktadır. Merkez kısımlarda süngerimsi doku gelişmiştir. Nadiren zonlanma gösterirler (Şekil 3c, d). Klinopiroksenler, öz ve yarı öz şeklli fenokristaller halinde görülürler. Tek nikolde renksiz ya da çok açık yeşil, çapraz nikolde II. sıranın canlı renklerinde ve zonlanmalar görülür. Genellikle opak ve olivin kapanımları içerirler. Bazıları ise kırıkları ve kenarları boyunca kloritleşme gösterirler (Şekil 3c, d). Olivinler genellikle iddingsitleşmiş olivine olarak hamurda ve klinoproksenler içerisinde kapanım olarak bulunurlar (Şekil 3c). Opak mineraller, genellikle hamurda mikro taneler halinde ve klinopiroksenler içerisinde kapanımlar halinde göze çarpmaktadırlar. İkincil mineral olarak ise ferromagnezyen minerallerden itibaren kloritleşme göze çarpmaktadır.

\subsubsection{Bazaltik dayklar}

Çalışma alanında hemem hemen her yerde yüzeyleme veren bazaltik dayklar, bazalt ve piroklastları kesmiştir (Şekil 4a). Daykların çoğu taze bir görünüme sahip olup, ayrışma yüzeyleri genelde açık kahve-bej, taze kırık yüzeyleri ise koyu gri- siyah renktedir. Dayklar özellikle masif yap1 sunarlar ve doğrultuları genellikle KD-GB olarak belirlenmiştir. Daykların genişlikleri 30 cm'den 2-3 m'ye kadar değişmektedir (Şekil 4b). 

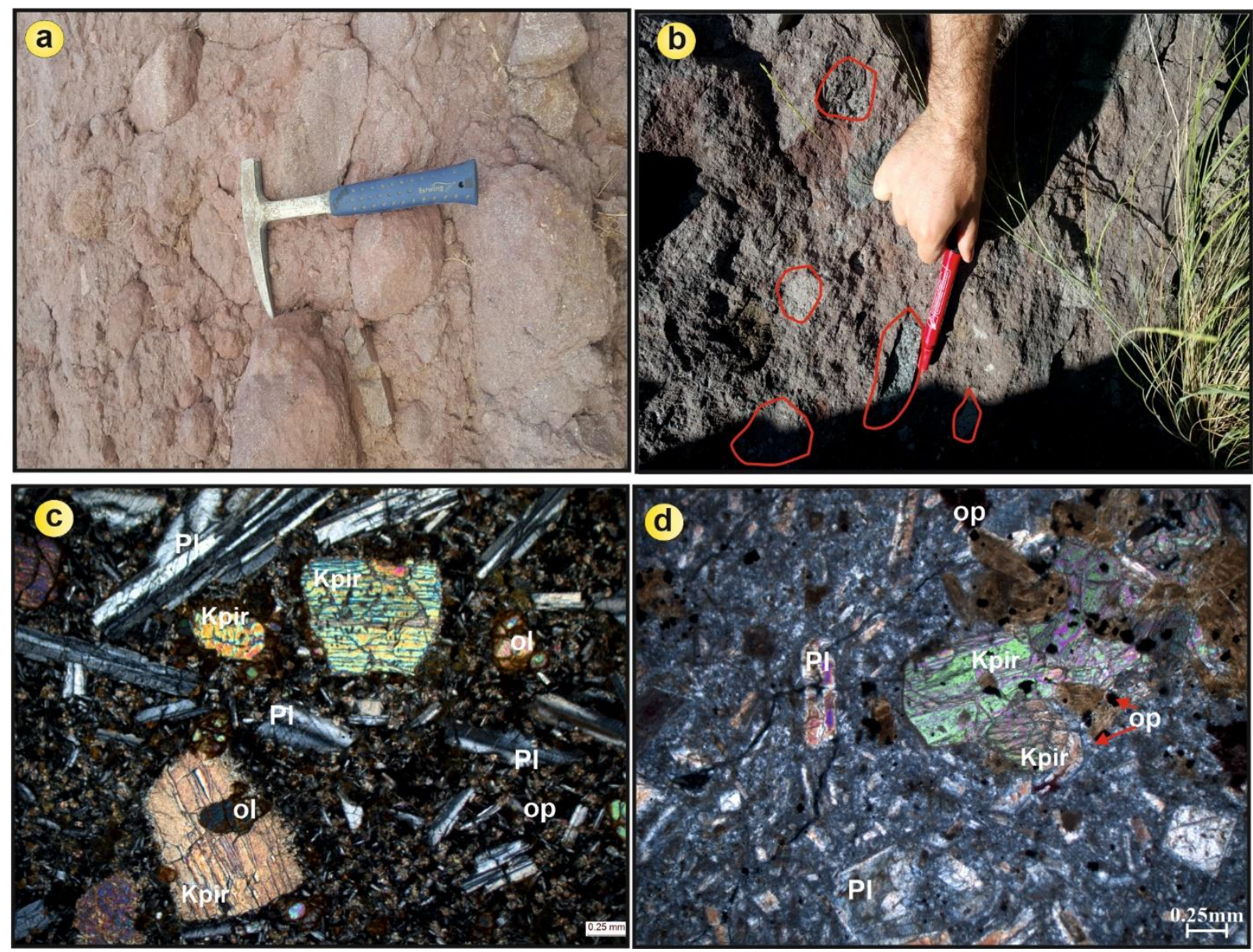

Şekil 3. (a, b) Kışlaköy Volkaniti içerisinde yer alan volkanik breşlerin görünümü (Kilimli köyü civarı), (c ve d) Bazaltik bileşimli volkanik breş çakıllarının mikroskobik görünümü. (Örnek No: N-22) (Ç.N.; Kpir: Klinopiroksen, Pl: Plajiyoklaz, ol: olivin, op: Opak mineral).

Bazaltik daykları oluşturan kayaçların petrografik bileşimleri, kpir + ol + plj + opak mineral şeklindedir. Bunlar genellikle mikrolitik porfirik, poikilitik, intersertal ve yer yer glomerofirik (Şekil $4 \mathrm{c}-\mathrm{f}) \quad$ dokular sergilerler. Klinopiroksenler genellikle özşekilli den özşekilsize kadar değişir. Genelde mega ve fenokristaller halinde gözlenen klinopiroksenler, hamurda ise öz şekilsiz mikro taneler halinde bulunur. $\mathrm{Bu}$ kristaller hamur tarafindan yenme, elek dokusu, kalıntı merkezler gösterirken çoğunlukla opak ve olivin kapanımları içerirler (Şekil 4c-f). Olivinler, genellikle özşekilli ve yarı özşekilli olarak bulunur. Tek nikolde renksiz, çapraz nikolde II. ve III. serinin canlı renklerindedirler (Şekil 4c). Kısmen ve tamamen kırık ve kenarları boyunca iddingisitleşmişlerdir (Şekil 4f). Bazen klinopiroksenler içerisinde kapanım olarak gözlemlenen olivinler bazen de klinopiroksenlerle beraber kümülofrik dokuyu oluştururlar (Şekil 4f). Plajiyoklazlar, genellikle özşeklili fenokristaller ve mikro fenokristaller halinde bulunur. Tipik olarak albit ikizi gösterirler. Yer yer kırılmalar gözlemlenir. Bazı mikro fenokristallerde hafif zonlanmalar göze çarpar (Şekil 4e, f). Opak mineraller, genellikle yarı özşekilli ve özşekilsiz kristaller halinde ferromagnezyen minerallerin çevresinde, klinopiroksenler içerisinde kapanım olarak ve hamurda mikro taneler halinde yer alırlar (Şekil 4). İkincil mineraller, genellikle boşluk dolgusu şeklinde gelişen zeolit mineralleri ve ferromagnezyen minerallerden itibaren gelişen kloritlerdir.

\subsubsection{Bazaltlar}

Kışlaköy Volkanitlerini oluşturan kayaçlar arasında yayılımı en geniş olan birimdir. Özellikle Narman ile Kışlaköy civarında masif yapılı bazaltlardan oluşmaktadır (Şekil 5a). Çalışma alanında özellikle tortul bir istif olan Oltu Formasyonu üzerine gelen arazide oldukça sarp kısımları temsil eder. Masif yapılı bazaltlar makroskobik olarak porfirik dokulu olup, iri ojit ve plajiyoklaz fenokristalleri rahatlikla tanınabilmektedir (Şekil 5b). Bol gaz boşlukludur ve bu boşluklar karbonat ve silis ile dolmuştur. Bazaltlar, genellikle siyah-mor renkli ve kalın bazalt düzeylerinden oluşmaktadır. 

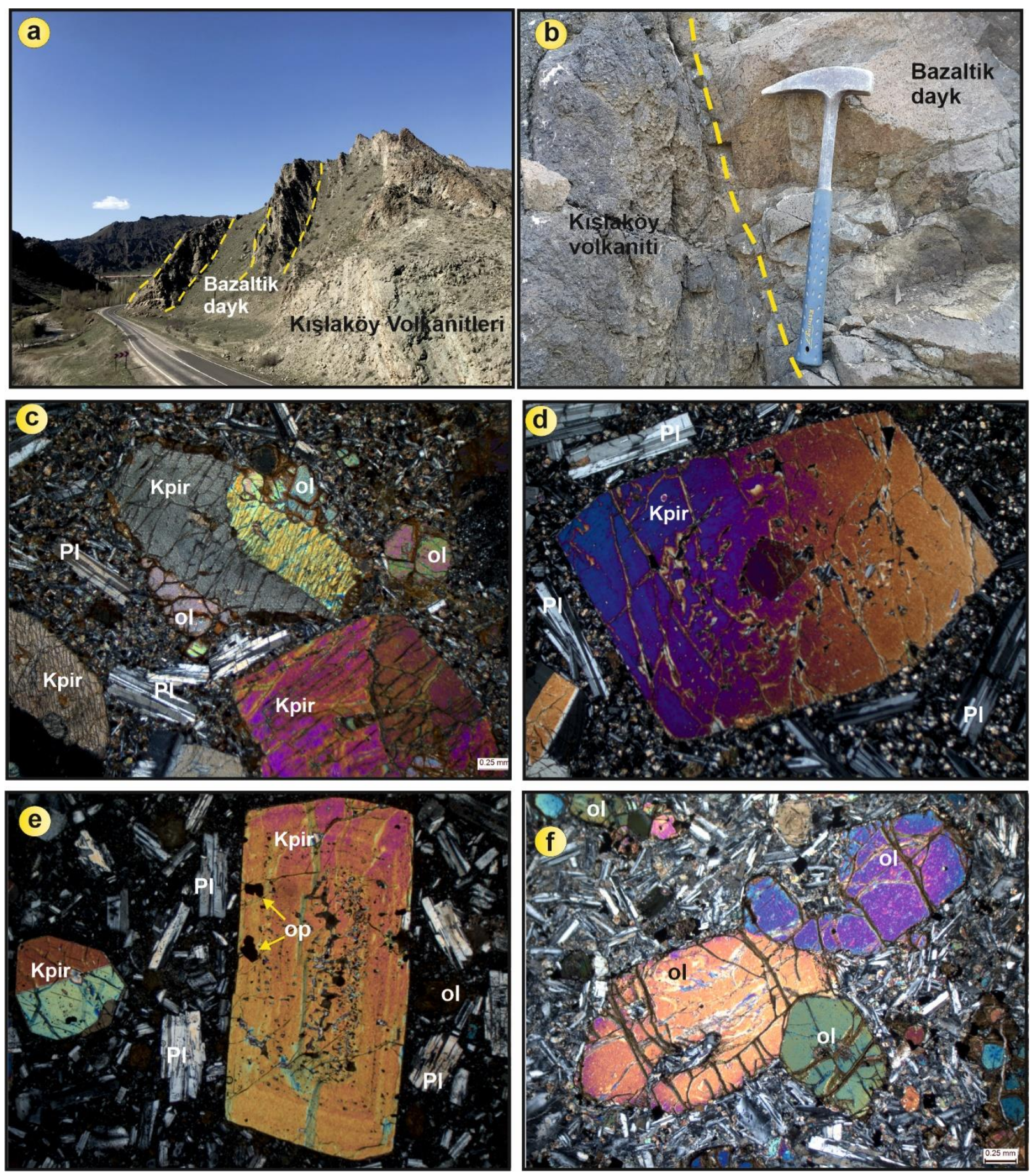

Şekil 4. Bazaltik daykların arazi görünümleri, a, b) Kilimli mevkiinde Kışlaköy volkanitini KD-GB istikametinde kesen bazaltik dayklar (Örnek No: N-5), (c,d) bazaltik dayklar içerisindeki kenarları yenmiş, kalıntı merkez içeren klinopiroksen ve öz şekilsiz olivin mineralleri (ÇN), e) zonlanma ve elek dokusu gösteren klinopiroksen minerali (ÇN), f) öz şekilli olivin fenokristalleri ve glomerofirik doku (ÇN), (Örnek No: N-5, N-8 ve N-33; kpir: klinopiroksen, ol: olivin, pl: plajiyoklaz, op: opak mineral).

Bazaltları oluşturan kayaçların petrografik bileşimleri, kpir + plj + ol + opak mineral şeklindedir. Bunlar genellikle mikrolitik porfirik, hyalo- mikrolitik porfirik, elek dokusu ve glomerofirik (Şekil 5c-f) dokular sergilerler. Klinopiroksen mineralleri çoğunlukla megakristal ve fenokristal olarak gözlenmektedir (Şekil 5d-f). Hamurda ise mikrolitler halinde bulunmaktadırlar. Klinopiroksenler özşekilli ve yarı özşekillidir ve dik iki yönlü dilinim sistemine sahiptir. Tek nikolde açık yeşil; çapraz nikolde mavi, sarı, kırmızı renkte gözlenirler. Sönme açıları $35^{\circ}-39^{\circ}$ arasında değişmektedir. Bol olarak plajiyoklaz, opak mineral ve olivin kapanımları içermektedir. Klinopiroksenlerde zonlanma yaygin olarak görülmektedir. (Şekil 5e). Ayrıca, bazı klinopiroksenler hamur tarafindan yenmiş ve kaba elek dokusu gösterirler (Şekil 5d). Çoğu 
klinopiroksen ve opak mineralin bir araya gelmesiyle glomerofirik doku oluşturdukları gözlenmiştir. Klinopiroksenler, bol çatlaklı ve kırıklı olup, kırıkları boyunca kalsitleşmişlerdir. Alterasyona uğramış olanlarında kloritleşme gözlenmektedir. Plajiyoklazlar, hem yarı özşekilli fenokristal hemde hamurda mikro-fenokristaller olarak gözlenmektedirler (Şekil 5c, d). Genellikle albit ikizlenmesi gösterirler. Süngerimsi doku ve hamur tarafından yenmeler oldukça yaygındır.
Süngerimsi doku içerisindeki boşluklar cam tarafindan doldurulmuştur. Bazı kristallerde hem ikizlenme hem de zonlanma görülürken bazı kristallerin en dış kısımlarında yeniden büyüme zarfı bulunmaktadır. Olivinler, genellikle özşekilli olup ve fenokristaller halinde bulunurlar (Şekil 5d, f). Tek nikolde renksiz, çapraz nikolde II. ve III. sıranın canlı renklerindedirler. Karakteristik olarak içerdikleri kırıklar ve kenarlar boyunca iddingsitleşmeler yaygın olarak gözlenir.
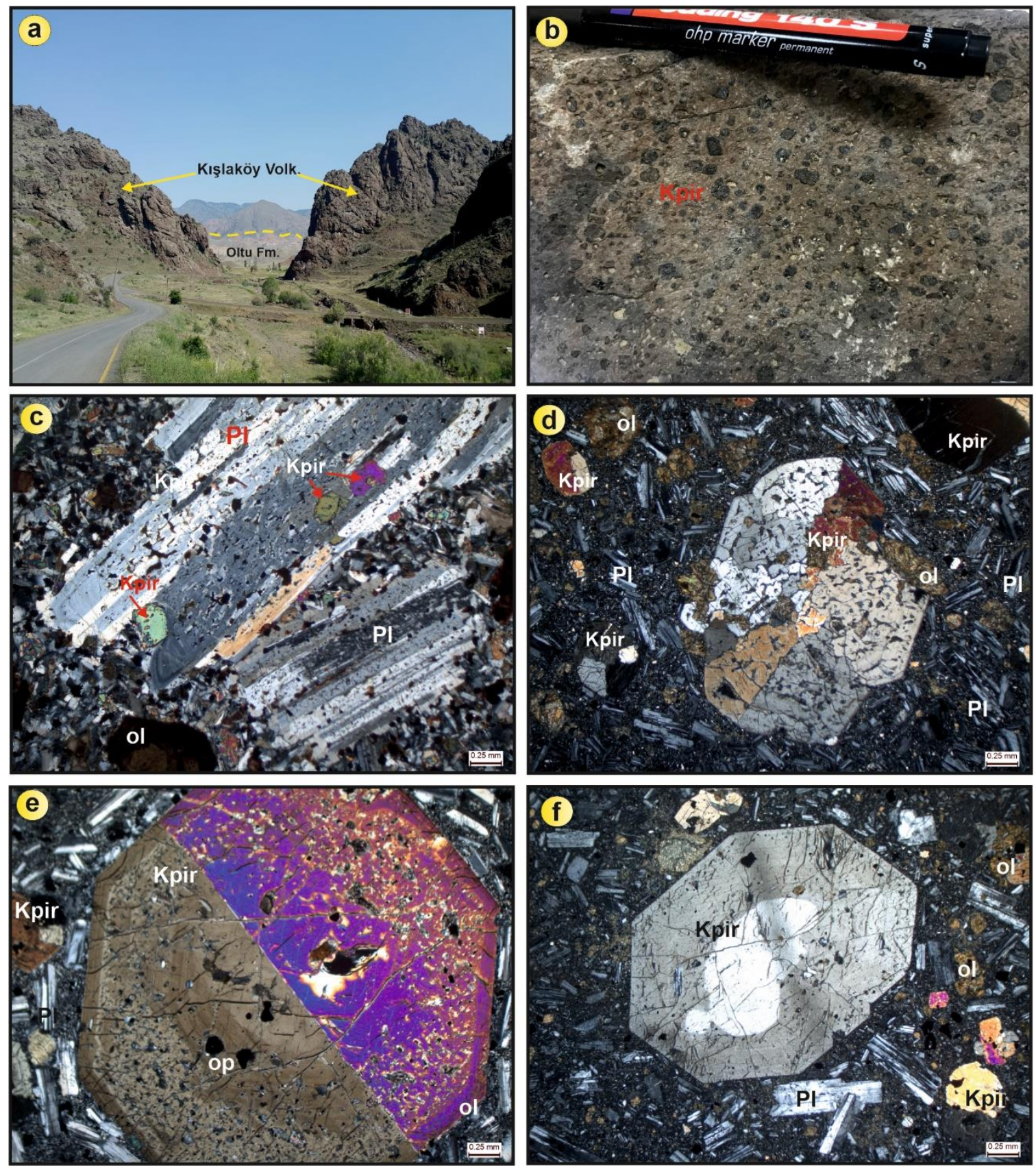

Şekil 5. a) Bazaltların yayılımı ve volkanitlerin arazi görünümü, b) iri klinopiroksenlerin makroskopik görünümü (Kışlaköy, Pınaryolu mevkii), c) klinopiroksen kapanımları içeren albit ikizli plajiyoklaz fenokristalleri ve elek dokusu (Örnek No: N-53), d) mikrolitik porfirik dokulu kayaçlardaki elek dokusu gösteren klinopiroksen fenokristali (Örnek No: N-50), e) öz şekilli ve zonlanma gösteren mega klinopiroksen minerali (Örnek No: N-21), f) kenarında elek dokusu gelişmiş ve kalıntı merkez içeren klinopiroksen fenokristali ve iddingsitleşmiş olivin mineralleri (Örnek No: N-50), (Kpir: klinopiroksen, ol: olivin, pl: plajiyoklaz, op: opak mineral). 


\subsection{Mineral kimyası}

Kışlaköy Volkanitleri'ni oluşturan bazalt ve bazaltik dayklara ait ana mineraller klinopiroksen, plajiyoklaz, olivin ve Fe-Ti oksit mineralleridir. Bu minerallerin, genel mineralojik ve kimyasal özellikleri bu bölümde özetlenmiştir.

\subsubsection{Klinopiroksen}

Klinopiroksen mineralleri inceleme alanında yüzeyleyen volkanik kayaç türlerinden bazaltik lav ve bazaltik dayk örneklerinde mevcuttur. Çoğunlukla öz ve yarı öz şekilli olan bu mineraller iri, orta ve küçük boyutlu kristaller halinde bulunurlar. Bazik kayaçlarda iri kristalli ve öz şekilli klinopiroksenler genellikle zonlanma ve yer yer de elek dokusu gösterirler.

Klinopiroksen mineralleri salınımlı zonlanma, normal ve ters zonlanma göstermektedirler (Şekil $6 a, b)$. Bu zonlanma tiplerini hem optiksel hem de kimyasal olarak görmek mümkündür. Salınımlı zonlanmada her zonun kalınlığg genellikle farklıdır (Şekil 6a, b). Klinopiroksenlerin yapısal formülleri 6 oksijene göre hesaplanmıştır (Ek Tablo 1). Kimyasal analizlerden elde edilen toplam demirin, $\mathrm{Fe}^{+2}$ ve $\mathrm{Fe}^{+3}$ ayrımı Droop (1987)'a göre yapılmıştır.

Bazaltlar ve bazaltik dayk örnekleri içerisindeki klinopiroksenlerin kimyasal bileşimleri Ek Tablo 1 'de verilmiştir. Bazaltlara ait örnekler Morimoto vd. (1988)'ne göre ojit olarak adlandırılmaktadır (Şekil 6c). Ojitler $\mathrm{Wo}_{40-45} \mathrm{En}_{41-50} \mathrm{Fs}_{9-18}$ bileşimindedir ve $\mathrm{Mg} /\left(\mathrm{Mg}+\mathrm{Fe}^{+2}\right)$ oran1 $0.70-0.84$ arasındadır. Normal zonlanma gösteren örneklerin merkezleri $\mathrm{Wo}_{40-45} \mathrm{En}_{42-50} \mathrm{Fs}_{9-16}$ bileşimli ojit iken, kenarları $\mathrm{Wo}_{40-44} \mathrm{En}_{41-44} \mathrm{Fs}_{15-18}$ bileşimli ojittir. $\mathrm{Mg} /\left(\mathrm{Mg}+\mathrm{Fe}^{+2}\right)$ oranlar1 merkezde 0.73 ile 0.84 arasinda iken, kenarda 0.70 ile 0.75 arasinda değişmektedir. Ters zonlanma gösteren örneklerde ise merkez bileşimi $\mathrm{Wo}_{41-44} \mathrm{En}_{41-43} \mathrm{Fs}_{14-16}$ ojit iken, kenar $\mathrm{Wo}_{42-44} \mathrm{En}_{42-44} \mathrm{Fs}_{13-15}$ bileşimi ojittir. $\mathrm{Mg} /\left(\mathrm{Mg}+\mathrm{Fe}^{+2}\right)$ oranları merkez kısımlar için 0.730.75 arasinda iken, kenar kisımlarda bu oran 0.740.78 arasında değişmektedir (Ek Tablo 1).

Bazaltik Dayklara ait örnekler içerisindeki klinopiroksenlerin kimyasal bileşimleri (Ek Tablo 1) Morimoto vd. (1988)'ne göre ojit bileşimindedir sadece iki örnek diyopsit olarak adlandırılmaktadır (Şekil 6d). Örneklerden 6 tanesinde ters zonlanma görülürken diğer örneklerde normal zonlanma mevcuttur. Klinopiroksen minerallerinden ojitler genel olarak $\mathrm{W}_{40-45} \mathrm{En}_{40-50} \mathrm{Fs}_{5-17}$ bileşimindedir ve $\mathrm{Mg} /\left(\mathrm{Mg}+\mathrm{Fe}^{+2}\right) \quad$ oranı $\quad 0.72-0.91$ arasındadır.
Diyopsitler $\mathrm{Wo}_{46} \mathrm{En}_{47} \mathrm{Fs}_{7}$ bileşiminde olup, $\mathrm{Mg} /\left(\mathrm{Mg}+\mathrm{Fe}^{+2}\right)$ oranı 0.87 arasındadır. Normal zonlanma gösteren örneklerin merkezleri $\mathrm{Wo}_{40}$ ${ }_{46} \mathrm{En}_{41-50} \mathrm{Fss}_{5-16}$ ojit bileşimindeyken, kenarları $\mathrm{Wo}_{41}$ ${ }_{45} \mathrm{En}_{40-47} \mathrm{Fss}_{8-17}$ ojit bileşimindedir. Örneklerin $\mathrm{Mg} /\left(\mathrm{Mg}+\mathrm{Fe}^{+2}\right)$ oranlar1 merkezde 0.73-0.91 arasında iken, kenar kısımlarda 0.72-0.86 arasında değişmektedir. Ters zonlanma gösteren örneklerde merkez bileşimi $\mathrm{Wo}_{41-43} \mathrm{En}_{41-44} \mathrm{Fs}_{14-16}$ ojit iken, kenar bileșimi $\mathrm{Wo}_{43-44} \mathrm{En}_{42-46} \mathrm{Fs}_{11-15}$ ojittir ve $\mathrm{Mg} /\left(\mathrm{Mg}+\mathrm{Fe}^{+2}\right)$ oran1 merkezde 0.73-0.76 iken, kenar da 0.74-0.81 dir (Ek Tablo 1).

\subsubsection{Plajiyoklaz}

Kışlaköy (Erzurum) volkanik kayaçlarını oluşturan kayaç türlerinin hepsinde plajiyoklaz mineraline sıkça rastlanmıştır. Plajiyoklaz mineralleri çoğunlukla ince-uzun ve öz şekilli kristalcikler halinde olup (Şekil 7a), 0,1-1 $\mathrm{mm}$ arasında değişmektedir. Plajiyoklaz mineralleri hem iri fenokristaller hem de mikrolitler şeklinde bütün kayaçlarda bulunmaktadır (Şekil 7b). Ayrıca örneklerde hem normal hem de ters zonlu plajiyoklazlar yaygındır. Kapanımlar şeklinde başka mineralllerin içinde fenokristal ve mikrolit olarak görülürler. Plajiyoklazlar ayrıca albit ikizlenmesi ve elek dokusu yaygındır.

Bazaltlar içeresinde fenokristal olarak bulunan plajiyoklazların analiz sonuçlarına göre zonlanma göstermeyenlerinin bileşimi genelde labradordur. Analiz edilen plajiyoklazların yedi tanesinde normal zonlanma gözlenmektedir. Mikrolitlerin bileşimi labradordur (Ek Tablo 2, Şekil 7c). Plajiyoklaz fenokristallerinden labrador olanların bileşimi merkezde $\mathrm{An}_{59} \mathrm{Ab}_{28} \mathrm{Or}_{2}$ ile $\mathrm{An}_{71} \mathrm{Ab}_{37} \mathrm{Or}_{4}$ arasinda kenarda $\mathrm{An}_{59} \mathrm{Ab}_{31} \mathrm{Or}_{2}$ ile $\mathrm{An}_{67} \mathrm{Ab}_{38} \mathrm{Or}_{3}$ arasında değişmektedir. Normal zonlanma gösteren plajiyoklaz fenokristalinin merkezlerinin bileşimli $\mathrm{An}_{64} \mathrm{Ab}_{28} \mathrm{Or}_{2}$ ile $\mathrm{An}_{71} \mathrm{Ab}_{34} \mathrm{Or}_{2}$ arasında ve kenarlar1 ise $\mathrm{An}_{59} \mathrm{Ab}_{33} \mathrm{Or}_{2}$ ile $\mathrm{An}_{65} \mathrm{Ab}_{38} \mathrm{Or}_{3}$ arasinda olduğu belirlenmiştir. Labrador bileşiminde olan mikrolitler ise $\mathrm{An}_{59} \mathrm{Ab}_{31} \mathrm{Or}_{2}$ ile $\mathrm{An}_{67} \mathrm{Ab}_{38} \mathrm{Or}_{3}$ arasındadır.

Bazaltik dayk içerisinde fenokristal olarak bulunan plajiyoklazların bileşimleri genellikle labrador ve bitovnittir (Ek Tablo 2, Şekil 7d). Analiz edilen plajiyoklaz minerallerinin bazılarında normal zonlanma görülmektedir. Normal zonlanma gösterenlerin merkez bileşimi çoğunlukla bitovnit, kenar bileşimi ise çoğunlukla labradordur. Üç örnek ters zonlanma göstermektedir. Analiz edilen mikrolitlerin bileşimi ise andezin, labrador ve bitovnittir (Şekil 7d). Labrador olanların bileşimi merkezde $\mathrm{An}_{69} \mathrm{Ab}_{26} \mathrm{Or}_{2}$ ile $\mathrm{An}_{72} \mathrm{Ab}_{29} \mathrm{Or}_{3}$ arasinda 
kenarda $\mathrm{An}_{55} \mathrm{Ab}_{23} \mathrm{Or}_{2}$ ile $\mathrm{An}_{72} \mathrm{Ab}_{41} \mathrm{Or}_{6}$ arasinda değişmektedir. Bitovnit olanların bileşimi ise merkezde $\mathrm{An}_{73} \mathrm{Ab}_{14} \mathrm{Or}_{1}$ ile $\mathrm{An}_{85} \mathrm{Ab}_{25} \mathrm{Or}_{2}$ arasinda kenarda $\mathrm{An}_{73} \mathrm{Ab}_{21} \mathrm{Or}_{1}$ ile $\mathrm{An}_{77} \mathrm{Ab}_{25} \mathrm{Or}_{2}$ arasinda değişmektedir Normal zonlanma gösteren plajiyoklaz fenokristalinin bitovnit olan merkezlerinin bileşimli $\mathrm{An}_{73} \mathrm{Ab}_{14} \mathrm{Or}_{1}$ ile
$\mathrm{An}_{85} \mathrm{Ab}_{25} \mathrm{Or}_{2}$ arasinda ve labrador olan kenarları ise $\mathrm{An}_{55} \mathrm{Ab}_{23} \mathrm{Or}_{2}$ ile $\mathrm{An}_{72} \mathrm{Ab}_{41} \mathrm{O}_{6}$ arasinda değişmektedir. Andezin olan mikrolitin bileşimi $\mathrm{An}_{49} \mathrm{Ab}_{45} \mathrm{Or}_{5}$, labrador mikrolitlerinin bileşimi $\mathrm{An}_{63} \mathrm{Ab}_{30} \mathrm{Or}_{2}$ ile $\mathrm{An}_{68} \mathrm{Ab}_{35} \mathrm{Or}_{3}$ arasinda ve bitovnit bileşiminde olanlar ise $\mathrm{An}_{74} \mathrm{Ab}_{24} \mathrm{Or}_{1}$ ile $\mathrm{An}_{75} \mathrm{Ab}_{24} \mathrm{Or}_{2}$ arasindadır.

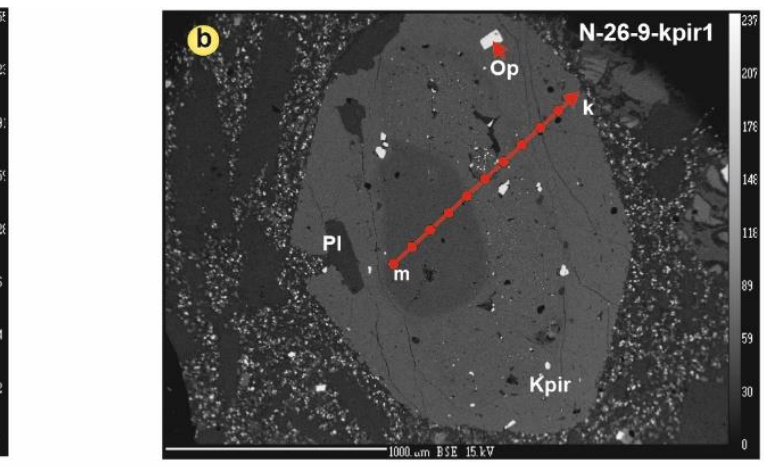

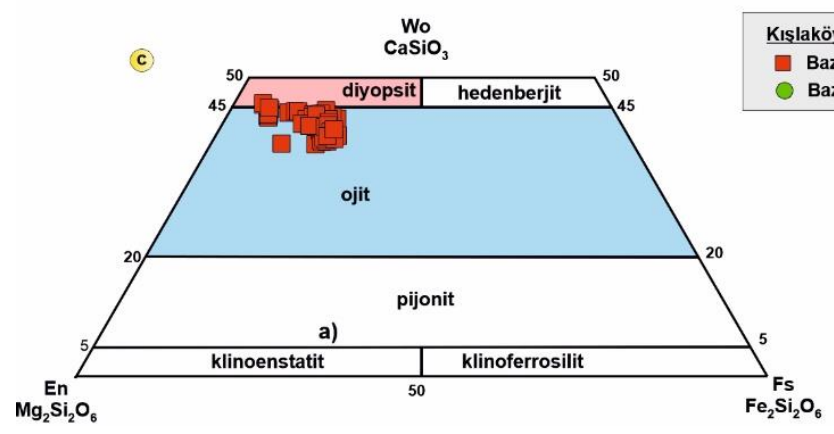

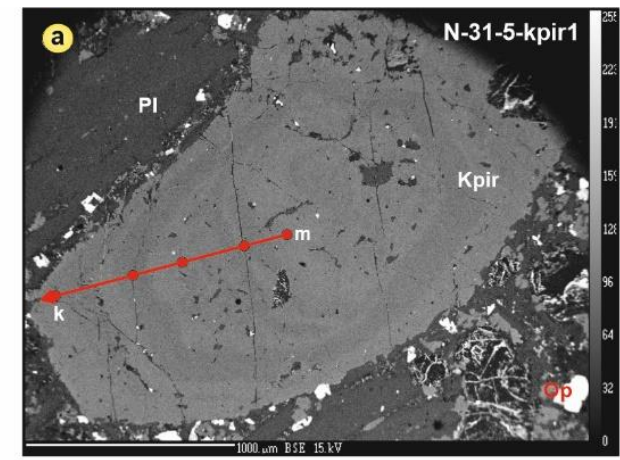

Şekil 6. Bazalt ve bazaltik dayk örneklerine ait a) normal zonlu klinopiroksen fenokristali, b) opak mineral ve plajiyoklaz minerali içeren kalıntı merkezli, salınımlı zonlanma gösteren iri klinopiroksen mineraline ait "BSE (Back-scattered electron)" görünümleri (Op: opak mineral, Kpir: Klinopiroksen, Pl: Plajiyoklaz, m: merkez, k: kenar, Örnek No: N-31 ve N-26), c, d) Bazaltik lav ve dayk örneklerine ait klinopiroksen minerallerinin, Wo-En-Fs üçgen diyagramıdaki (Morimoto vd., 1988) bileşimleri.

\subsubsection{Olivin}

Kışlaköy (Erzurum) volkanik kayaçlarını oluşturan kayaç türlerinden bazaltik lav, bazaltik volkanik breş ve bazaltik dayk örneklerinde rastlanmıştır. Bazaltik dayk ve bazaltik lav örneklerindeki olivin mineralleri özşekilli olup, fenokristaller halinde bulunurlar. Ayrica, hamurda mikro taneler halinde ve klinopiroksenler içerisinde kapanımlar halinde göze çarpmaktadırlar. Karakteristik olarak içerdikleri kırıklar ve kenarlar boyunca iddingsitleşmeler yaygın olarak gözlenir.
Bazaltik lav örnekleri içerisinde yer alan olivinler üzerinde yapılan elektron mikroprop analiz sonuçlarına göre olivinler hyalosiderit ve krizolit olarak isimlendirilmiştir. Hyalosideritlerin bileşimleri $\mathrm{Fo}_{58}$ 'dir. Krizolitlerin bileşimleri $\mathrm{Fo}_{69}$ ile $\mathrm{FO}_{75}$ arasındadır. (Ek Tablo 3). Bazaltik dayklar içerisinde yer alan olivinler üzerinde yapılan elektron mikroprob analiz sonuçlarına göre olivinlerin çoğunluğu krizolit bileşiminde olup, sadece iki örnek hyalosiderit olarak isimlendirilmiştir. Hyalosideritlerin bileşimleri $\mathrm{Fo}_{68}$ ile $\mathrm{FO}_{69}$ arasında değişim gösterirken, krizolitlerin bileşimleri $\mathrm{Fo}_{69}$ ile $\mathrm{Fo}_{86}$ arasındadır. (Ek Tablo 3). 

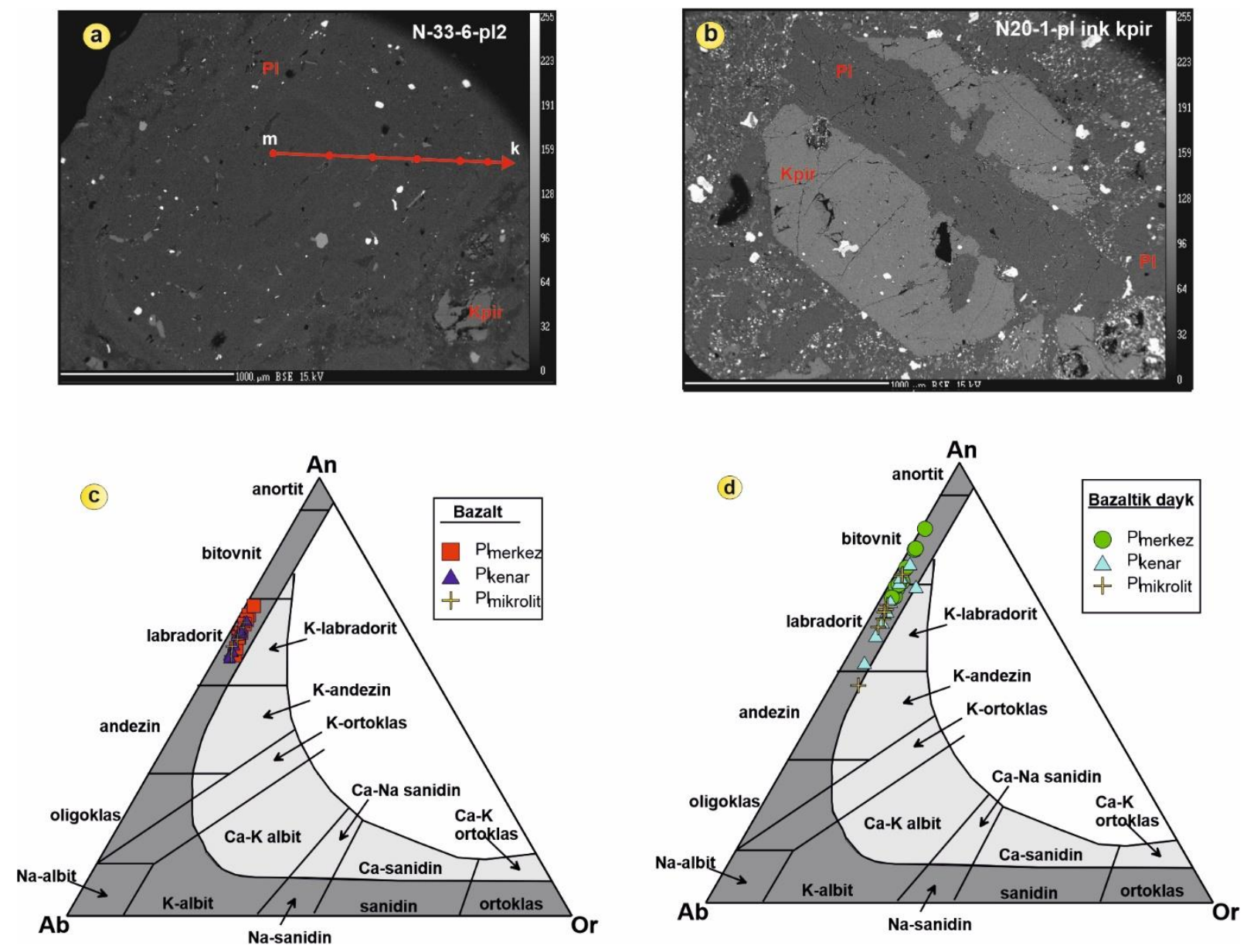

Şekil 7. İncelenen volkanitlerdeki bazı plajiyoklazların "BSE” görünümleri, a) bazaltik kayaçlardaki zonlu plajiyoklaz (Pl) kristalleri, b) klinopiroksen içerisinde yer alan zonlu plajiyoklaz minerali (Örnek no: N-33, N-20), c, d) Bazaltlara ve bazaltik dayklara ait plajiyoklazların Ab-An-Or üçgen diyagramı.

\subsubsection{Fe-Ti oksit}

$\mathrm{Fe}-\mathrm{Ti}$ oksit mineralleri inceleme alanında yüzeyleyen bazaltik lav ve bazaltik dayk örneklerinde mevcuttur. Volkanik kayaçlarda genellikle ortaç-küçük ve öz-yarı öz şekilli kristaller halinde bulunurlar. Dokusal olarak Fe-Ti oksit minerallerinin klinopiroksenlerle birlikte bulunması ve yer yer onların içinde özşekilli kapanımlar halinde görülmesi, göreceli olarak daha erken kristallenmeyi işaret eder (Şekil 8a,b). Fe-Ti oksit minerallerinin kimyasal analizlerinden yapısal parametreleri ve formülleri elde etmek için, 32 oksijene göre normalleştirilmiş katyonlardan itibaren hesaplamalar yapılmıştır (Ek Tablo 4).
Bazaltlarda gözlenen opak mineraller genel olarak magnetit ve titano-magnetit ve bir tanesi ilmenit bileşimindeyken (Şekil 8c), bazaltik daykları oluşturan bazaltlarda, magnetit ve titano-magnetit bileşimindedir (Ek Tablo 4, Şekil 8d).

\subsection{Kimyasal sinıflandirma}

Le Maitre vd. (1989)'nin $\mathrm{SiO}_{2}$ 'ye karş1 $\mathrm{Na}_{2} \mathrm{O}+\mathrm{K}_{2} \mathrm{O}$ (TAS) diyagramina göre bazaltik lav ve bazaltik dayk örneklerinin hepsi bazalt alanına düşmektedir (Şekil 9). Ayrıca, yine bu diyagram üzerinde Irvine ve Baragar (1971)'in alkali-yarıalkali ayrımına göre incelenen volkanik kayaçlardan 1 tane bazaltik dayk örneği alkali alana düşerken diğer bütün örnekler yarıalkali alanda yer almaktadır. (Tablo 1). 

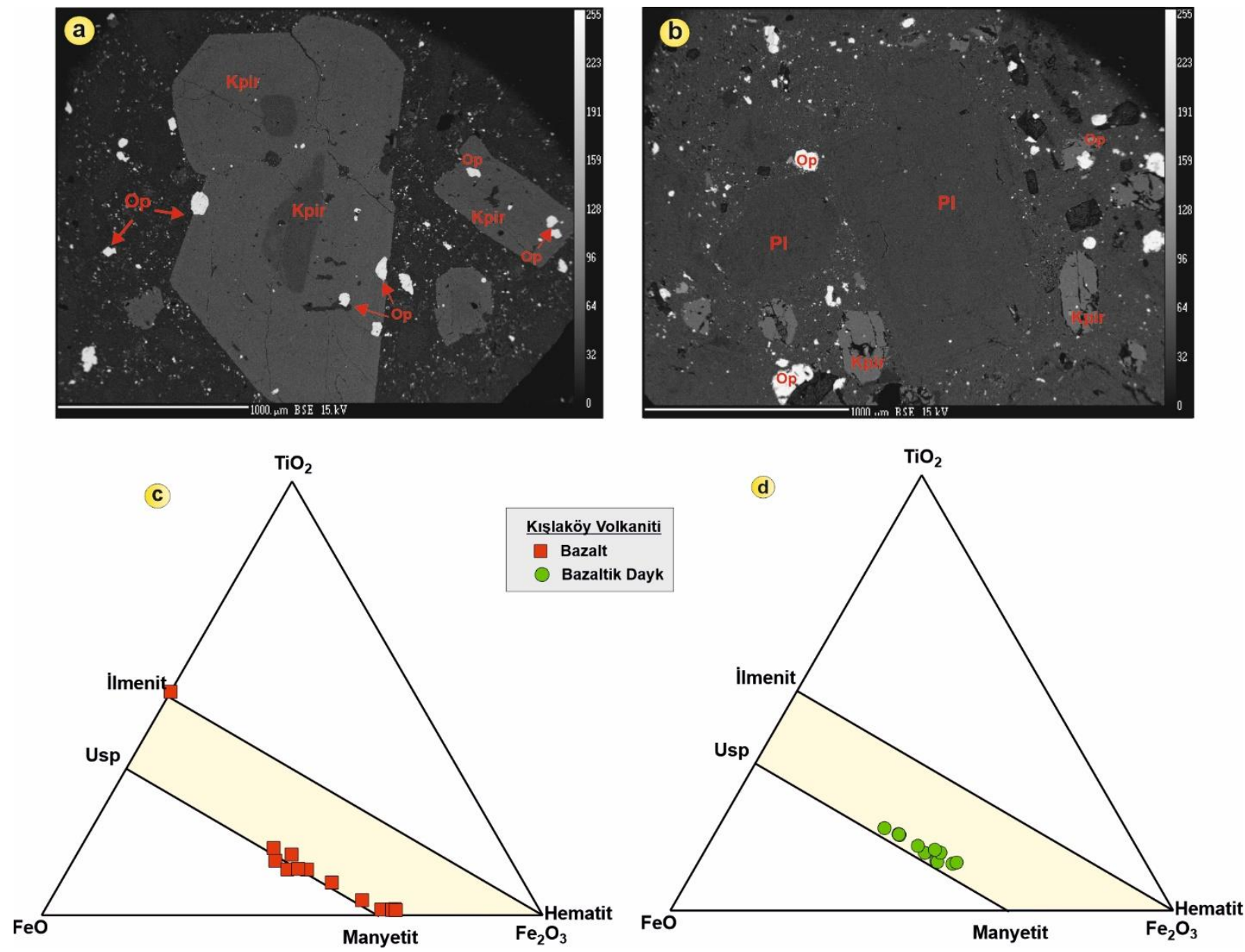

Şekil 8. İncelenen volkanitlerdeki bazı Fe-Ti oksitlerin "BSE" görünümleri, a ve b) Bazaltlardaki klinopiroksenlerde kapanım halinde olan öz-yarı öz şekilli Fe-Ti oksitler (Op), Klinopiroksen (Kpir), (Örnek no: N-5, N-20), c, d) Bazaltlara ve bazaltik dayk örneklerine ait Fe-Ti oksit bileşimini gösteren üçgen diyagram (Bacon ve Hirschmann, 1988).

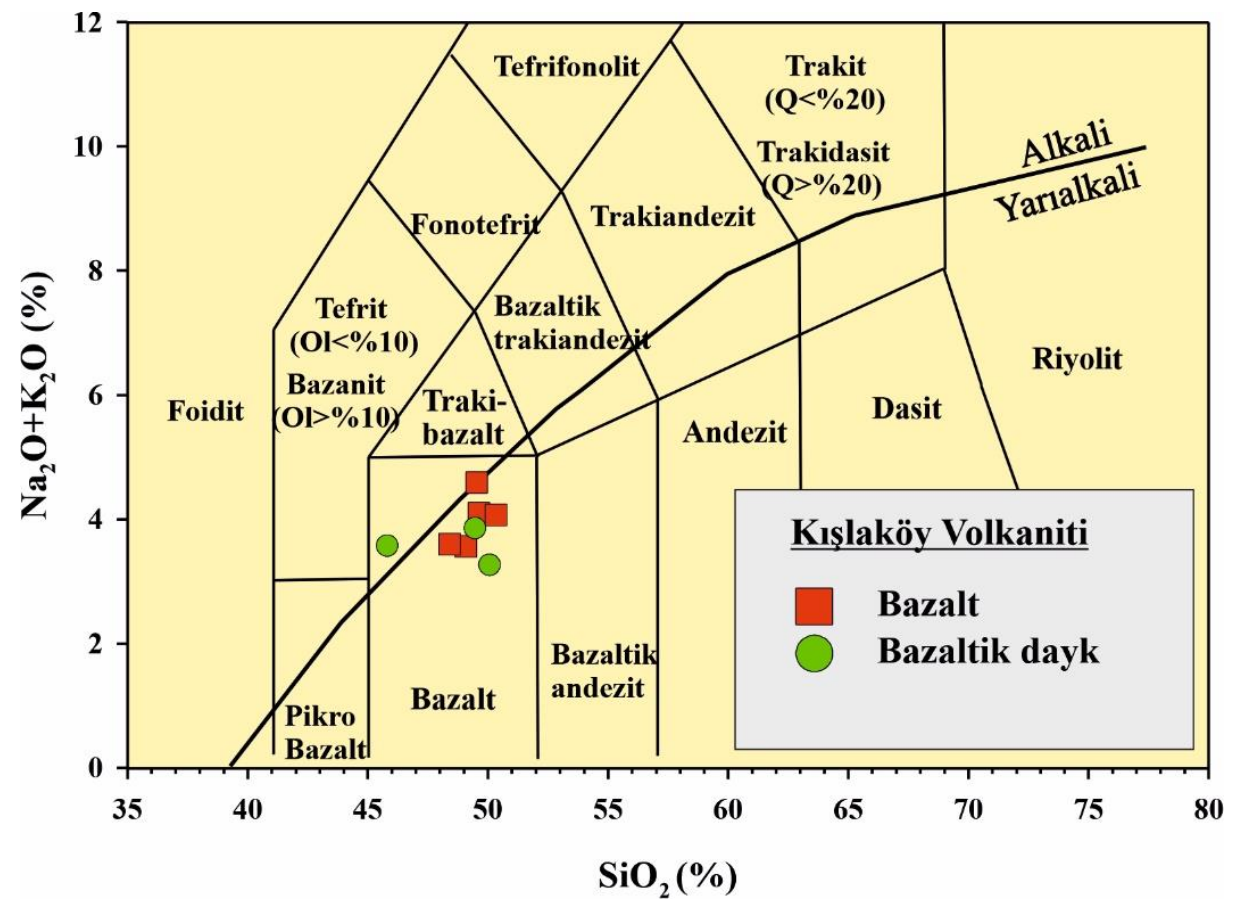

Şekil 9. Kışlaköy volkanik kayaçlarının $\mathrm{SiO}_{2}$ 'ye karşı $\mathrm{Na}_{2} \mathrm{O}+\mathrm{K}_{2} \mathrm{O}$ (TAS) sınıflama diyagramındaki konumları (Le Maitre vd., 1989). Alkali- yarıalkali eğrisi (Irvine ve Baragar, 1971). 
Tablo 1. Kışlaköy Volkanitlerine ait kayaçların tüm kayaç ana (\%) ve iz (ppm) element analiz sonuçları

\begin{tabular}{|c|c|c|c|c|c|c|c|c|}
\hline \multirow{2}{*}{$\begin{array}{l}\text { Birim } \\
\text { Örnek No }\end{array}$} & \multicolumn{3}{|c|}{ Bazaltik Dayk } & \multicolumn{5}{|c|}{ Bazaltik Lav } \\
\hline & A5 & A8 & A33 & $\mathrm{N}-20$ & $\mathrm{~N}-26$ & $\mathbf{N}-30$ & $\mathrm{~N}-36$ & N-38 \\
\hline $\mathrm{SiO}_{2} \quad(\%)$ & 45.80 & 50.06 & 49.46 & 49.52 & 49.07 & 49.62 & 50.34 & 48.40 \\
\hline $\mathrm{TiO}_{2}$ & 0.69 & 0.76 & 0.86 & 1.17 & 1.04 & 0.89 & 0.86 & 0.92 \\
\hline $\mathrm{Al}_{2} \mathrm{O}_{3}$ & 13.57 & 12.96 & 14.22 & 15.20 & 15.40 & 15.26 & 14.85 & 12.67 \\
\hline $\mathrm{Fe}_{2} \mathrm{O}_{3}$ & 8.04 & 8.61 & 8.31 & 9.91 & 9.61 & 8.67 & 8.54 & 8.85 \\
\hline $\mathrm{MnO}$ & 0.17 & 0.21 & 0.16 & 0.18 & 0.17 & 0.15 & 0.16 & 0.15 \\
\hline $\mathrm{MgO}$ & 6.20 & 8.26 & 9.84 & 6.77 & 5.83 & 6.98 & 7.05 & 11.43 \\
\hline $\mathrm{CaO}$ & 14.54 & 11.63 & 9.65 & 10.30 & 10.25 & 9.49 & 10.34 & 9.93 \\
\hline $\mathrm{Na}_{2} \mathrm{O}$ & 2.20 & 1.97 & 2.20 & 2.66 & 2.46 & 2.48 & 2.41 & 2.22 \\
\hline $\mathrm{K}_{2} \mathrm{O}$ & 1.38 & 1.30 & 1.66 & 1.93 & 1.10 & 1.62 & 1.66 & 1.38 \\
\hline $\mathrm{Cr}_{2} \mathrm{O}_{3}$ & 0.04 & 0.08 & 0.09 & 0.04 & 0.03 & 0.03 & 0.04 & 0.12 \\
\hline $\mathrm{P}_{2} \mathrm{O}_{5}$ & 0.21 & 0.19 & 0.19 & 0.30 & 0.20 & 0.19 & 0.19 & 0.20 \\
\hline A.K. & 6.0 & 2.6 & 2.1 & 0.70 & 3.50 & 3.3 & 2.3 & 2.3 \\
\hline Toplam & 99.75 & 99.68 & 99.69 & 99.8 & 99.81 & 99.73 & 99.73 & 99.67 \\
\hline $\mathrm{Zr}(\mathrm{ppm})$ & 51.2 & 63.4 & 77.9 & 108.7 & 81.8 & 79.4 & 76.2 & 74.8 \\
\hline
\end{tabular}

\section{Tartışmalar}

\subsection{Volkanitleri oluşturan magmanın kristallenme koşulları $(P-T)$}

Kışlaköy volkanik kayaç örneklerinin mineral kimyası (Ek Tablo 1) ile tüm kayaç analiz sonuçları kullanilarak (Tablo 1) termobarometre hesaplamaları yapılmıştır. Böylece incelenen volkanitlerin kristallenme şartları (P-T) belirlenmiştir. Bunun yanı sıra, incelenmiş olan volkanitlerin oluşmasını sağlayan ve gelişimlerindeki süreçlerin etkisi araştırılarak, bu ortamlar yorumlanmaya çalışılmıştır.

\subsubsection{Jeotermobarometre}

Lindsley (1983) ile Lindsley ve Andersen (1983)'in önermiş̧ olduğu, piroksen jeotermometresindeki, Di-Hd-En-Fs piroksen dörtyüzlüsü üzerinde farklı sıcaklık değerlerinin gösterildiği izoterm eğrileri çizilmek koşuluyla bir abak tasarlanmıştır (Şekil 10). Buna ek olarak, söz konusu diyagram üzerine düşürülen piroksen bileşimlerinin belirlenebilmesi için $\mathrm{Wo}+\mathrm{En}+\mathrm{Fs}$ $\geq 90$ şartının sağlanması gereklidir. Klinopiroksen mineral bileşimleri söz konusu diyagrama düşürüldüğü zaman; klinopiroksenlerin katılaşma sıcaklıkları genelikle Kışlaköy Volkanitini temsilen Bazaltik Daykları oluşturan bazaltlar için 600-1000 ${ }^{\circ} \mathrm{C}$ iken, Bazaltik Lavlar için ise 550$1050^{\circ} \mathrm{C}$ arasında değişkenlik göstermektedir (Şekil $10)$.

Klinopiroksen ve ergiyik arasında oluşan dengeyle ilgili, kayaçlarda kristallenme sırasındaki basınç ve sicaklığın hesaplanabilmesi için Putirka vd. (1996, 2003) ve Putirka $(1999,2005,2008)$ tarafindan yapılan çalışmalar bulunmaktadır. Putirka (2008), yaptığ1 deneysel gözlemler yardımıyla, klinopiroksen ve ergiyik arasındaki denge halini test edebilmek için, Fe-Mg değişim sabiti $\mathrm{KD}(\mathrm{Fe}-$ $\mathrm{Mg}$ ) kpir-erg $=0.27 \pm 0.03$ hesaplaması yapmıştır. Klinopiroksen kristallenme sicaklığının hesaplanabilmesi için, klinopiroksen ile denge halindeki ergiyik bileşiminin bilinmesi gereklidir. Klinopiroksen bileşimine yönelik minerallerin elektron mikroprop analiz sonuçlarından yararlanılarak (Ek Tablo 1), ergiyik bileşimi için mikroprop analizi değerlerinden bulunan camın bileşimi veya tüm kayaç analizleri (Tablo 1) sonuçlarından hesaplanan değerler kullanılabilir.

Yapılan bu çalışmasında, Putirka (2008) tarafinca susuz magmalar için önerilmiş olan, klinopiroksen ve ergiyik bileşimine dayanılarak kalibre edilen termobarometre kullanılmak suretiyle elde edilen sonuçlar Tablo 2'de gösterilmiştir. Putirka (2008)'e göre hesaplanmış olan kristallenme sıcaklık değerleri, Kışlaköy volkanitlerini oluşturan bazaltik dayklar için $1174-1247{ }^{\circ} \mathrm{C}$ arasında iken, bazaltik lav örnekleri için bu değer $1139-1178{ }^{\circ} \mathrm{C}$ arasında değişmektedir (Tablo 2).

Putirka (2008)'deki yönteme göre, Kışlaköy (Erzurum) volkanitlerine ait klinopiroksenlerden elde edilen kristallenme basınç (P-kbar) değişimleri; bazaltik dayklarda 0.5-4.7 kbar arasında, bazaltik lav örneklerinde ise 0.1-4.4 kbar arasında değişmektedir. (Tablo 2). Elde edilen ortalama klinopiroksen basınç değerlerine (0.5-4.7 kbar arasında) karşılık gelen kristallenme derinliği 
4.1-11.8 km'dir (kıtasal kabuk için $1 \mathrm{kbar}=3.7 \mathrm{~km}$, Tulloch ve Challis, 2000). Bu değerler, volkanik kayaçların orta-sığ kıtasal kabuk ( 4-12 km) içerisinde yerleştiğini göstermektedir.

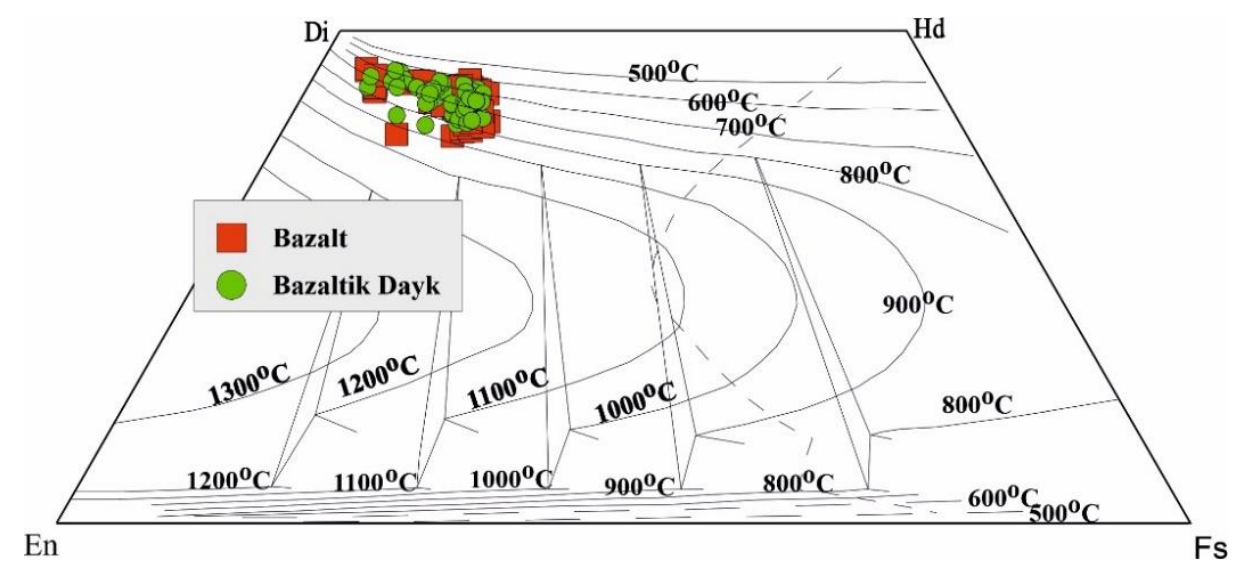

Şekil 10. Kışlaköy (Erzurum) volkanitlerinin içerdiği klinopiroksen bileşimlerine ait Di-HdEn-Fs piroksen dörtyüzlüsü. İzoterm eğrileri $100^{\circ} \mathrm{C}$ aralıklarla ve $1 \mathrm{~atm}$ basınç altında oluşturulmuştur (Lindsley, 1983; Lindsley ve Anderson, 1983).

Tablo 2. Kışlaköy Volkanitlerini oluşturan kayaçlarda Putirka (2008)'e göre hesaplanan klinopiroksenergiyik jeotermobarometresi

\begin{tabular}{|c|c|c|c|c|c|c|c|c|c|}
\hline & & & \multicolumn{6}{|c|}{ Putirka (2008) } & \multirow{3}{*}{$\begin{array}{c}\text { Tulloch ve } \\
\text { Callis, 2000 }\end{array}$} \\
\hline & & & \multicolumn{3}{|c|}{ Sıcaklık T $\left({ }^{\circ} \mathrm{C}\right)$} & \multicolumn{3}{|c|}{ P (32a, kbar) } & \\
\hline & & Örnek No & Min & Mak & Ort & Min & Mak & Ort & \\
\hline \multirow{4}{*}{ 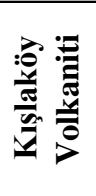 } & \multirow{2}{*}{$\begin{array}{c}\text { Bazaltik } \\
\text { Dayk }(n=8)\end{array}$} & $\mathrm{N}-5$ & 1174 & 1195 & $1183 \pm 10$ & 0.5 & 2.2 & $1.1 \pm 0.8$ & 4.1 \\
\hline & & $\mathrm{N}-33$ & 1201 & 1247 & $1217 \pm 21$ & 1.0 & 4.7 & $3.2 \pm 2.1$ & 11.8 \\
\hline & \multirow{2}{*}{$\begin{array}{c}\text { Bazal tik Lav } \\
(n=13)\end{array}$} & $\mathrm{N}-20$ & 1139 & 1197 & $1173 \pm 19$ & 0.1 & 4.3 & $2.3 \pm 1.7$ & 8.5 \\
\hline & & $\mathrm{N}-26$ & 1161 & 1178 & $1168 \pm 7$ & 1.0 & 4.4 & $2.5 \pm 1.1$ & 9.3 \\
\hline
\end{tabular}

* $\mathrm{n}=$ analiz sayısı, 1 kbar=3.7 km olarak alınmıştır ( Tulloch ve Callis, 2000).

Kışlaköy volkanitlerini oluşturan bazaltik dayk ve bazaltik lav örneklerine ait tüm-kayaç analizlerinden (Tablo 1) yararlanılarak zirkon (Miller vd., 2003) ve apatit (Harrison ve Watson, 1984) doygunluk sıcaklıkları hesaplanmıştır (Tablo 3). Zirkon doygunluk sicaklıkları, bazaltik dayk örnekleri için $513-611{ }^{\circ} \mathrm{C}$ arasında iken, bazaltik lav örnekleri için $582-628^{\circ} \mathrm{C}$ arasındadır (Tablo 3). Apatit doygunluk sicaklıkları ise bazaltik dayk örnekleri için $489-716^{\circ} \mathrm{C}$ arasında iken, bazaltik lav örnekleri için $550-721^{\circ} \mathrm{C}$ dir.

Tablo 3. Kışlaköy Volkanitlerine ait tüm kayaç analiz sonuçları kullanılarak hesaplanmış zirkon ve apatit doygunluğu için hesaplanan sıcaklık değerleri

\begin{tabular}{l|c|c}
\hline Kışlaköy Volkanitleri & $\begin{array}{c}\text { Zirkon doygunluk sıcaklı̆̆ı } \\
\text { Miller vd. (2003) }\end{array}$ & $\begin{array}{c}\text { Apatit doygunluk sicaklığı } \\
\text { Harrison ve Watson } \\
\text { (1984) }\end{array}$ \\
\hline Bazaltik dayk (n=3) & & 489 \\
\hline Min. & 513 & 716 \\
\hline Max. & 611 & 621 \\
\hline Ort. & 562 & \\
\hline Bazaltik Lav (n=5) & & 550 \\
\hline Min. & 582 & 721 \\
\hline Max. & 627 & 622 \\
\hline Ort. & 604 &
\end{tabular}




\subsection{Dengesizlik parametreleri}

Kayaçların dokusal özellikleri ve mineral bileşimlerinin, magma oluşumu sırasındaki dengesizliklerle bağlantılı oldukları bilinmektedir. Magmanın karışımındaki mineraller, soğuma veya basıncın aniden düşmesi; sıcaklık, basınç ve bileşiminin değişmesindeki tetikleyici faktörler arasındadır. Bahsedilen etkenlerin sonucunda ise denge halindeki magma dengesiz hale gelebilmektedir (Nixon 1988; Simonetti vd., 1996; Rutherford ve Hill 1993; Perugini vd., 2003). Dengesiz kristallenmenin işareti olan dokusal özellikler arasında, salınımlı zonlanma gösteren plajiyoklaz kristallerinde elek dokusunun görülmesi (Dungan ve Rhodes, 1978), ters ve normal plajiyoklazların birlikte aynı kayaçta bulunmaları (Venezky ve Rutherford, 1997; Stimac ve Pearce, 1992) ve kemirilmiş minerallerin görülmesi söylenebilir (Stimac ve Pearce, 1992). Aynı örneğin içerisinde bulunan minerallerdeki normal ve ters zonlanmanın birlikte görülmelerinin bilimsel bir kriter olduğu söylenebilir (Sakuyama, 1981; Yücel vd., 2014).

Kışlaköy Volkanitleri'nde gözlenen dokusal, petrografik ve mineral bileşim özellikleri dengesiz kristallenmelerin varllğını göstermiştir. İncelenmiş örneklerde bulunan plajiyoklazlar içerisindeki zonlanma ile birlikte gözlenmiş olan elek dokusunun, dengesizlik olduğunu belirten başkaca dokusal özellikler arasında olduğu söylenebilir. Ayrıca plajiyoklaz minerallerindeki ters ve normal zonlu plajiyoklaz minerallerinin birlikte yer alması kristallenmenin dengesiz olduğunu göstermektedir (Şekil 11a-c). Bunun yanı sıra, plajiyoklazlar poikilitik olarak olivin ve opak mineralleri içermekte ve gözlemlenen bu dokusal özellik de dengesiz kristallenmenin olduğuna işaret eden başka bir veridir.

Plajiyoklazlardaki normal zonlanmanın açıklanmasında fraksiyonel kristallenme kullanılırken, ters zonlanmada ise farklı görüşler öne sürülmektedir: (i) Basınç ve sıcaklığın, suya doygun koşullarda artmaları (Blundy ve Cashman 2001), (ii) Suya doygun magmaların yükselmesi esnasında sıcaklık artışının olması (Blundy vd., 2006) ve (iii) magma odalarındaki oluşan yeni karışımlar (back mixing) (Couch vd., 2001) ve daha sicak bir magma ile yenilenme sonucunda, magma odası sıcaklığının artması (Streck, 2008). Kışlaköy volkanik kayaçlarındaki plajiyoklazların kenar An bileşim değerleri geniş bir aralıkta değişiklik $\left(\mathrm{An}_{55-77}\right)$ göstermektedir. Aynı kayaçtaki plajiyoklazların kenarlarında görülen bileşimsel değişimler magma karışımından ötürü kompleks bir kökene işaret etmektedir (Wallace ve Carmichael, 1994).

İncelenen Kışlaköy volkanitlerine ait kayaçlardaki klinopiroksenler tipik olarak normal ve ters zonlanma, hamur tarafindan yenme, kemirilme, kalıntı merkezler gösterirken çoğunlukla opak ve olivin kapanımları içermeleri gibi dengesizlik dokuları gösterirler (Şekil 4, 5). İncelenen klinopiroksenler aynı örnekte hem normal zonlu hemde ters zonlanma göstermektedir (Şekil $11 \mathrm{~d}$ f). Bazaltik lavlardaki klinopiroksenlerde normal zonlanma gösteren örneklerin $\mathrm{Mg} /\left(\mathrm{Mg}+\mathrm{Fe}^{+2}\right)$ oranları merkezde 0.73 ile 0.84 arasinda iken, kenarda 0.70 ile 0.75 arasında değişmektedir. Ters zonlanma gösteren örneklerde ise $\mathrm{Mg}$ $\mathrm{Mg} /\left(\mathrm{Mg}+\mathrm{Fe}^{+2}\right)$ oranları merkez kısımlar için 0.730.75 arasinda iken, kenar kisımlarda bu oran 0.740.78 arasında değişmektedir. Bazaltik dayklardaki klinopiroksenlerde ise normal zonlanma gösteren örneklerin $\mathrm{Mg} /\left(\mathrm{Mg}+\mathrm{Fe}^{+2}\right)$ oranları merkezde 0.730.91 arasinda iken, kenar kisimlarda 0.72-0.86 arasında değişmektedir. Ters zonlanma gösteren örneklerde $\mathrm{Mg} /\left(\mathrm{Mg}+\mathrm{Fe}^{+2}\right)$ oranı merkezde 0.730.76 iken, kenar da 0.74-0.81 dir (Şekil $11 \mathrm{~d}$-f). Anderson (1974)'a göre normal ve ters zonlu klinopirksenlerin aynı örnekte bulunması magma karışımıyla açıklanmaktadır ve bu durum Kışlaköy volkanitlerinde de görülmektedir. Ayrıca magma karışımına bir delil de Şekil 11a'da An içeriği önce artıyor daha sonra başlangıç değerinden daha fazla azalarak An değeri düşüyor. Bu örnek bize sisteme daha mafik bir magmanın girdiğinin göstergesi olarak yorumlanabilinir ve bu da ancak magma karışımı ile açıklanabilir. 

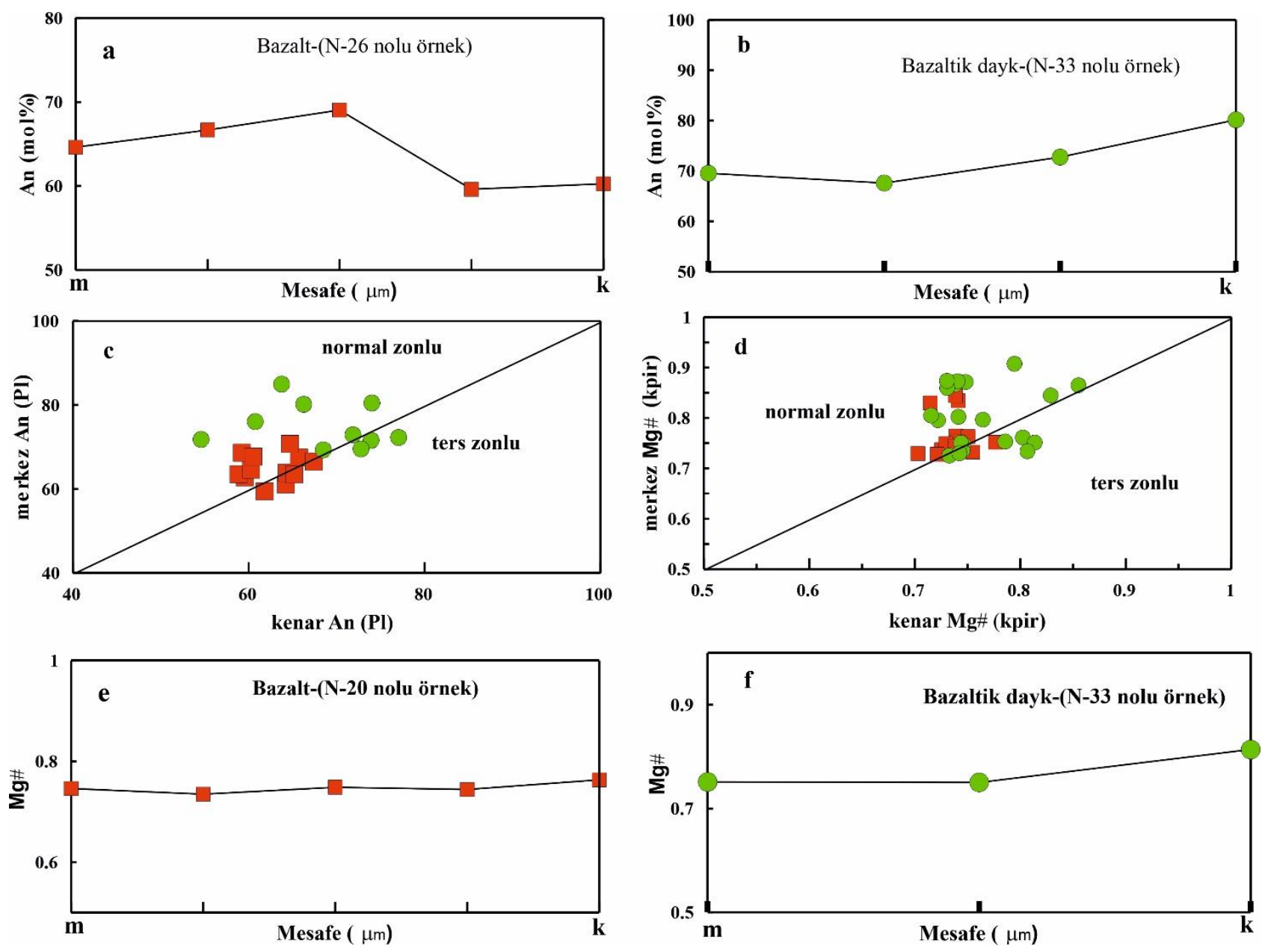

Şekil 11. Eosen yaşlı Kışlaköy volkanitleri içerisinde yer alan (a-c) normal ve ters zonlu plajiyoklazların merkez-kenar An değişimi, (d-f) normal ve ters zonlanma gösteren klinopiroksenlerin merkez-kenar $\mathrm{Mg}$ numarası (Mg\#) değişimi (semboller Şekil 10'daki gibidir, m: merkez, k: kenar).

\section{Sonuçlar}

$\mathrm{Bu}$ çalışma ile Kışlaköy (Narman) yöresinde gözlenen volkanik kayaçların detaylı petrografik ve mineral kimyası verileri irdelenerek; magmaların kristallenme sirasında etkili olan sıcaklık ve basınç gibi fizikokimyasal özellikleri ile jeolojik verilerle birleştirerek bu kayaçları oluşturan magmaların kabuktaki gelişim süreçleri ortaya konmuş ve elde edilen sonuçlar ana hatları ile aşağıda özetlenmiştir:

- Eosen yaşlı Kışlaköy Volkaniti çalışma alanının en yaşlı birimi olup, üzerine uyumsuz olarak, jips ara katkılı kumtaşı ve çamurtaşından oluşan oligomiyosen yaşlı Oltu Formasyonu, onun da üzerine andezitik lav ve arakatk1lı tüf ve aglomeralardan oluşan Alabalık Formasyonu (Oligo-Miyosen) gelmektedir.

- Kışlaköy Volkanik kayaçları volkanik fasiyes özelliklerine göre piroklastit (bazaltik volkanik breş), bazalt ve bazaltik dayk başlıkları altında incelenmiş olup, bazalt ve bazaltik daykları oluşturan kayaçların başlica plajiyoklaz $\left(\mathrm{An}_{49-85}\right)$, piroksen $\left(\mathrm{Wo}_{40-46} \mathrm{En}_{41-50} \mathrm{Fs}_{5-18}\right)$, olivin $\left(\mathrm{Fo}_{68-75}\right)$ ve Fe-Ti oksit mineralleri içermektedirler.

-Kışlaköy volkanik kayaçları petrografik olarak incelendiğinde genel olarak hyalo-mikrolitik porfirik, glomeroporfirik, glomerofirik, mikrolitik porfirik, poikilitik ve intersertal doku göstermektedirler.

-Volkanik kayaçlarda görülen salınımlı zonlanma gösteren plajiyoklaz kristallerinin elek dokusu göstermesi, normal ve ters zonlanmalı plajiyoklazların ve piroksenlerin aynı kayaçta birlikte bulunması dengesiz kristallenme olduğunu göstermekte ve bu dengesizlik parametrelerinden magma karışımı ile açıklanabilir.

-Volkanik kayaçların jeotermobarometre hesaplamalarına göre sicaklık $489-1247 \quad{ }^{0} \mathrm{C}$ arasında, basınç 0.5-4.7 kbar arasında değişmektedir. Elde edilen tüm veriler göz önüne alındığında incelenmiş olan volkanik kayaçların 
orta-sığ kıtasal kabuk ( 4-12 km) içerisinde yerleştiği görülmektedir.

\section{Katkı Belirtme}

$\mathrm{Bu}$ çalışma, ikinci yazarın Gümüşhane Üniversitesi, Fen Bilimleri Enstitüsü, Jeoloji Mühendisliği Anabilim Dalında yapmış olduğu yüksek lisans tez çalışmasından üretilmiştir. Ayrıca, bu çalışma TÜBİTAK tarafindan 118Y258 numaralı proje ile maddi olarak desteklenmiştir. Makalenin inceleme ve değerlendirme aşamasında yapmış oldukları katkılardan dolayı Baş Editör Serhat DAĞ, Alan Editörü Ferkan SİPAHI ve Hakemlere teşekkür ederiz.

\section{Kaynaklar}

Agard, P., Omrani, J., Jolivet, L. and Mouthereau, F., (2005). Convergence history across Zagros (Iran): constraints from collisional and earlier deformation. International Journal of Earth Sciences, $\quad 94, \quad 401-419$. https://doi.org/10.1007/s00531-005-0481-4

Allen, M. and Armstrong, H.A., (2008). Arabia-eurasia collision and the forcing of mid-cenozoic global cooling. paleogeography, paleoclimatology, palaeoecology, 265, 52-58. https://doi.org/10.1016/j.palaeo.2008.04.021

Anderson, A.T., (1974). Evidenceforapicritic, volatilerichmagmabeneath mt. shasta, california. Journal of Petrology, 15, 243-267. https://doi.org/10.1093/petrology/15.2.243

Arslan, M., Tüysüz, N., Korkmaz, S. and Kurt, H. (1997). Geochemistry and petrogenesis of the eastern Pontide volcanic rocks, Northeast Turkey. Chemie der Erde, 57, 157-187.

Arslan, M., Temizel, İ., Abdioğlu, E., Kolaylı, H., Yücel, C., Boztuğ, D. and Şen, C. (2013). 40Ar39Ar dating, whole-rock and sr-nd-pb isotope geochemistry of post-collisional eocene volcanic rocks in the southern part of the eastern pontides (NE Turkey): implications for magma evolution in extension-induced origin. Contributions to Mineralogy and Petrology, 166, 113-142. https://doi.org/10.1007/s00410-013-0868-3

Aslan, Z., (2010). U-Pb zircon SHRIMP age, geochemical and petrographical characateristics of tuffs within calcalkaline eocene volcanics around Gümüş̧ane (NE Turkey), eastern pontides. Neues Jahrbuch für Mineralogie, 187(3), 329-346. https://doi.org/10.1127/0077$7757 / 2010 / 0181$

Aslan, Z., Arslan, M., Temizel, I. and Kaygusuz, A., (2014). K-Ar dating, whole-rock and sr-nd isotope geochemistry of calc-alkaline volcanic rocks around the Gümüşhane area: implications for post-collisional volcanism in the Eastern Pontides, Northeast Turkey. Mineralogy and Petrology, 108, 245-267. https://doi.org/10.1007/s00710-013-0294-2

Aydın, F., Karslı, O. and Chen, B., (2008). Petrogenesis of the Neogene alkaline volcanics with implications for post collisional lithospheric thinning of the Eastern Pontides, NE Turkey. Lithos, 104, 249-266. https://doi.org/10.1016/j.lithos.2007.12.010

Aydin, F., Oğuz Saka, S., Şen, C., Dokuz, A., Aiglsperger, T., Uysal, İ., Kandemir, R., Karsli, O., Sarı, B. and Başer, R., (2020). Temporal, geochemical and geodynamic evolution of the late cretaceous subduction zone volcanism in the eastern Sakarya Zone, NE Turkey: implications for mantle-crust interaction in an arc setting, Journal of Asian Earth Sciences. 192, 104-217. https://doi.org/10.1016/j.jseaes.2019.104217

Aydınçakır, E. and Şen, C., (2013). Petrogenesis of the postcollisional volcanic rocks from the Borçka (Artvin) area: implications for the evolution of the Eocene magmatism in the Eastern Pontides (NE Turkey). Lithos, 172-173, 98-117. https://doi.org/10.1016/j.lithos.2013.04.007

Aydınçakır, E., (2014). The Petrogenesis of EarlyEocene non-adakitic volcanism in NE Turkey: constraints on geodynamic implications. Lithos, 208 , 361-377. https://doi.org/10.1016/j.lithos.2014.08.019

Aydınçakır, E., (2016). Subduction-related Late Cretaceous high- $\mathrm{K}$ volcanism in the Central Pontides orogenic belt: constraints on geodynamic implications. Geodinamica Acta, 28 (4), $379-411$. https://doi.org/10.1080/09853111.2016.1208526

Aydınçakır, E., Gündüz, R. and Yücel, C., (2020). Emplacement conditions of magma(s) forming Jurassic plutonic rocks in Gümüşhane (Eastern Pontides, Turkey). Bulletin of the Mineral Research and Exploration, 162, 175-196. https://doi.org/10.19111/bulletinofmre.649808

Bacon, C.R. and Hirschmann, M.M., (1988). Mg/Mn partitioning As a test for equilibrium between coexisting Fe-Ti oxides. American Mineralogist, 73, 57-61.

Bayraktutan, S., (1994). Narman-Gaziler bölgesinin Tersiyer'deki volkano-tektonik evrimi. 47. Türkiye Jeoloji Kurultayı, Bildiri Özleri.

Blundy, J. and Cashman, K., (2001). Ascent driven crystallization of dacite magmas at mount St. Helens, 1980-1986. Contributions to Mineralogy and Petrology, 140, 631-650. https://doi.org/10.1007/s004100000219 
Blundy, J., Cashman, K. and Humhreys, M., (2006). Magma heating by decompression-driven crystallization beneath andesite volcanoes. Nature, 443, 76-80. https://doi.org/10.1038/nature05100

Buket, E. and Temel, A., (1998). Major-element, trace element, and sr-nd isotopic geochemistry and genesis of Varto (Muş) volcanic rocks, Eastern Turkey. Journal of Volcanology and Geothermal Research, 85, 405-422. https://doi.org/10.1016/S0377-0273(98)00064$\mathrm{X}$

Couch, S., Sparks, R.S.J. and Carroll, M.R., (2001). Mineral disequilibriumin lavas explained by convective self-mixing in open magma chambers. Nature, 411, 1037-1039. https://doi.org/10.1038/35082540

Dewey, J.F., Hempton, M.R.S., Kidd, W.S.F., Saroğlu, F. and Şengör, A.M.C., (1986). Shortening of continental lithosphere: the neotectonics of Eastern Anatolia, a young collision zone in: Coward, M.P., Ries, A.C. (Eds.), Collision Zone Tectonics. Geological Society of London Special Publication, 19, 3-36.

Dokuz, A., Aydin, F. And Karsli, O., (2019). Postcollisional transition from subduction-to intraplate-type magmatism in the eastern Sakarya zone, Turkey: Indicators of northern Neotethyan slab breakoff, Geology Society of American Bulletin. 131, 1623-1642. https://doi.org/10.1130/B31993.1

Droop, G.T.R., (1987). A general equation for estimating $\mathrm{Fe} 3+$ concentrations in ferromagnesian silicates and oxides from microprobe analysis, using Stoichiometric criteria. Mineralogical Magazine, 51, 431-437. https://doi.org/10.1180/minmag.1987.051.361.1 0

Dungan, M.A. and Rhodes, J.M., (1978). Residual glasses and melt inclusions in basalts from DSDP legs 45 and 46: evidence for magma mixing. Contributions to Mineralogy and Petrology, 67, 417-431. https://doi.org/10.1007/BF00383301

Ercan, T., Fujitani, T., Matsuda, J.L, Notsu, K., Tokel, S. ve Di, T., (1990). Doğu ve Güneydoğu Anadolu neojen-kuvatemer volkanitlerine ilişkin yeni jeokimyasal, radyometrik ve izotopik verilerin yorumu. Maden Tetkik ve Arama Dergisi, 110, 143-164.

Gülen, L., (1980a). Strontium isotope geochemistry of mount Ararat and mount Süphan volcanics, Eastern Turkey. EOS, 61, 17, 412.

Gülen, L., (1980b). Sr, Nd and Pb isotope systematics of Ararat and Süphan volcanoes, Eastern Turkey. EOS, 63, 45, 1145.
Güleç, N., (1991). Crust-mantle interaction in western Turkey: implications from $\mathrm{Sr}$ and $\mathrm{Nd}$ geochemistry of Tertiary and Quaternary volcanics. Geological Magazine, 128, 417-435. https://doi.org/10.1017/S0016756800018604

Hall, R., (1976). Ophiolite emplacement and the evolution of the Taurus Suture Zone, Southeastern Turkey. Geological Society of America Bulletin, 87, 1078-1088. https://doi.org/10.1130/0016-7606(1976)87< 1078:OEATEO > 2.0.CO;2

Harrison, T.M. and Watson, E.B., (1984). The behaviour of apatite during crustal anatexis: equilibrium and kinetic considerations. Geochimica et Cosmochimica Acta, 48, 1467-1477. https://doi.org/10.1016/0016-7037(84)90403-4

Innocenti, F., Mazzuoli, R., Pasquare, G., Redicat di Brozolo, F. and Villari, L., (1976). Evolution of the volcanism in the area of interaction between the Arabian, Anatolian and Iranian Plates (Lake Van, Eastern Turkey). Journal of Volcanology and Geothermal Research, 1, 103-112. https://doi.org/10.1016/0377-0273(76)90001-9

Innocenti, F., Mazzuoli, R., Pasquare, G., Radicati Di Brozolo, F. and Villari, L., (1982). Tertiary and Quaternary Volcanism of the Erzurum-Kars area (Eastern Turkey). Journal of Volcanology and Geothermal Research, 13, 223-240. https://doi.org/10.1016/0377-0273(82)90052-X

Jolivet, L. and Faccenna, C., (2000). Mediterranean extension and the Africa-Eurasia Collision. Tectonics, 19, 1095-1106. https://doi.org/10.1029/2000TC900018

Karslı, O., Chen, B., Uysal, I., Aydın, F., Wijbrans, J.R. and Kandemir, R., (2008). Elemental and Sr- Nd$\mathrm{Pb}$ isotopic geochemistry of the most recent Quaternary Volcanism in the Erzincan basin, Eastern Turkey: framework for the evalution of basalt-lower crust interaction. Lithos, 106, 5570. https://doi.org/10.1016/j.lithos.2008.06.008

Kaygusuz, A., (2009). K/Ar ages and geochemistry of the collision related volcanic rocks in the Ilica (Erzurum) area, eastern Turkey. Neues Jahrbuch für Mineralogie, $186 \quad$ (1), 21-36. https://doi.org/10.1127/0077-7757/2009/0134

Kaygusuz, A. and Aydınçakır, E., (2009). Minerology, whole-rock and Sr-Nd isotope geochemistry of mafic microgranular enclaves in cretaceous Dağbaşı Granitoids, Eastern Pontides, NE Turkey: evidence of magma mixing, mingling and chemical equilibration. Chemie der Erde, 69, 247-277. https://doi.org/10.1016/j.chemer.2008.08.002

Kaygusuz, A. and Aydınçakır, E. (2011). Petrogenesis of a Late Cretaceous composite pluton from the 
eastern Pontides: the Dağbaşı pluton, NE Turkey. Neues Jahrbuch für Mineralogie (Abhandlungen), 188, 211-233. https://doi.org/10.1127/0077-7757/2011/0201

Kaygusuz A, Aslan Z, Siebel W. and Şen, C., (2011) Geochemical and Sr-Nd isotopic characteristics of post-collisional calc-alkaline volcanics in the Eastern Pontides (NE Turkey). Turkish Journal Earth Sciences, 20, 137-159. doi:10.3906/yer$1002-8$

Kaygusuz, A., Aslan, Z., Aydınçakır, E., Yücel, C., Gücer, M.A. and Şen, C., (2018). Geochemical and $\mathrm{Sr}-\mathrm{Nd}-\mathrm{Pb}$ isotope characteristics of the Miocene to Pliocene volcanic rocks from the Kandilli (Erzurum) area, Eastern Anatolia (Turkey): implications for magma evolution in extension-related origin. Lithos, 296/299, 332351. https://doi.org/10.1016/j.lithos.2017.11.003

Kaygusuz, A., Arslan, M., Temizel, İ., Yücel, C. and Aydınçakır, E., (2021). U-Pb zircon ages and petrogenesis of the Late Cretaceous I-type granitoids in arc setting, Eastern Pontides, NE Turkey. Journal of African Earth Sciences, 174, 10404.

https://doi.org/10.1016/j.jafrearsci.2020.104040

Keskin, M., (1994). Genesis of Collision-Related Volcanism On The Erzurum-Kars Plateau, Northeastern Turkey. Ph. D. Thesis (Doktora Tezi), University of Durham, U.K.

Keskin, M., Pearce, J.A. and Mitchell, J.G., (1998). Volcano-stratigraphy and geochemistry of collision volcanism on the Erzurum-Kars Plateau, Northeastern Turkey. Journal of Volcanology and Geothermal Research, 85, 355$404 . \quad$ https://doi.org/10.1016/S03770273(98)00063-8

Keskin, M., (2003). Magma generation by slab steepening and breakoff beneath a subductionaccretion complex: an alternative model for collision-related volcanism in Eastern Anatolia, Turkey. Geophysical Research Letters, 30, 24, 8046. https://doi.org/10.1029/2003GL018019

Keskin, M., Pearce, J.A., Kempton, P.D. and Greenwood, P., (2006). Magma-crust interactions and magma plumbing in a postcollisional setting: geochemical evidence from the Erzurum-Kars volcanic plateau, Eastern Turkey in: Dilek, Y., Pavlides, S. (Eds.), postcollisional tectonics and magmatism in the Mediterranean Region and Asia. Geological Society of America, Special Publication, 409, 475-505. https://doi.org/10.1130/2006.2409(23)

Keskin, M., (2007). Eastern Anatolia: a hotspot in a collision zone without a mantle plume. in: foulger, G.R., Jurdy, D.M. (Eds.), plates, plumes, and planetary processes. Geological Society of
America, Special Publication, 430, 693-722. https://doi.org/10.1130/2007.2430(32)

Keskin, M., Genç, Ş. C. and Tüysüz, O., (2008). Petrology and geochemistry of postcollisional middle eocene volcanic units in North-Central Turkey: evidence for magma generation by slab breakoff following the closure of the Northern Neotethys Ocean. Lithos, 104, 267-305. https://doi.org/10.1016/j.lithos.2007.12.011

Konak, N. and Hakyemez, H.Y., (2001). Tectonic units of the easternmost part of the Pontides: stratigraphical and structural implications, proceedings of the 2nd Int. Symp. on the petroleum geology and hydrocarbon potential of the Black sea area. Turkish Association of Petroleum Geologists, Spec. Publ., 4, 93-103.

Kürüm, S., Önal, A., Boztuğ, D., Spell, T. and Arslan, M., (2008). 40Ar/39Ar Age and geochemistry of the post-collisional Miocene Yamadağ Volcanics in the Arapkir area (Malatya Province), Eastern Anatolia, Turkey. Journal of Asian Earth Sciences, 33, 229-251. https://doi.org/10.1016/j.jseaes.2007.12.001

Le Maitre, R.W., Bateman, P., Dudek, A., Keller, J., Lameyre, J., Le Bas, M.J., Sabine, P.A.,Schmid, R., Sorensen, H., Strekeisen, A., Woolley, A.R. and Zanettin, B., (1989). A classification of igneous rocks and glossary of terms: recommendations of the international union of geological sciences, subcommission on the systematics of igneous rocks (No. 552.3 CLA), Blackwell, https://doi.org/10.1017/CBO9780511535581

Lebedev, V.A., Sharkov, E.V., Ünal, E. and Keskin, M., (2016a). Late Pleistocene Tendürek Volcano (Eastern Anatolia, Turkey). I. geochronology and petrographic characteristics of igneous rocks. Petrology, 24, 2, 127-152. https://doi.org/10.1134/S0869591116020041

Lebedev, V.A., Chugaev, A.V., Ünal, E., Sharkov, E.V. and Keskin, M., (2016b). Late Pleistocene Tendürek Volcano (Eastern Anatolia, Turkey). II. geochemistry and petrogenesis of the rocks. Petrology, 24, 3, 234-270. https://doi.org/10.1134/S0869591116030048

Lebedev, V.A., Chernyshev, I.V. and Shatagin, K.N., (2013). Geochronology, isotope $\mathrm{Sr}-\mathrm{Nd}$ characteristics and origin of Quaternary volcanic rocks within Geghama Highland (Lesser Caucasus, Armenia). Journal of Volcanology and Seismology, 7, 3, 204-229. https://doi.org/10.1134/S0742046313030044

Lambert, R.J. and Holland, J.G., (1974). Yttrium geocemistry applied to petrogenesis utilizing calcium-yttrium relationships in minerals and rocks. Geochimica et Cosmochimica Acta, 38, 
1393-1414. https://doi.org/10.1016/00167037(74)90095-7

Lindsley, D.H., (1983). Pyroxene thermometry. American Mineralogist, 68, 477-493.

Lindsley, D.H. and Andersen, D.J., (1983). A twopyroxene thermometer. Journal of Geophysical Research, 88, A887-A906. https://doi.org/10.1029/JB088iS02p0A887

Lustrino, M., Keskin, M., Mattioli, M. and Kavan, O., (2012). Heterogeneous mantle sources feeding the volcanic activity of Mt. Karacadag. Journal of Asian Earth Sciences, 46, 120-139. https://doi.org/10.1016/j.jseaes.2011.11.016

Miller, C.F., McDowell, S.M. and Mapes, R.W., (2003). Hot and cold granites?: Implications of zircon saturation temperatures and preservation of inheritance. Geology, 31, 529-532. https://doi.org/10.1130/00917613(2003)031\%3C0529:HACGIO\%3E2.0.CO; 2

Morimoto, M., Fabries, J., Ferguson, A.K., Ginzburg, I.V., Ross, M., Seifert, F.A., Zussman, J., Aoki, K. and Gottardi, G., (1988). Nomenclature of pyroxenes. Mineralogical Magazine, 52, 535550.

https://doi.org/10.1180/minmag.1988.052.367.1 5

Nixon, G.T., (1988). Petrology of the younger andesites and dacites of Iztaccihuatl Volcano, Mexico: disequilibrium phenocryst assemblages as indicators of magma chamber processes. Journal of Petrology, 29, 213-264. https://doi.org/10.1093/petrology/29.2.213

Notsu, K., Fujitani, T., Ui, T., Matsuda, J. and Ercan, T., (1995). Geochemical features of collision related volcanic rocks in Central and Eastern Anatolia, Turkey. Journal of Volcanology and Geothermal Research, 64, 171-192. https://doi.org/10.1016/0377-0273(94)00077-T

Okay, A.I., Zattin, M. and Cavazza, W., (2010). Apatite fission-track data for the Miocene Arabia^${ }^{\wedge}$ Eurasia collision. Geology, 38, 35-38. https://doi.org/10.1130/G30234.1

Okay, A.I. and Şahintürk, O., (1997). Geology of the Eastern Pontides, In: A. G. Robinson, (Ed.), Regional and Petroleum Geology of The Black Sea and Surrounding Region. American Association of Petroleum Geologist Memoir, 68, 291-311. https://doi.org/10.1306/M68612C15

Oyan, V., Keskin, M., Lebedev, V.A., Chugaev, A.V. and Sharkov, E.V., (2016). Magmatic evolution of the Early Pliocene etrüsk stratovolcano, Eastern Anatolian Collision Zone, Turkey.
Lithos, 256-257, $88-108$. https://doi.org/10.1016/j.lithos.2016.03.017

Özdemir, Y., Karoğlu, O., Tolluoğlu, A. U. and Güleç, N., (2006). Volcanostratigraphy and petrogenesis of the Nemrut Stratovolcano (East Anatolian High Plateau): The most recent postcollisional volcanism In Turkey. Chemical Geology, 226, 189-211. https://doi.org/10.1016/j.chemgeo.2005.09.020

Özdemir, Y., Blundy, J.D. and Güleç, N., (2011). The importance of fractional crystallization and magma mixing in controlling chemical differentiation at Suphan Stratovolcano, Eastern Anatolia, Turkey. Contributions to Mineralogy and Petrology, 162, 573-597. https://doi.org/10.1007/s00410-011-0613-8

Özdemir, Y. and Güleç, N., (2014). Geological and geochemical evolution of the Quaternary Süphan stratovolcano, Eastern Anatolia, Turkey: evidence for the lithosphere-asthenosphere interaction in post-collision volcanism. Journal of Petrology, 55, 37-52. https://doi.org/10.1093/petrology/egt060

Papike, J.J., Cameron, K.L. and Baldwin, K., (1974). Amphiboles and pyroxenes: characterization of other than quadrilateral components and estimates of Ferric Iron from microprobe data. Geology Society of America, 6, 1053-1054.

Pearce, J.A., Bender, J.F., De Long, S.E., Kidd, W.S.F., Low, PJ., Güner, Y., Şaroğlu, F., Yılmaz, Y., Moorbath, S. and Mitchell, J.J., (1990). Genesis of collision volcanism in Eastern Anatolia Turkey. Journal of Volcanology and Geothermal Research, 44, 189-229. https://doi.org/10.1016/0377-0273(90)90018-B

Perugini D., Poli G., Christofides G. and Eleftheriadis G., (2003). Magma mixing in the sithonia plutonic complex, Greece: evidence from mafic microgranular enclaves. Mineralogy and Petrology, 78, 173-200. https://doi.org/10.1007/s00710-002-0225-0

Putirka, K.D., Johnson, M., Kinzler, R. and Walker, D., (1996). Thermobarometry of mafic igneous rocks based on clinopyroxene-liquid equilibria, 0-30 kbar. Contributions to Mineralogy and Petrology, 123, 92-108. https://doi.org/10.1007/s004100050145

Putirka, K.D., (1999). Clinopyroxene+liquid equilibrium to $100 \mathrm{kbar}$ and $2450 \mathrm{~K}$. Contributions to Mineralogy and Petrology, 135, 151-163.

https://doi.org/10.1007/s004100050503

Putirka, K.D., Ryerson, F.J. and Mikaelian, H. (2003). New igneous thermobarometers for mafic and evolved lava compositions, based on 
clinopyroxene+liquid equilibria. American Mineralogist, $\quad 88, \quad 1542-1554$. https://doi.org/10.2138/am-2003-1017

Putirka, K.D., (2005). Igneous thermometers and barometers based on plagioclase+liquid equilibria: tests of some existing models and new calibrations. American Mineralogist, 90, 336346. https://doi.org/10.2138/am.2005.1449

Putirka, K.D., (2008). Thermometers and barometers for volcanic systems. in Putirka, K.D., Tepley, F.E. Reviews in Mineralogy and Geochemistry, 69, 61120.

Robertson, A.H.F., Parlak, O., Rızaoğlu, T., Ünlügenç, Ü., Inan, N., Taşl1, K. and Ustaömer, T., (2007). Tectonic evolution of the South Tethyan Ocean: evidence from The Eastern Taurus Mountains (Elazığ Region, SE Turkey). in: Ries, A. C., Butler, R. W. H. \& Graham, R. H. (eds) Deformation of Continental Crust. Geological Society, London, Special Publications, 272, 231270.

http://dx.doi.org/10.1144/GSL.SP.2007.272.01. 14

Rutherford, M.J. and Hill, P.M., (1993). Magma ascent rates from amphibole breakdown: an experimental study appliedtothe 1980-1986 Mount St. Helens eruptions. Journal of Geophysical Research, 98, 19667-19685. https://doi.org/10.1029/93JB01613

Sakuyama, M., (1981). Petrological study of the Myoko and Kurohime volcanoes, Japan: crystallization sequence and evidence magma mixing. Journal of Petrology, 22, 553-583. https://doi.org/10.1093/petrology/22.4.553

Schmid, R., (1981). Descriptive nomenclature and classification of pyroclastic deposits and fragments: recommendations of the IUGS subcommission on the systematics of igneous rocks. Geology, 9, 41-43. https://doi.org/10.1130/00917613(1981)9\%3C41:DNACOP\%3E2.0.CO;2

Simonetti, A., Shore, M. and BelI, K., (1996). Diopside phenocrysts from Nephelinite lavas, Napak Volcano, Eastem Uganda: evidence for magma mixing. Canadian Mineralogist, 34, 411-421.

Sipahi, F. and Sadıklar, M.B., (2014). Geochemistry of dacitic volcanics in the eastern pontides (NE Turkey), Geochemistry International, 4, 329349.

http://dx.doi.org/10.7868/S0016752514040086

Sipahi, F., Sadıklar, M.B. and Şen, C., (2014). The geochemical and $\mathrm{Sr}-\mathrm{Nd}$ isotopic characteristics of Murgul (Artvin) volcanics in the Eastern Black Sea Region (NE Turkey), Chemie der
Erde/Geochemistry, $\quad 74, \quad 331-342$.
https://doi.org/10.1016/j.chemer.2013.08.005

Sipahi, F., Kaygusuz, A., Saydam Eker, Ç., Vural, A. and Akpinar, I., (2018). Late Cretaceous arc igneous activity: the Eğrikar Monzogranite example. International Geology Review, 60/3, 382-400.

https://doi.org/10.1080/00206814.2017.1336120

Stimac, J.A. and Pearce, T.H., (1992). Textural evidence of mafic-felsic magma interaction in dacite lavas, Clear Lake, California. American Mineralogist, 77, 795-809.

Streck, M.J., (2008). Mineral textures and zoning as evidence for open system processes. in: Putirka $\mathrm{KD}$, Tepley III FJ (eds) minerals, inclusions and volcanic processes. Mineralogical Society of America and Geochemical Society, Review Mineral, 69, 1, 595-622. https://doi.org/10.2138/rmg.2008.69.15

Şen, C., (2007). Jurassic volcanism in the eastern Pontides: is it rift related or subduction related, Turkish Journal of Earth Sciences, 16, 523-539.

Şengör, A.M.C., (1980). Türkiye'nin neotektoniğinin esasları. Türkiye Jeoloji Kurumu, Konferans Serisi, 2, 40.

Şengör, A.M.C. and Yılmaz, Y., (1981). Tethyan evolution of Turkey: a plate tectonic approach. Tectonophysics, 75, 181241.

Şengör, A.M.C., (1990). Plate tectonics and orogenic research after 25 Years: a Tethyan perspective. Earth-Science Reviews, 27, 1-2, 1-201. https://doi.org/10.1016/0012-8252(90)90002-D

Şengör, A.M.C., Özeren, S., Genç, T. and Zor, E., (2003). East Anatolian high plateau As a mantle supported, north-south shortened domal structure. Geophysical Research Letters, 30, 24, 8045. https://doi.org/10.1029/2003GL017858

Şaroğlu, F. ve Güner, Y., (1981). Doğu Anadolu'nun jeomorfolojik gelişimine etki eden öğeler, jeomorfoloji, tektonik, volkanizma ilişkileri. Türkiye Jeoloji Kurumu Bülteni, 24, 39-52.

Venezky, D.Y. and Rutherford, M.J., (1997). Preeruption conditions and timing of daciteandesite magma mixing in the $2.2 \mathrm{Ka}$ eruption at mount Rainier. Journal of Geophysical Research, 102 , 20069-20086. https://doi.org/10.1029/97JB01590

Wallace, P.J. and Carmichael, I.S.E., (1994). Petrology of volcan tequila, jalisco, Mexico: disequilibrium phenocryst assemblages and evolution of the subvolcanic magma system. Contributions to Mineralogy and Petrology, 117, 345- 361. https://doi.org/10.1007/BF00307270 
Yılmaz, Y., Saroğlu, F. and Güner, Y., (1987). Initiation of the neomagmatism in East Anatolia. Tectonophysics, 134, 177-199. https://doi.org/10.1016/0040-1951(87)90256-3

Yılmaz, C., (1993). Doğu pontid güney zonu'nun stratigrafik deneştirmesi ve paleo coğrafik evrimi, Akdeniz Üniversitesi. Isparta Mühendislik Fakültesi Dergisi, 7, 199-214.

Yücel, C., Arslan, M., Temizel, İ. and Abdioğlu, E., (2014). Volcanic facies and mineral chemistry of Tertiary volcanics in the northern part of the Eastern Pontides, northeast Turkey: implications for pre-eruptive crystallization conditions and magma chamber processes. Mineraogy and Petrology, 108-3, 439-467. https://doi.org/10.1007/s00710-013-0306-2

Yücel, C., Arslan M., Temizel, İ., Abdioğlu, Y. and Ruffet, G., (2017). Evolution of K-rich magmas derived from a net veined lithospheric mantle in an ongoing extensional setting: geochronology and geochemistry of eocene and miocene volcanic rocks from Eastern Pontides (Turkey). Gondwana Research, 45, 65-86. https://doi.org/10.1016/j.gr.2016.12.016 
Ek Tablo 1. Kışlaköy (Erzurum-Narman) yöresi Eosen yaşlı volkanik kayaçlara ait klinopiroksen minerallerinin mikroprob analiz sonuçları

\begin{tabular}{|c|c|c|c|c|c|c|c|c|c|c|c|c|c|c|c|c|c|c|c|c|c|c|c|c|c|}
\hline Birim Adı & & & & & & & & & & & & Baza & & & & & & & & & & & & & \\
\hline Örnek No & $\begin{array}{r}\mathrm{N}-20 \\
\text { kpir } 1 \\
\text { feno } \\
\mathrm{m} \\
\end{array}$ & $\begin{array}{r}\mathrm{N}-20 \\
\text { kpir } 1 \\
\text { feno } \\
\mathrm{o} \\
\end{array}$ & $\begin{array}{r}\mathrm{N}-20 \\
\text { kpir } 1 \\
\text { feno } \\
\mathrm{k} \\
\end{array}$ & $\begin{array}{r}\mathrm{N}-20 \\
\text { kpir } 1 \\
\text { feno } \\
\mathrm{m}\end{array}$ & $\begin{array}{r}\mathrm{N}-20 \\
\text { kpir } 1 \\
\text { feno } \\
\mathrm{o} 1 \\
\end{array}$ & $\begin{array}{r}\mathrm{N}-20 \\
\text { kpir } 2 \\
\text { feno } \\
02 \\
\end{array}$ & $\begin{array}{r}\mathrm{N}-20 \\
\text { kpir } 1 \\
\text { feno } \\
03 \\
\end{array}$ & $\begin{array}{r}\mathrm{N}-20 \\
\text { kpir } 1 \\
\text { feno } \\
\mathrm{k} \\
\end{array}$ & $\begin{array}{r}\mathrm{N}-20 \\
\text { kpir } 1 \\
\text { feno } \\
\mathrm{m} \\
\end{array}$ & $\begin{array}{r}\mathrm{N}-20 \\
\text { kpir } 1 \\
\text { feno } \\
\mathrm{o} 1 \\
\end{array}$ & $\begin{array}{r}\mathrm{N}-20 \\
\text { kpir } 1 \\
\text { feno } \\
02 \\
\end{array}$ & $\begin{array}{r}\mathrm{N}-20 \\
\text { kpir } 1 \\
\text { feno } \\
\text { o3 }\end{array}$ & $\begin{array}{r}\mathrm{N}-20 \\
\text { kpir } 1 \\
\text { feno } \\
\mathrm{k} \\
\end{array}$ & $\begin{array}{r}\mathrm{N}-20 \\
\text { kpir } 2 \\
\text { feno } \\
\mathrm{m} \\
\end{array}$ & $\begin{array}{r}\mathrm{N}-20 \\
\text { kpir } 2 \\
\text { feno } \\
\mathrm{k} \\
\end{array}$ & $\begin{array}{r}\mathrm{N}-20 \\
\text { kpir } 1 \\
\text { feno } \\
\mathrm{m} \\
\end{array}$ & $\begin{array}{r}\mathrm{N}-20 \\
\text { kpir } 1 \\
\text { feno } \\
\mathrm{o} 1 \\
\end{array}$ & $\begin{array}{r}\mathrm{N}-20 \\
\text { kpir } 1 \\
\text { feno } \\
02 \\
\end{array}$ & $\begin{array}{r}\mathrm{N}-20 \\
\text { kpir } 1 \\
\text { feno } \\
\mathrm{k} \\
\end{array}$ & $\begin{array}{r}\mathrm{N}-20 \\
\text { kpir } 1 \\
\text { feno } \\
\mathrm{m} \\
\end{array}$ & $\begin{array}{r}\mathrm{N}-20 \\
\text { kpir } 1 \\
\text { feno } \\
\mathrm{o} 1 \\
\end{array}$ & $\begin{array}{r}\mathrm{N}-20 \\
\text { kpir } 1 \\
\text { feno } \\
02 \\
\end{array}$ & $\begin{array}{r}\mathrm{N}-20 \\
\text { kpir } 1 \\
\text { feno } \\
\mathrm{k} \\
\end{array}$ & $\begin{array}{r}\mathrm{N}-20 \\
\text { kpir } 1 \\
\text { feno } \\
\mathrm{m}\end{array}$ & $\begin{array}{r}\mathrm{N}-20 \\
\text { kpir } 1 \\
\text { feno } \\
\mathrm{O}\end{array}$ \\
\hline $\mathrm{SiO}_{2}(\%)$ & 50.83 & 49.51 & 49.12 & 49.86 & 549.98 & 51.03 & 49.94 & 50.23 & 49.74 & 50.22 & 49.46 & 49.35 & 48.55 & 53.04 & 48.76 & 49.78 & 49.57 & 49.77 & 49.23 & 50.23 & 50.46 & 50.40 & 50.27 & 52.28 & 50.26 \\
\hline $\mathrm{TiO}_{2}$ & 0.68 & 0.97 & 1.00 & 0.88 & 0.87 & 0.83 & 0.88 & 0.70 & 0.86 & 0.88 & 1.04 & 1.01 & 1.07 & 0.29 & 1.08 & 0.84 & 0.96 & 0.92 & 0.84 & 0.64 & 0.76 & 0.73 & 0.80 & 0.23 & 0.85 \\
\hline $\mathrm{Al}_{2} \mathrm{O}_{3}$ & 2.64 & 3.69 & 3.97 & 3.17 & 3.17 & 2.37 & 3.21 & 2.62 & 3.44 & 3.09 & 3.79 & 3.51 & 4.14 & 1.67 & 4.13 & 3.97 & 3.72 & 3.60 & 3.79 & 3.37 & 2.69 & 2.57 & 3.38 & 2.16 & 3.20 \\
\hline $\mathrm{FeO}^{*}$ & 8.58 & 8.99 & 9.32 & 8.87 & 8.75 & 8.82 & 9.08 & 8.08 & 9.00 & 8.81 & 9.34 & 9.45 & 9.40 & 6.38 & 8.93 & 9.00 & 9.54 & 8.81 & 9.02 & 8.54 & 9.58 & 8.58 & 9.07 & 5.52 & 9.05 \\
\hline $\mathrm{MnO}$ & 0.31 & 0.25 & 0.27 & 0.28 & 0.27 & 0.29 & 0.28 & 0.31 & 0.30 & 0.28 & 0.24 & 0.28 & 0.25 & 0.23 & 0.20 & 0.27 & 0.34 & 0.24 & 0.23 & 0.28 & 0.29 & 0.27 & 0.25 & 0.13 & 0.27 \\
\hline $\mathrm{MgO}$ & 15.60 & 14.92 & 14.81 & 15.06 & 15.05 & 15.50 & 14.81 & 15.74 & 15.08 & 15.38 & 14.38 & 14.50 & 14.27 & 18.04 & 14.33 & 14.83 & 14.84 & 14.73 & 14.71 & 15.44 & 16.20 & 15.52 & 15.28 & 16.81 & 15.03 \\
\hline $\mathrm{CaO}$ & 20.93 & 21.28 & 20.80 & 21.35 & 20.99 & 21.00 & 21.20 & 21.03 & 21.28 & 20.55 & 21.18 & 21.28 & 21.26 & 19.78 & 21.49 & 21.10 & 20.51 & 20.96 & 21.30 & 20.90 & 19.57 & 20.92 & 20.34 & 22.42 & 21.12 \\
\hline $\mathrm{Na}_{2} \mathrm{O}$ & 0.30 & 0.34 & 0.36 & 0.29 & 0.32 & 0.32 & 0.35 & 0.33 & 0.36 & 0.29 & 0.39 & 0.31 & 0.30 & 0.36 & 0.30 & 0.35 & 0.38 & 0.30 & 0.33 & 0.33 & 0.31 & 0.24 & 0.34 & 0.29 & 0.28 \\
\hline Toplam & 99.86 & 99.94 & 99.66 & 99.76 & 99.40 & 100.15 & 99.76 & 99.05 & 100.06 & 99.50 & 99.83 & 99.68 & 99.25 & 99.78 & 99.22 & 100.15 & 99.86 & 99.33 & 99.45 & 99.73 & 99.85 & 99.24 & 99.72 & 99.86 & 100.08 \\
\hline $\mathrm{Si}$ & 1.90 & 1.86 & 1.85 & 1.87 & 1.88 & 1.90 & 1.87 & 1.89 & 1.86 & 1.88 & 1.86 & 1.86 & 1.84 & 1.94 & 1.84 & 1.86 & 1.86 & 1.87 & 1.85 & 1.88 & 1.89 & 1.89 & 1.88 & 1.92 & 1.88 \\
\hline $\mathrm{Ti}$ & 02 & 0.03 & 0.03 & 0.02 & 0.02 & 0.02 & 0.02 & 0.02 & 0.02 & 0.02 & 0. & 0. & 0.03 & 0.01 & 0.03 & 0.02 & 0.03 & 0.03 & 0.02 & 0.02 & 0.02 & 0.02 & 0.02 & 0.01 & 0.02 \\
\hline $\mathrm{Al}$ & 0.12 & 0.16 & 0.18 & 0.14 & 0.14 & 0.10 & 0.14 & 0.12 & 0.15 & 0.14 & 0.17 & 0.16 & 0.18 & 0.07 & 0.18 & 0.17 & 0.16 & 0.16 & 0.17 & 0.15 & 0.12 & 0.11 & 0.15 & 0.09 & 0.14 \\
\hline $\mathrm{Fe}^{+3}$ & 0.11 & 0.14 & 0.15 & 0.13 & 0.11 & 0.10 & 0.13 & 0.13 & 0.15 & 0.10 & 0.13 & 0.13 & 0.15 & 0.07 & 0.14 & 0.13 & 0.13 & 0.10 & 0.15 & 0.12 & 0.13 & 0.11 & 0.10 & 0.09 & 0.11 \\
\hline $\mathrm{Fe}^{+2}$ & 0.16 & 0.14 & 0.14 & 0.14 & 0.16 & 0.17 & 0.16 & 0.12 & 0.13 & 0.17 & 0.16 & 0.16 & 0.15 & 0.13 & 0.14 & 0.15 & 0.16 & 0.17 & 0.13 & 0.14 & 0.16 & 0.16 & 0.18 & 0.08 & 0.17 \\
\hline $\mathrm{Mn}$ & 0.01 & 0.01 & 0.01 & 0.01 & 0.01 & 0.01 & 0.01 & 0.01 & 0.01 & 0.01 & 0.01 & 0.01 & 0.01 & 0.01 & 0.01 & 0.01 & 0.01 & 0.01 & 0.01 & 0.01 & 0.01 & 0.01 & 0.01 & 0.00 & 0.01 \\
\hline $\mathrm{Mg}$ & 0.87 & 0.83 & 0.83 & 0.84 & 0.84 & 0.86 & 0.83 & 0.88 & 0.84 & 0.86 & 0.81 & 0.81 & 0.81 & 0.99 & 0.81 & 0.83 & 0.83 & 0.83 & 0.83 & 0.86 & 0.90 & 0.87 & 0.85 & 0.92 & 0.84 \\
\hline $\mathrm{Ca}$ & 0.84 & 0.85 & 0.84 & 0.86 & 0.85 & 0.84 & 0.85 & 0.85 & 0.85 & 0.82 & 0.85 & 0.86 & 0.86 & 0.78 & 0.87 & 0.84 & 0.82 & 0.84 & 0.86 & 0.84 & 0.78 & 0.84 & 0.81 & 0.88 & 0.85 \\
\hline $\mathrm{Na}$ & 0.02 & 0.02 & 0.03 & 0.02 & 0.02 & 0.02 & 0.03 & 0.02 & 0.03 & 0.02 & 0.03 & 0.02 & 0.02 & 0.03 & 0.02 & 0.03 & 0.03 & 0.02 & 0.02 & 0.02 & 0.02 & 0.02 & 0.02 & 0.02 & 0.02 \\
\hline Toplam & 4.03 & 4.04 & 4.05 & 4.04 & 4.03 & 4.03 & 4.04 & 4.04 & 4.05 & 4.03 & 4.04 & 4.04 & 4.05 & 4.01 & 4.04 & 4.04 & 4.04 & 4.03 & 4.04 & 4.04 & 4.04 & 4.03 & 4.03 & 4.02 & 4.04 \\
\hline $\mathrm{Al}^{(\mathrm{IV})}$ & 0.10 & 0.14 & 0.15 & 0.13 & 0.12 & 0.10 & 0.13 & 0.11 & 0.14 & 0.12 & 0.14 & 0.14 & 0.16 & 0.06 & 0.16 & 0.14 & 0.14 & 0.13 & 0.15 & 0.12 & 0.11 & 0.11 & 0.12 & 0.08 & 0.12 \\
\hline $\mathrm{Al}^{(\mathrm{VI})}$ & 0.01 & 0.02 & 0.02 & 0.01 & 0.02 & 0.01 & 0.02 & 0.01 & 0.01 & 0.02 & 0.03 & 0.02 & 0.02 & 0.02 & 0.03 & 0.03 & 0.02 & 0.03 & 0.02 & 0.03 & 0.00 & 0.01 & 0.03 & 0.01 & 0.02 \\
\hline $\mathrm{Mg}^{\#}$ & 0.76 & 0.75 & 0.74 & 0.75 & 0.75 & 0.76 & 0.74 & 0.78 & 0.75 & 0.76 & 0.73 & 0.73 & 0.73 & 0.83 & 0.74 & 0.75 & 0.73 & 0.75 & 0.74 & 0.76 & 0.75 & 0.76 & 0.75 & 0.84 & 0.75 \\
\hline Wo & 42.26 & 43.28 & 42.62 & 43.24 & 42.93 & 42.33 & 43.22 & 42.55 & 43.05 & 41.96 & 43.58 & 43.45 & 43.77 & 39.55 & 44.32 & 43.15 & 42.04 & 43.24 & 43.54 & 42.48 & 39.36 & 42.38 & 41.67 & 44.67 & 42.88 \\
\hline En & 43.85 & 42.22 & 42.22 & 42.44 & 42.81 & 43.46 & 42.02 & 44.32 & 42.44 & 43.69 & 41.18 & 41.21 & 40.89 & 50.19 & 41.14 & 42.19 & 42.32 & 42.30 & 41.87 & 43.66 & 45.32 & 43.74 & 43.56 & 46.61 & 42.47 \\
\hline Fs & 13.9 & 14.5 & 15.2 & 14.3 & 14.3 & 14.2 & 14.8 & 13.1 & 14.5 & 14.4 & 15.2 & 15.3 & 15.3 & 10.3 & 14.5 & 14.7 & 15.6 & 14.5 & 14.6 & 13.9 & 15.3 & 13.9 & 14.8 & 8.7 & 14.6 \\
\hline
\end{tabular}


Ek Tablo 1'in devamı

\begin{tabular}{|c|c|c|c|c|c|c|c|c|c|c|c|c|c|c|c|c|c|c|c|c|c|c|c|c|}
\hline \multirow{3}{*}{$\begin{array}{l}\text { Birim Adı } \\
\text { Örnek No }\end{array}$} & \multicolumn{24}{|c|}{ Bazalt } \\
\hline & & & & & & & & & & & $-26 \mathrm{c} 1$ & $\mathrm{~N}-26$ & & & & & & & & 26 & 26 & $26 \mathrm{c}$ & 26 & $-26 c 7$ \\
\hline & & & & & & & & & & & & & & & 01 & 02 & & $\mathrm{~m}$ & $\mathrm{k}$ & $\mathrm{m}$ & $\mathrm{k}$ & $\mathrm{m}$ & $\mathrm{k}$ & $\mathrm{m}$ \\
\hline $\mathrm{SiO}_{2}(\%)$ & 49.57 & 48.71 & 49.50 & 49.28 & 49.67 & 48.49 & 48.56 & 48.71 & 51.3 & 50.8 & 50.6 & 50.7 & 49.9 & 52.0 & 51.4 & 50.0 & 49.0 & 50.4 & 50.3 & 49.6 & 50.1 & 50.6 & 50.3 & 49.7 \\
\hline $\mathrm{TiO} 2$ & 0.96 & 1.11 & 0.97 & 0.86 & 0.90 & 1.26 & 1.13 & 1.18 & 0.6 & 0.6 & 0.6 & 0.7 & 0.8 & 0.3 & 0.4 & 0.5 & 0.8 & 0.7 & 0.6 & 0.8 & 0.7 & 0.6 & 0.6 & 0.8 \\
\hline $\mathrm{Al} 2 \mathrm{O} 3$ & 4.01 & 4.19 & 3.89 & 3.58 & 3.38 & 4.34 & 3.86 & 4.10 & 2.3 & 2.4 & 2.7 & 3.2 & 3.5 & 2.2 & 3.1 & 4.3 & 4.1 & 2.8 & 3.1 & 3.9 & 3.3 & 2.6 & 2.5 & 3.4 \\
\hline $\mathrm{FeO}^{*}$ & 9.08 & 9.09 & 9.20 & 8.62 & 9.48 & 9.84 & 9.50 & 9.10 & 9.9 & 9.6 & 10.2 & 9.1 & 10.0 & 6.0 & 6.2 & 7.3 & 10.5 & 9.8 & 8.9 & 9.8 & 10.1 & 9.3 & 9.8 & 9.7 \\
\hline $\mathrm{MnO}$ & 0.26 & 0.28 & 0.29 & 0.26 & 0.32 & 0.27 & 0.29 & 0.25 & 0.3 & 0.3 & 0.3 & 0.3 & 0.3 & 0.2 & 0.2 & 0.2 & 0.3 & 0.3 & 0.3 & 0.3 & 0.3 & 0.3 & 0.3 & 0.2 \\
\hline $\mathrm{MgO}$ & 14.38 & 14.10 & 14.62 & 14.72 & 14.57 & 13.82 & 14.25 & 14.60 & 15.6 & 15.5 & 15.1 & 15.3 & 15.1 & 16.4 & 16.0 & 15.6 & 14.8 & 15.1 & 15.3 & 14.7 & 14.7 & 15.1 & 15.5 & 14.7 \\
\hline $\mathrm{CaO}$ & 21.38 & 21.19 & 21.34 & 21.04 & 20.92 & 20.95 & 21.53 & 21.33 & 19.6 & 19.5 & 19.4 & 20.8 & 19.5 & 22.6 & 22.2 & 21.4 & 19.8 & 20.1 & 20.8 & 19.9 & 19.9 & 20.5 & 20.0 & 20.5 \\
\hline $\mathrm{Na} 2 \mathrm{O}$ & 0.33 & 0.39 & 0.36 & 0.29 & 0.34 & 0.36 & 0.34 & 0.40 & 0.3 & 0.3 & 0.3 & 0.3 & 0.3 & 0.2 & 0.3 & 0.3 & 0.3 & 0.3 & 0.2 & 0.3 & 0.3 & 0.2 & 0.3 & 0.3 \\
\hline Toplam & 99.97 & 99.06 & 100.18 & 98.66 & 99.59 & 99.33 & 99.46 & 99.67 & 99.80 & 98.93 & 99.30 & 100.25 & 99.43 & 99.88 & 99.77 & 99.63 & 99.67 & 99.54 & 99.57 & 99.25 & 99.42 & 99.19 & 99.14 & 99.23 \\
\hline $\mathrm{Si}$ & 1.86 & 1.84 & 1.85 & 1.87 & 1.87 & 1.83 & 1.83 & 1.83 & 1.9 & 1.9 & 1.9 & 1.9 & 1.9 & 2.0 & 1.9 & 1.9 & 1.8 & 1.9 & 1.9 & 1.9 & 1.9 & 1.9 & 1.9 & 1.9 \\
\hline $\mathrm{Ti}$ & 0.03 & 0.03 & 0.03 & 0.02 & 0.03 & 0.04 & 0.03 & 0.03 & 0.02 & 0.02 & 0.02 & 0.02 & 0.02 & 0.01 & 0.01 & 0.01 & 0.02 & 0.02 & 0.02 & 0.02 & 0.02 & 0.02 & 0.02 & 0.02 \\
\hline $\mathrm{Al}$ & 0.18 & 0.19 & 0.17 & 0.16 & 0.15 & 0.19 & 0.17 & 0.18 & 0.1 & 0.1 & 0.1 & 0.1 & 0.2 & 0.1 & 0.1 & 0.2 & 0.2 & 0.1 & 0.1 & 0.2 & 0.1 & 0.1 & 0.1 & 0.1 \\
\hline $\mathrm{Fe}+3$ & 0.12 & 0.13 & 0.14 & 0.12 & 0.12 & 0.06 & 0.10 & 0.16 & 0.2 & 0.1 & 0.1 & 0.2 & 0.1 & 0.3 & 0.3 & 0.3 & 0.1 & 0.1 & 0.2 & 0.1 & 0.1 & 0.1 & 0.1 & 0.1 \\
\hline $\mathrm{Fe}+2$ & 0.16 & 0.15 & 0.15 & 0.15 & 0.17 & 0.25 & 0.20 & 0.13 & 0.1 & 0.2 & 0.2 & 0.0 & 0.2 & -0.1 & -0.1 & 0.0 & 0.2 & 0.2 & 0.1 & 0.2 & 0.2 & 0.2 & 0.2 & 0.2 \\
\hline $\mathrm{Mn}$ & 0.01 & 0.01 & 0.01 & 0.01 & 0.01 & 0.01 & 0.01 & 0.01 & 0.0 & 0.0 & 0.0 & 0.0 & 0.0 & 0.0 & 0.0 & 0.0 & 0.0 & 0.0 & 0.0 & 0.0 & 0.0 & 0.0 & 0.0 & 0.0 \\
\hline $\mathrm{Mg}$ & 0.80 & 0.80 & 0.82 & 0.83 & 0.82 & 0.78 & 0.80 & 0.82 & 0.9 & 0.9 & 0.8 & 0.9 & 0.8 & 0.9 & 0.9 & 0.9 & 0.8 & 0.8 & 0.9 & 0.8 & 0.8 & 0.8 & 0.9 & 0.8 \\
\hline $\mathrm{Ca}$ & 0.86 & 0.86 & 0.86 & 0.85 & 0.84 & 0.84 & 0.87 & 0.86 & 0.8 & 0.8 & 0.8 & 0.8 & 0.8 & 0.9 & 0.9 & 0.9 & 0.8 & 0.8 & 0.8 & 0.8 & 0.8 & 0.8 & 0.8 & 0.8 \\
\hline $\mathrm{Na}$ & 0.02 & 0.03 & 0.03 & 0.02 & 0.03 & 0.03 & 0.02 & 0.03 & 0.0 & 0.0 & 0.0 & 0.0 & 0.0 & 0.0 & 0.0 & 0.0 & 0.0 & 0.0 & 0.0 & 0.0 & 0.0 & 0.0 & 0.0 & 0.0 \\
\hline Toplam & 4.04 & 4.04 & 4.04 & 4.04 & 4.04 & 4.02 & 4.03 & 4.05 & 4.05 & 4.02 & 4.03 & 4.08 & 4.04 & 4.10 & 4.10 & 4.08 & 4.04 & 4.04 & 4.05 & 4.03 & 4.03 & 4.03 & 4.03 & 4.02 \\
\hline $\mathrm{Al}(\mathrm{IV})$ & 0.14 & 0.16 & 0.15 & 0.13 & 0.13 & 0.17 & 0.17 & 0.17 & 0.07 & 0.09 & 0.09 & 0.09 & 0.12 & 0.04 & 0.06 & 0.12 & 0.15 & 0.10 & 0.10 & 0.13 & 0.11 & 0.09 & 0.11 & 0.13 \\
\hline $\mathrm{Al}(\mathrm{VI})$ & 0.03 & 0.03 & 0.02 & 0.03 & 0.02 & 0.02 & 0.00 & 0.02 & 0.03 & 0.02 & 0.03 & 0.05 & 0.03 & 0.06 & 0.07 & 0.07 & 0.03 & 0.02 & 0.03 & 0.04 & 0.03 & 0.02 & 0.00 & 0.02 \\
\hline Mg\# & 0.74 & 0.73 & 0.74 & 0.75 & 0.73 & 0.71 & 0.73 & 0.74 & 0.7 & 0.7 & 0.7 & 0.7 & 0.7 & 0.8 & 0.8 & 0.8 & 0.7 & 0.7 & 0.8 & 0.7 & 0.7 & 0.7 & 0.7 & 0.7 \\
\hline Wo & 43.98 & 44.10 & 43.54 & 43.48 & 42.90 & 43.64 & 44.00 & 43.65 & 39.8 & 40.1 & 39.9 & 42.1 & 40.2 & 44.9 & 44.9 & 43.6 & 40.6 & 41.1 & 42.3 & 41.2 & 41.0 & 41.9 & 40.5 & 42.1 \\
\hline En & 41.17 & 40.84 & 41.52 & 42.32 & 41.57 & 40.07 & 40.54 & 41.56 & 44.2 & 44.2 & 43.4 & 43.2 & 43.4 & 45.5 & 45.1 & 44.5 & 42.2 & 42.9 & 43.3 & 42.6 & 42.3 & 43.0 & 43.7 & 42.0 \\
\hline Fs & 14.9 & 15.1 & 14.9 & 14.2 & 15.5 & 16.3 & 15.5 & 14.8 & 16.0 & 15.7 & 16.7 & 14.8 & 16.4 & 9.5 & 10.0 & 11.9 & 17.2 & 16.0 & 14.4 & 16.2 & 16.7 & 15.0 & 15.8 & 15.8 \\
\hline
\end{tabular}


Ek Tablo 1'in devamı

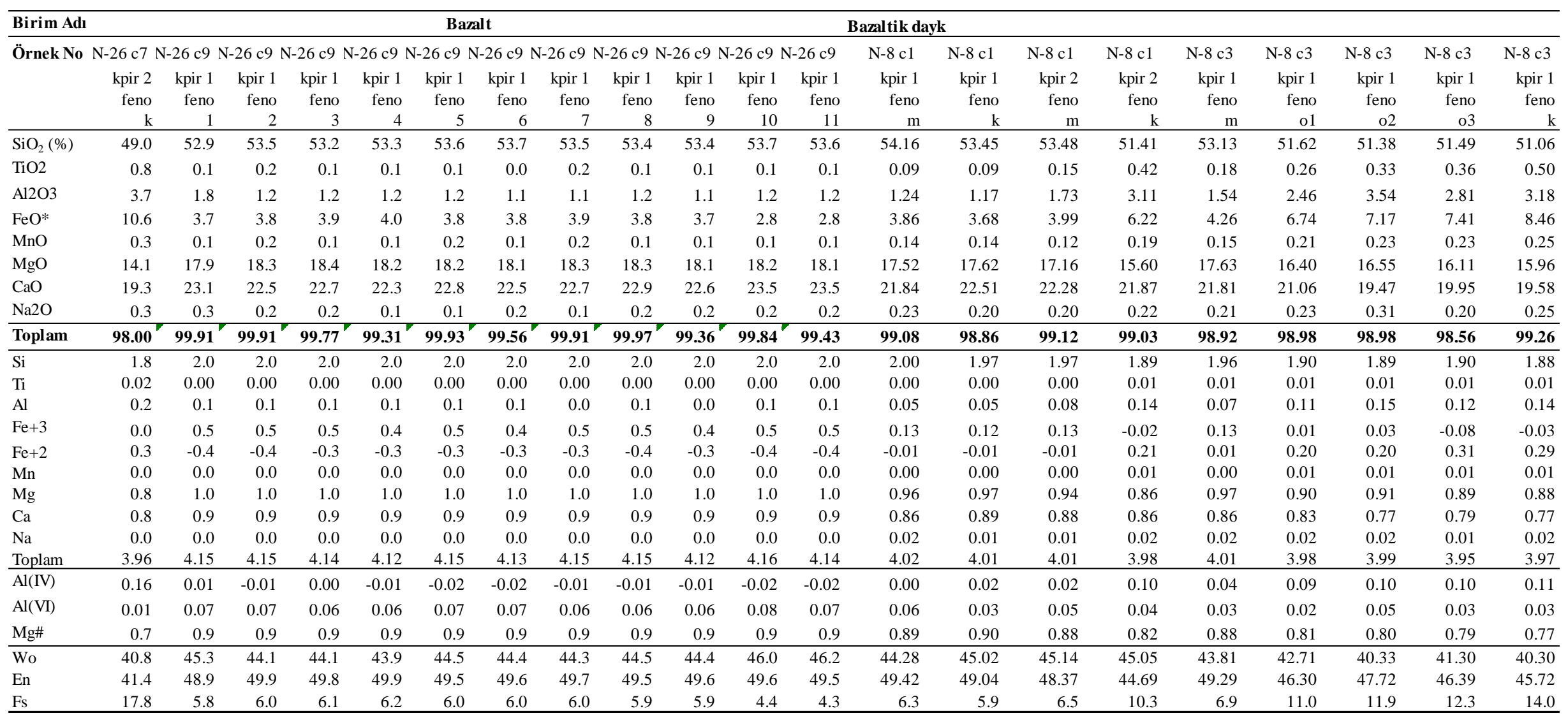


Ek Tablo 1'in devamı

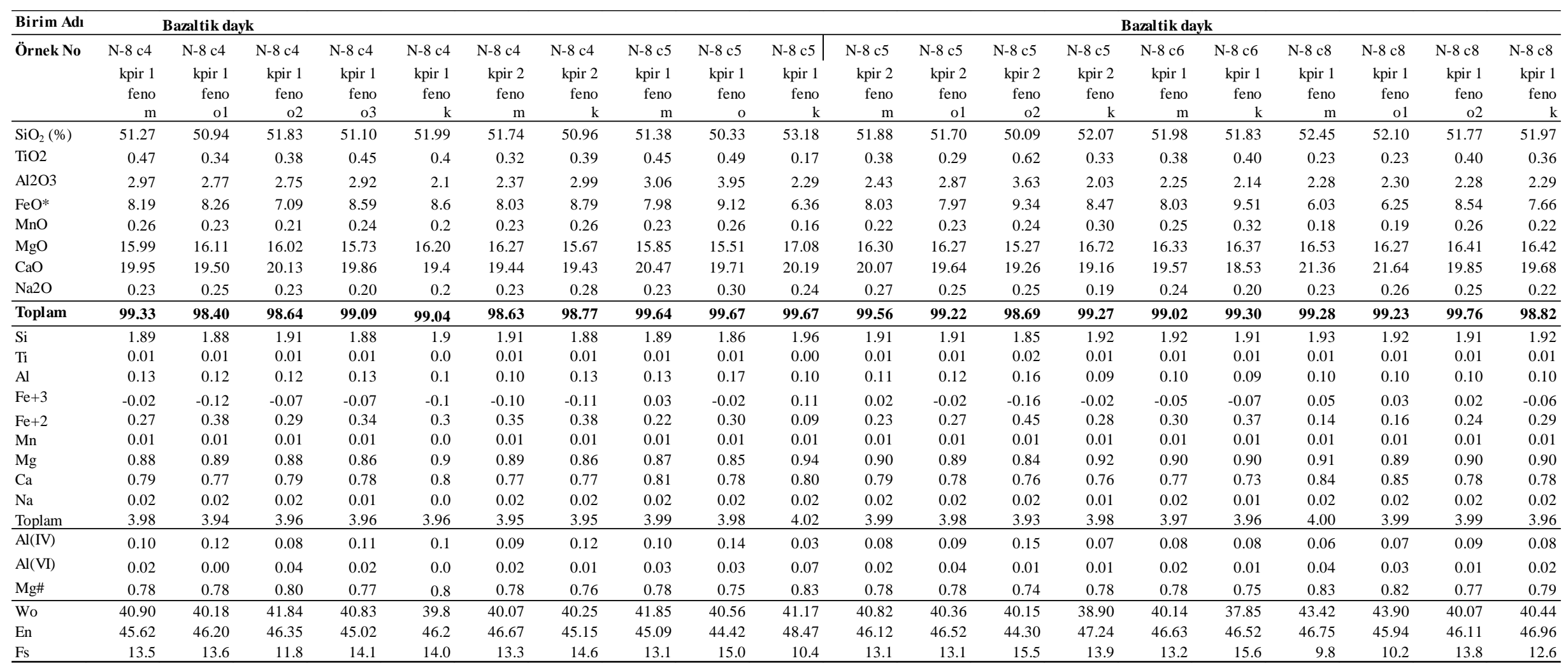


Ek Tablo 1'in devamı

\section{Birim Adı Bazaltik dayk}

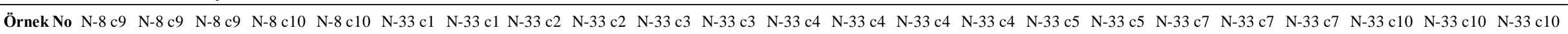

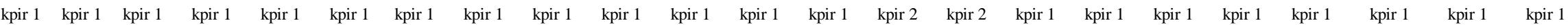
feno feno feno feno feno feno feno feno feno feno feno feno feno feno feno feno feno feno feno feno feno feno feno

\begin{tabular}{|c|c|c|c|c|c|c|c|c|c|c|c|c|c|c|c|c|c|c|c|c|c|c|c|}
\hline & $\mathrm{m}$ & $\mathrm{m}$ & $\mathrm{k}$ & $\mathrm{m}$ & $\mathrm{k}$ & $\mathrm{m}$ & $\mathrm{k}$ & $\mathrm{m}$ & $\mathrm{k}$ & $\mathrm{m}$ & $\mathrm{k}$ & $\mathrm{m}$ & $\mathrm{k}$ & $\mathrm{m}$ & $\mathrm{k}$ & $\mathrm{m}$ & $\mathrm{k}$ & $\underline{\mathrm{m}}$ & $\mathrm{o}$ & $\mathrm{k}$ & $\mathrm{m}$ & 0 & $\mathrm{k}$ \\
\hline $\mathrm{SiO}_{2}(\%)$ & 53.79 & 50.48 & 51.24 & 49.71 & 51.83 & 53.50 & 51.02 & 51.28 & 51.33 & 51.89 & 51.09 & 52.11 & 51.98 & 50.36 & 50.78 & 51.78 & 51.09 & 51.19 & 50.91 & 51.80 & 48.91 & 49.08 & 51.69 \\
\hline $\mathrm{TiO} 2$ & 0.13 & 0.55 & 0.5 & 0.65 & 0.42 & 0.06 & 0.58 & 0.59 & 0.40 & 0.43 & 0.56 & 0.27 & 0.40 & 0.75 & 0.72 & 0.34 & 0.51 & 0.7 & 0.68 & 0.51 & 0.89 & 0.70 & 0.39 \\
\hline $\mathrm{Al} 2 \mathrm{O} 3$ & 1.31 & 3.80 & 2.9 & 3.87 & 2.22 & 1.52 & 2.83 & 2.85 & 3.10 & 2.44 & 2.56 & 2.57 & 2.97 & 3.47 & 3.30 & 3.12 & 3.82 & 2.9 & 3.39 & 2.94 & 5.78 & 6.19 & 2.47 \\
\hline $\mathrm{FeO} *$ & 4.06 & 8.95 & 7.9 & 9.66 & 7.89 & 3.26 & 7.26 & 8.57 & 7.02 & 7.49 & 8.34 & 4.60 & 4.93 & 8.64 & 7.37 & 5.63 & 5.87 & 9.1 & 8.98 & 6.52 & 9.32 & 7.98 & 6.97 \\
\hline $\mathrm{MnO}$ & 0.14 & 0.25 & 0.2 & 0.22 & 0.20 & 0.14 & 0.19 & 0.24 & 0.19 & 0.23 & 0.23 & 0.12 & 0.16 & 0.23 & 0.21 & 0.20 & 0.13 & 0.3 & 0.27 & 0.18 & 0.22 & 0.21 & 0.21 \\
\hline $\mathrm{MgO}$ & 17.69 & 15.68 & 16.03 & 14.22 & 16.37 & 17.92 & 15.74 & 15.33 & 15.98 & 16.47 & 15.18 & 16.54 & 16.32 & 14.79 & 15.15 & 17.21 & 15.93 & 15.42 & 15.14 & 15.97 & 14.41 & 14.77 & 16.32 \\
\hline $\mathrm{CaO}$ & 22.18 & 19.74 & 20.4 & 20.47 & 19.77 & 21.96 & 21.09 & 20.05 & 20.77 & 19.66 & 20.48 & 22.66 & 21.94 & 20.75 & 21.22 & 20.17 & 21.35 & 19.6 & 19.69 & 21.31 & 19.66 & 20.03 & 21.04 \\
\hline $\mathrm{Na} 2 \mathrm{O}$ & 0.22 & 0.28 & 0.2 & 0.34 & 0.23 & 0.20 & 0.27 & 0.28 & 0.22 & 0.20 & 0.32 & 0.19 & 0.17 & 0.30 & 0.30 & 0.15 & 0.18 & 0.2 & 0.30 & 0.21 & 0.37 & 0.39 & 0.22 \\
\hline Toplam & 99.50 & 99.73 & 99.33 & 99.15 & 98.95 & 98.56 & 98.98 & 99.21 & 99.00 & 98.82 & 98.75 & 99.06 & 98.85 & 99.28 & 99.05 & 98.60 & 98.89 & 99.32 & $\begin{array}{l}99.35 \\
\end{array}$ & $\begin{array}{l}99.43 \\
\end{array}$ & 99.56 & \begin{tabular}{|l|}
99.34 \\
\end{tabular} & $\begin{array}{l}99.31 \\
\end{array}$ \\
\hline $\mathrm{Si}$ & 1.98 & 1.86 & 1.9 & 1.83 & 1.91 & 1.97 & 1.88 & 1.89 & 1.89 & 1.91 & 1.88 & 1.92 & 1.92 & 1.86 & 1.87 & 1.91 & 1.88 & 1.9 & 1.88 & 1.91 & 1.80 & 1.81 & 1.91 \\
\hline Ti & 0.00 & 0.02 & 0.0 & 0.02 & 0.01 & 0.00 & 0.02 & 0.02 & 0.01 & 0.01 & 0.02 & 0.01 & 0.01 & 0.02 & 0.02 & 0.01 & 0.0 & 0.0 & 0.02 & 0.01 & 0.02 & 0.02 & 0.01 \\
\hline Al & 0.06 & 0.17 & 0.1 & 0.17 & 0.10 & 0.07 & 0.12 & 0.12 & 0.13 & 0.11 & 0.11 & 0.11 & 0.13 & 0.15 & 0.14 & 0.14 & 0.17 & 0.1 & 0.15 & 0.13 & 0.25 & 0.27 & 0.11 \\
\hline $\mathrm{Fe}+3$ & 0.17 & 0.01 & 0.0 & -0.15 & -0.05 & 0.14 & -0.05 & -0.09 & -0.01 & -0.05 & -0.15 & 0.10 & 0.07 & -0.09 & -0.05 & 0.05 & 0.02 & -0.1 & -0.08 & 0.04 & -0.05 & 0.00 & 0.02 \\
\hline $\mathrm{Fe}+2$ & -0.05 & 0.27 & 0.2 & 0.45 & 0.29 & -0.04 & 0.27 & 0.35 & & 0.28 & 0.40 & 0.04 & 0.08 & 0.36 & 0.28 & 0.13 & & 0.4 & & & 0.34 & 0.24 & 0.20 \\
\hline Mn & 0.00 & 0.01 & 0.0 & 0.01 & 0.01 & 0.00 & 0.01 & 0.01 & 0.01 & 0.01 & 0.01 & 0.00 & 0.00 & 0.01 & 0.01 & 0.01 & 0.00 & 0.0 & 0.01 & 0.01 & 0.01 & 0.01 & 0.01 \\
\hline $\mathrm{Mg}$ & 0.97 & 0.86 & 0.9 & 0.78 & 0.90 & 0.98 & 0.87 & 0. & 0.88 & 0.90 & 0.83 & 0.91 & 0.90 & 0.81 & 0.83 & 0.95 & & 0. & 0.83 & 88 & 0.79 & 0.81 & 0.90 \\
\hline $\mathrm{Ca}$ & 0.88 & 0.78 & 0.8 & 0.81 & 0.78 & 0.87 & 0.83 & 0.79 & 0.82 & 0.78 & 0.81 & 0.89 & 0.87 & 0.82 & 0.84 & 0.80 & 0.84 & 0.8 & 0.78 & 0.84 & 0.78 & 0.79 & 0.83 \\
\hline $\mathrm{Na}$ & 0.02 & 0.02 & 0.0 & 0.02 & 0.02 & 0.01 & 0.02 & 0.02 & 0.02 & 0.01 & 0.02 & 0.01 & 0.01 & 0.02 & 0.02 & 0.01 & 0.01 & 0.0 & 0.02 & 0.01 & 0.03 & 0.03 & 0.02 \\
\hline & 4.04 & 3.99 & 3.98 & 3.94 & 3.97 & 4.01 & 3.97 & 3.96 & 3.97 & 3.96 & 3.94 & 4.00 & 3.99 & 3.95 & 3.96 & 3.99 & 3.98 & 3.96 & 3.96 & 3.99 & 3.97 & 3.98 & 3.99 \\
\hline $\mathrm{Al}(\mathrm{IV})$ & 0.01 & 0.13 & 0.1 & 0.16 & 0.08 & 0.02 & 0.11 & 0.10 & 0.10 & 0.08 & 0.11 & 0.07 & 0.08 & 0.14 & 0.12 & 0.09 & 0.11 & 0.1 & 0.12 & 0.08 & 0.19 & 0.19 & 0.09 \\
\hline $\mathrm{Al}(\mathrm{VI})$ & 0.05 & 0.03 & 0.0 & 0.01 & 0.01 & 0.04 & 0.01 & 0.02 & 0.03 & 0.02 & 0.00 & 0.04 & 0.05 & 0.01 & 0.02 & 0.05 & 0.06 & 0.0 & 0.03 & 0.04 & 0.06 & 0.08 & 0.02 \\
\hline Mg\# & 0.89 & 0.76 & 0.8 & 0.72 & 0.79 & 0.91 & 0.79 & 0.76 & 0.80 & 0.80 & 0.76 & 0.87 & 0.86 & 0.75 & 0.79 & 0.84 & 0.83 & 0.8 & 0.75 & 0.81 & 0.73 & 0.77 & 0.81 \\
\hline Wo & 44.31 & 40.51 & 41.6 & 42.7 & 40.5 & 44.33 & 43.22 & 41.55 & 42.73 & 40.47 & 42.43 & 45.91 & 45.14 & 43.01 & 44.03 & 41.46 & 44.31 & 40.6 & 41.05 & 43.72 & 41.70 & 42.65 & 42.65 \\
\hline En & 49.16 & 44.79 & 45.5 & 41.3 & 46.6 & 50.33 & 44.89 & 44.22 & 45.74 & 47.16 & 43.76 & 46.65 & 46.72 & 42.67 & 43.74 & 49.21 & 46.00 & 44.4 & 43.94 & 45.59 & 42.54 & 43.77 & 46.02 \\
\hline Fs & 6.5 & 14.7 & 12.9 & 16.0 & 12.9 & 5.3 & 11.9 & 14.2 & 11.5 & 12.4 & 13.8 & 7.4 & 8.1 & 14.3 & 12.2 & 9.3 & 9.7 & 15.1 & 15.0 & 10.7 & 15.8 & 13.6 & 11.3 \\
\hline
\end{tabular}


Ek Tablo 2. Kışlaköy (Erzurum-Narman) yöresi Eosen yaşlı volkanik kayaçlara ait plajiyoklaz minerallerinin mikroprob analiz sonuçları

\begin{tabular}{|c|c|c|c|c|c|c|c|c|c|c|c|c|c|c|c|c|c|c|c|c|c|c|c|c|}
\hline Birim Adı & & & & & & & & Baz: & & & & & & & & & & & & & & & & \\
\hline Örn & 5601 & & & & & & & & & & & & & & & & & & & & & & & \\
\hline & plaj-1 & plaj-1 & plaj-1 & plaj-1 & plaj & plaj-1 & plaj-1 & plaj-1 & plaj-1 & plaj-2 & plaj-2 & plaj & plaj & plaj-1 & plaj-1 & plaj & plaj-1 & plaj-1 & plaj & plaj-1 & plaj-1 & plaj & plaj & plaj-1 \\
\hline & feno & feno & feno & feno & mik1 & feno & feno & feno & feno & feno & feno & mik2 & mik3 & feno & feno & mik4 & feno & feno & mik1 & feno & feno & mik2 & mik3 & feno \\
\hline & $\mathrm{m}$ & $\mathrm{k}$ & $\mathrm{m}$ & $\mathrm{k}$ & $\mathrm{m}$ & $\mathrm{m}$ & $\mathrm{k}$ & $\mathrm{m}$ & $\mathrm{k}$ & $\mathrm{m}$ & $\mathrm{k}$ & $\mathrm{m}$ & $\mathrm{m}$ & $\mathrm{m}$ & $\mathrm{k}$ & $\mathrm{m}$ & $\mathrm{m}$ & $\mathrm{k}$ & $\mathrm{m}$ & $\mathrm{m}$ & $\mathrm{k}$ & $\mathrm{m}$ & $\mathrm{m}$ & $\mathrm{m}$ \\
\hline $\mathrm{SiO}_{2}(\%)$ & 52.67 & 52.73 & 49.01 & 52.26 & 52.26 & 53.71 & 52.00 & 52.94 & 52.08 & 50.25 & 52.56 & 51.44 & 50.66 & 52.11 & 52.11 & 51.46 & 52.65 & 52.45 & 52.78 & 52.68 & 51.78 & 51.54 & 51.10 & 51.98 \\
\hline $\mathrm{Al}_{2} \mathbf{O}_{3}$ & 29.14 & 29.09 & 32.09 & 29.33 & 29.35 & 26.77 & 29.93 & 29.20 & 29.49 & 30.89 & 29.39 & 30.02 & 30.82 & 29.55 & 29.27 & 30.09 & 28.65 & 29.31 & 29.49 & 29.00 & 29.63 & 29.81 & 30.31 & 29.60 \\
\hline $\mathrm{FeO}^{*}$ & 0.87 & 0.80 & 0.74 & 0.79 & 0.88 & 0.98 & 0.82 & 0.88 & 0.91 & 0.86 & 0.84 & 0.82 & 0.87 & 0.88 & 1.29 & 0.91 & 0.95 & 1.02 & 1.03 & 0.99 & 1.07 & 1.12 & 1.12 & 0.91 \\
\hline $\mathrm{CaO}$ & 12.39 & 12.56 & 15.60 & 12.87 & 12.49 & 10.77 & 13.00 & 12.52 & 12.92 & 14.20 & 12.88 & 13.07 & 13.83 & 12.89 & 12.53 & 13.53 & 12.26 & 12.91 & 12.64 & 12.63 & 13.18 & 13.20 & 13.96 & 12.95 \\
\hline $\mathrm{Na}_{2} \mathrm{O}$ & 3.99 & 4.05 & 2.52 & 3.96 & 3.98 & 3.34 & 3.76 & 3.85 & 3.85 & 3.08 & 3.75 & 3.70 & 3.27 & 3.75 & 3.83 & 3.53 & 4.22 & 4.15 & 4.15 & 4.10 & 3.87 & 3.85 & 3.62 & 3.96 \\
\hline $\mathrm{K}_{2} \mathrm{O}$ & 0.57 & 0.56 & 0.27 & 0.52 & 0.56 & 3.61 & 0.53 & 0.58 & 0.51 & 0.42 & 0.51 & 0.48 & 0.38 & 0.52 & 0.67 & 0.42 & 0.61 & 0.40 & 0.36 & 0.53 & 0.29 & 0.34 & 0.29 & 0.43 \\
\hline Toplam & 99.62 & 99.78 & 100.23 & 99.73 & 99.53 & \begin{tabular}{|l|l|}
99.18 \\
\end{tabular} & 100.04 & 99.95 & 99.75 & \begin{tabular}{|c|}
99.70 \\
\end{tabular} & \begin{tabular}{|l|l|}
99.93 \\
\end{tabular} & 99.54 & \begin{tabular}{|l|l|}
99.83 \\
\end{tabular} & \begin{tabular}{|l|l|}
99.70 \\
\end{tabular} & \begin{tabular}{|l|l|}
99.70 \\
\end{tabular} & 99.95 & \begin{tabular}{|l|l|}
99.34 \\
\end{tabular} & 100.23 & 100.45 & 99.93 & \begin{tabular}{|c|}
99.82 \\
\end{tabular} & 99.85 & 100.40 & 99.83 \\
\hline $\mathbf{S i}$ & 9.63 & 9.63 & 8.98 & 9.56 & 9.57 & 9.96 & $\begin{array}{l}9.48 \\
\end{array}$ & 9.64 & 9.53 & 9.23 & 9.58 & 9.43 & 9.28 & 9.53 & 9.55 & 9.41 & 9.66 & 9.55 & 9.58 & 9.62 & 9.47 & 9.44 & 9.32 & 9.50 \\
\hline $\mathbf{A l}(\mathbf{t})$ & 6.28 & 6.26 & 6.93 & 6.32 & 6.33 & 5.85 & 6.43 & 6.27 & 6.36 & 6.68 & 6.31 & 6.49 & 6.65 & 6.37 & 6.32 & 6.48 & 6.20 & 6.29 & 6.31 & 6.24 & 6.39 & 6.43 & 6.52 & 6.38 \\
\hline $\mathrm{Fe}^{+2}$ & 0.13 & 0.12 & 0.11 & 0.12 & 0.14 & 0.15 & 0.13 & 0.13 & 0.14 & 0.13 & 0.13 & 0.13 & 0.13 & 0.13 & 0.20 & 0.14 & 0.15 & 0.16 & 0.16 & 0.15 & 0.16 & 0.17 & 0.17 & 0.14 \\
\hline $\mathrm{Ca}$ & 2.43 & 2.46 & 3.06 & 2.52 & 2.45 & 2.14 & 2.54 & 2.44 & 2.53 & 2.79 & 2.52 & 2.57 & 2.71 & 2.53 & 2.46 & 2.65 & 2.41 & 2.52 & 2.46 & 2.47 & 2.58 & 2.59 & 2.73 & 2.54 \\
\hline $\mathrm{Na}$ & 1.41 & 1.43 & 0.90 & 1.40 & 1.41 & 1.20 & 1.33 & 1.36 & 1.37 & 1.10 & 1.33 & 1.31 & 1.16 & 1.33 & 1.36 & 1.25 & 1.50 & 1.46 & 1.46 & 1.45 & 1.37 & 1.37 & 1.28 & 1.40 \\
\hline $\mathbf{K}$ & 0.13 & 0.13 & 0.06 & 0.12 & 0.13 & 0.85 & 0.12 & 0.13 & 0.12 & 0.10 & 0.12 & 0.11 & 0.09 & 0.12 & 0.16 & 0.10 & 0.14 & 0.09 & 0.08 & 0.12 & 0.07 & 0.08 & 0.07 & 0.10 \\
\hline Toplam & 20.01 & 20.03 & 20.04 & 20.04 & 20.03 & 20.15 & 20.03 & 19.97 & 20.04 & 20.03 & 19.99 & 20.04 & 20.02 & 20.01 & 20.05 & 20.03 & 20.06 & 20.08 & 20.04 & 20.05 & 20.05 & 20.07 & 20.09 & 20.06 \\
\hline$\%$ An & 61.08 & 61.12 & 76.14 & 62.31 & 61.35 & 51.00 & 63.64 & 62.07 & 63.05 & 70.00 & 63.49 & 64.27 & 68.50 & 63.53 & 61.86 & 66.24 & 59.45 & 61.81 & 61.45 & 61.08 & 64.23 & 64.19 & 66.92 & 62.77 \\
\hline$\% \mathbf{A b}$ & 35.56 & 35.64 & 22.30 & 34.67 & 35.35 & 28.64 & 33.27 & 34.51 & 33.99 & 27.52 & 33.49 & 32.91 & 29.28 & 33.41 & 34.21 & 31.31 & 37.01 & 35.93 & 36.48 & 35.87 & 34.11 & 33.86 & 31.41 & 34.72 \\
\hline$\%$ Or & 3.36 & 3.24 & 1.56 & 3.02 & 3.30 & 20.36 & 3.09 & 3.41 & 2.96 & 2.47 & 3.02 & 2.82 & 2.22 & 3.05 & 3.94 & 2.45 & 3.54 & 2.26 & 2.07 & 3.04 & 1.66 & 1.95 & 1.67 & 2.51 \\
\hline
\end{tabular}

Not: Ana oksit değerleri \% ağılık cinsindendir. \% An, Ab ve Or: Sirasıyla anortit, albit ve ortoklas yüzdeleri, Fe ${ }^{+2}$ toplam Fe olarak alınmıştır. Plaj-plajiyoklas, feno-fenokristal,

m: kristal merkezi, o: orta, k:kristal kenarı. Yapısal parametreler 32 oksijene göre hesaplanmıştır. 


\section{Ek Tablo 2'nin devamı}

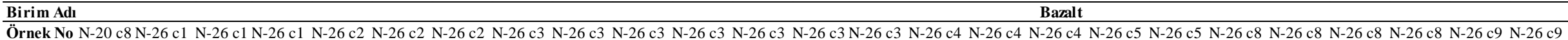

Bazalt

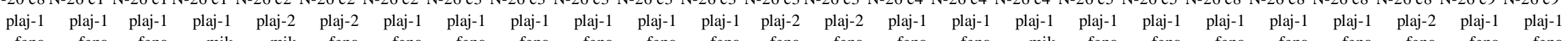
feno feno reno mik mik reno reno reno reno reno reno feno feno feno feno feno mik feno feno feno feno feno feno feno feno \begin{tabular}{rrrrrrrrrrrrrrrrrrrrrrrrrrr} 
& $\mathrm{k}$ & $\mathrm{m}$ & $\mathrm{k}$ & $\mathrm{m}$ & $\mathrm{m}$ & $\mathrm{m}$ & $\mathrm{k}$ & $\mathrm{m}$ & $\mathrm{o} 1$ & $\mathrm{o} 2$ & $\mathrm{o} 3$ & $\mathrm{k}$ & $\mathrm{m}$ & $\mathrm{k}$ & $\mathrm{m}$ & $\mathrm{k}$ & $\mathrm{m}$ & $\mathrm{m}$ & $\mathrm{k}$ & $\mathrm{m}$ & $\mathrm{k}$ & $\mathrm{m}$ & $\mathrm{k}$ & $\mathrm{m}$ & $\mathrm{k}$ \\
\hline $\mathbf{S i O}_{2}(\%)$ & 52.546 & 51.77 & 52.07 & 51.44 & 52.50 & 51.58 & 52.57 & 51.99 & 50.88 & 50.55 & 53.17 & 52.62 & 50.67 & 53.22 & 51.14 & 51.34 & 53.11 & 50.90 & 52.74 & 51.21 & 51.62 & 50.64 & 50.71 & 49.84 & 51.90
\end{tabular}

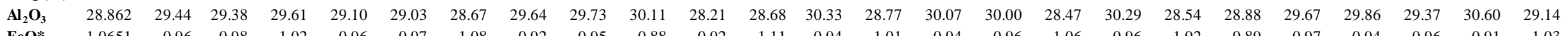

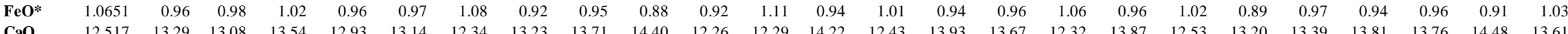

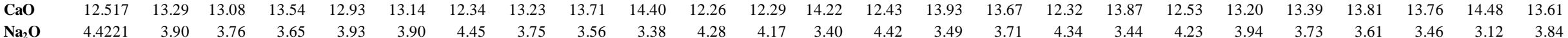
\begin{tabular}{llllllllllllllllllllllllllllll}
$\mathrm{Na}_{2} \mathbf{O}$ & 4.4221 & .90 & 3.76 & 3.65 & 3.93 & .90 & 4.45 & 3.75 & 3.56 & 3.38 & 4.28 & 4.17 & 3.40 & 4.42 & 3.49 & 3.71 & 4.34 & 3.44 & 4.23 & 3.94 & 3.73 & 3.61 & 3.46 & 3.12 & 3.84 \\
$\mathbf{K}_{2} \mathbf{O}$ & 0.4293 & 0.38 & 0.38 & 0.36 & 0.40 & 0.41 & 0.49 & 0.38 & 0.35 & 0.29 & 0.47 & 0.47 & 0.30 & 0.48 & 0.33 & 0.34 & 0.50 & 0.34 & 0.44 & 0.39 & 0.34 & 0.34 & 0.33 & 0.29 & 0.40 \\
\hline
\end{tabular}

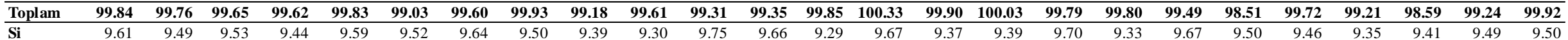

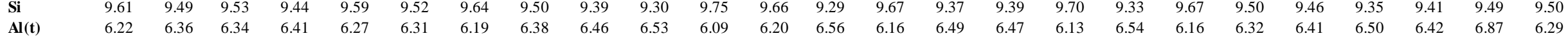

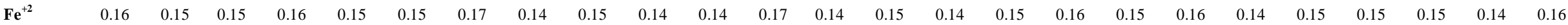
$\begin{array}{llllllllllllllllllllllllll}\mathbf{C a} & 2.45 & 2.61 & 2.57 & 2.66 & 2.53 & 2.60 & 2.42 & 2.59 & 2.71 & 2.84 & 2.41 & 2.42 & 2.79 & 2.42 & 2.73 & 2.68 & 2.41 & 2.72 & 2.46 & 2.63 & 2.63 & 2.73 & 2.74 & 2.95 & 2.67\end{array}$

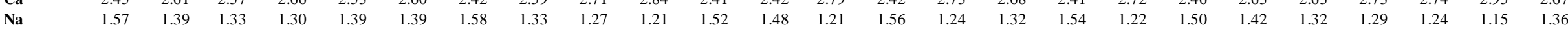
$\begin{array}{llllllllllllllllllllllllllll}\mathbf{K} & & 0.10 & 0.09 & 0.09 & 0.08 & 0.09 & 0.10 & 0.12 & 0.09 & 0.08 & 0.07 & 0.11 & 0.11 & 0.07 & 0.11 & 0.08 & 0.08 & 0.12 & 0.08 & 0.10 & 0.09 & 0.08 & 0.08 & 0.08 & 0.07 & 0.09\end{array}$ \begin{tabular}{lrrrrrrrrrrrrrrrrrrrrrrrrr} 
Toplam & $\mathbf{2 0 . 1 1}$ & $\mathbf{2 0 . 0 7}$ & $\mathbf{2 0 . 0 1}$ & $\mathbf{2 0 . 0 5}$ & $\mathbf{2 0 . 0 2}$ & $\mathbf{2 0 . 0 7}$ & $\mathbf{2 0 . 1 1}$ & $\mathbf{2 0 . 0 2}$ & $\mathbf{2 0 . 0 6}$ & $\mathbf{2 0 . 0 7}$ & $\mathbf{2 0 . 0 2}$ & $\mathbf{2 0 . 0 4}$ & $\mathbf{2 0 . 0 7}$ & $\mathbf{2 0 . 0 8}$ & $\mathbf{2 0 . 0 5}$ & $\mathbf{2 0 . 0 8}$ & $\mathbf{2 0 . 0 6}$ & $\mathbf{2 0 . 0 5}$ & $\mathbf{2 0 . 0 5}$ & $\mathbf{2 0 . 0 9}$ & $\mathbf{2 0 . 0 4}$ & $\mathbf{2 0 . 0 9}$ & $\mathbf{2 0 . 0 4}$ & $\mathbf{2 0 . 6 8}$ & $\mathbf{2 0 . 0 8}$ \\
\hline & & & 20.5 &
\end{tabular}

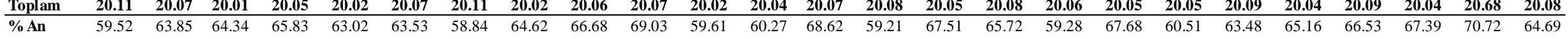
\begin{tabular}{llllllllllllllllllllllllllll} 
\% An & 59.52 & 63.85 & 64.34 & 65.83 & 63.02 & 63.53 & 58.84 & 64.62 & 66.68 & 69.03 & 59.61 & 60.27 & 68.62 & 59.21 & 67.51 & 65.72 & 59.28 & 67.68 & 60.51 & 63.48 & 65.16 & 66.53 & 67.39 & 70.72 & 64.69 \\
\% Ab & 38.05 & 33.96 & 33.46 & 32.10 & 34.65 & 34.11 & 38.36 & 33.16 & 31.31 & 29.34 & 37.66 & 36.96 & 29.66 & 38.09 & 30.61 & 32.31 & 37.85 & 30.36 & 36.98 & 34.28 & 32.85 & 31.50 & 30.66 & 27.56 & 33.06 \\
\hline
\end{tabular}

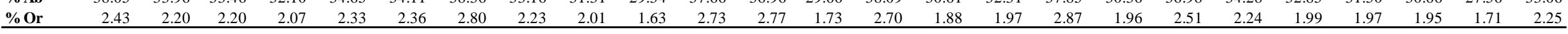


Ek Tablo 2'nin devamı

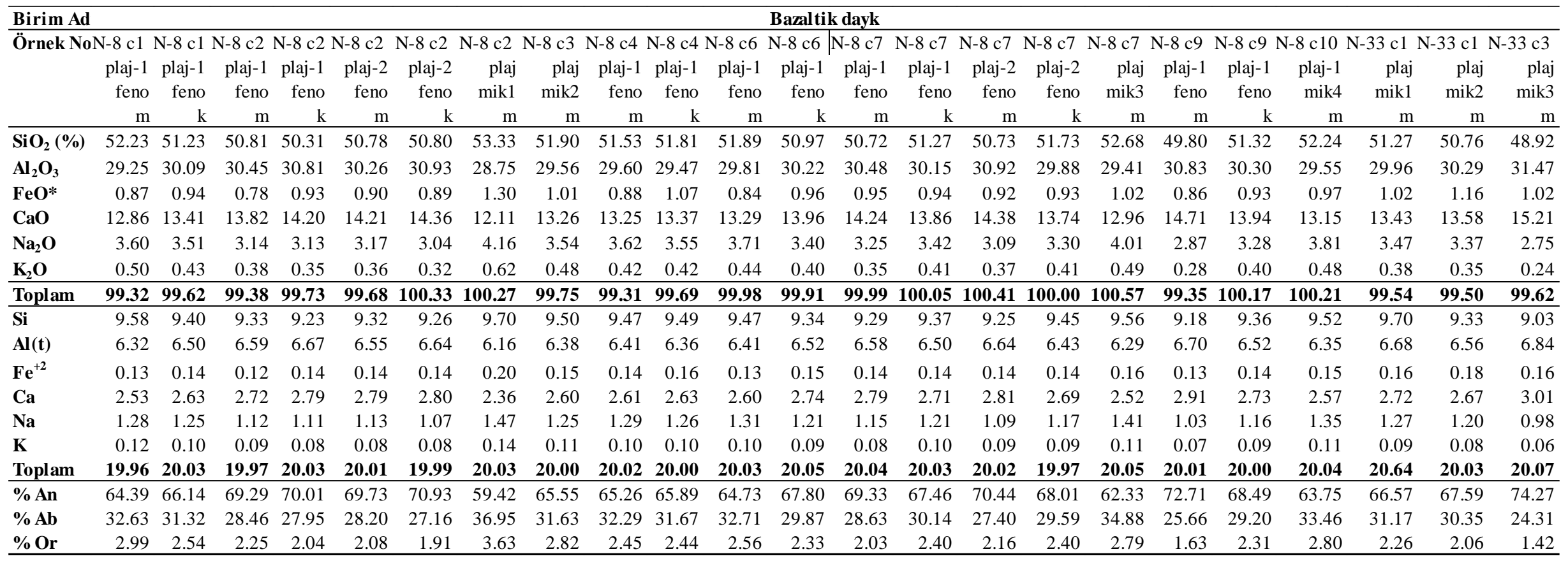


Ek Tablo 2'nin devamı

\begin{tabular}{|c|c|c|c|c|c|c|c|c|c|c|c|c|c|c|c|c|c|c|c|c|}
\hline \multirow{3}{*}{$\begin{array}{l}\text { Birim Ad } \\
\text { Örnek NoN }\end{array}$} & \multicolumn{20}{|c|}{ Bazal tik dayk } \\
\hline & $\begin{array}{r}\mathrm{N}-33 \mathrm{c} 5 \\
\text { plaj-1 } \\
\text { feno }\end{array}$ & $\begin{array}{r}\text { N-33 c5 } \\
\text { plaj-1 } \\
\text { feno }\end{array}$ & $\begin{array}{r}\text { N-33 c8 } \\
\text { plaj-1 } \\
\text { feno }\end{array}$ & $\begin{array}{r}\text { N-33 c8 } \\
\text { plaj-1 } \\
\text { feno }\end{array}$ & $\begin{array}{r}\mathrm{N}-33 \mathrm{c} 8 \\
\text { plaj } \\
\text { mik4 }\end{array}$ & $\begin{array}{r}\mathrm{N}-33 \mathrm{c} 11 \\
\mathrm{j} \\
4\end{array}$ & $\begin{array}{rr} & \mathrm{V}-33 \mathrm{c} 11 \\
1 & \text { plaj-1 } \\
0 & \text { feno }\end{array}$ & $\begin{array}{r}\mathrm{N}-33 \text { c11 } \\
\text { plaj-1 } \\
\text { feno }\end{array}$ & $\begin{array}{r}\mathrm{N}-5 \mathrm{c} 1 \\
\text { plaj-1 } \\
\text { feno }\end{array}$ & $\begin{array}{r}\mathrm{N}-5 \mathrm{c} 1 \\
\text { plaj-1 } \\
\text { feno }\end{array}$ & $\begin{array}{r}\mathrm{N}-5 \mathrm{c} 3 \\
\text { plaj } \\
\text { mik1 }\end{array}$ & $\begin{array}{r}\mathrm{N}-5 \mathrm{c} 3 \\
\text { plaj } \\
\text { mik2 }\end{array}$ & $\begin{array}{r}\mathrm{N}-5 \text { c5 } \\
\text { plaj-1 } \\
\text { feno }\end{array}$ & $\begin{array}{r}\mathrm{N}-5 \mathrm{c} 5 \\
\text { plaj-1 } \\
\text { feno }\end{array}$ & $\begin{array}{r}\mathrm{N}-5 \text { c5 } \\
\text { plaj } \\
\text { mik }\end{array}$ & $\begin{array}{r}\mathrm{N}-5 \mathrm{c} 6 \\
\text { plaj } \\
\text { mik4 }\end{array}$ & $\begin{array}{r}\text { N-5 c7 } \\
\text { j plaj-1 } \\
\text { feno }\end{array}$ & $\begin{array}{r}\text { N-5 c7 } \\
\text { plaj-1 } \\
\text { feno }\end{array}$ & $\begin{array}{r}\mathrm{N}-5 \mathrm{c} 8 \\
\text { plaj-1 } \\
\text { feno }\end{array}$ & $\begin{array}{r}\text { N-5 c8 } \\
\text { plaj-1 } \\
\text { feno }\end{array}$ \\
\hline & $\mathrm{m}$ & $\mathrm{k}$ & $\mathrm{m}$ & $\mathrm{k}$ & $\mathrm{m}$ & $\mathrm{m}$ & n orta & $\mathrm{k}$ & $\mathrm{m}$ & $\mathrm{k}$ & $\mathrm{m}$ & $\mathrm{m}$ & $\mathrm{m}$ & $\mathrm{k}$ & $\mathrm{m}$ & $\mathrm{m}$ & $\mathrm{m}$ & $\mathrm{k}$ & $\mathrm{m}$ & $\mathrm{k}$ \\
\hline $\mathrm{SiO}_{2}(\%)$ & 49.39 & 49.77 & 50.57 & 49.37 & 48.99 & 50.80 & 50.89 & 48.97 & 47.94 & 50.90 & 51.99 & 55.61 & 47.58 & 49.09 & 51.71 & 52.19 & 49.93 & 54.45 & 49.61 & 48.61 \\
\hline $\mathbf{A l}_{2} \mathbf{O}_{3}$ & 31.53 & 27.16 & 30.91 & 31.64 & 31.26 & 30.17 & 30.18 & 31.11 & 33.01 & 30.35 & 29.98 & 27.88 & 33.19 & 30.94 & 30.52 & 29.63 & 31.15 & 28.38 & 31.37 & 31.73 \\
\hline $\mathrm{FeO}^{*}$ & 0.64 & 3.31 & 0.84 & 0.88 & 1.03 & 0.84 & 1.06 & 0.93 & 0.80 & 0.71 & 0.64 & 0.73 & 0.74 & 1.13 & 0.67 & 0.77 & 0.80 & 0.70 & 0.72 & 0.89 \\
\hline $\mathrm{CaO}$ & 14.70 & 12.74 & 14.33 & 15.15 & 15.33 & 14.29 & 13.90 & 14.75 & 16.61 & 13.69 & 13.17 & 10.04 & 16.81 & 14.74 & 13.54 & 13.18 & 14.80 & 11.29 & 14.91 & 15.70 \\
\hline $\mathrm{Na}_{2} \mathrm{O}$ & 2.76 & 2.22 & 2.92 & 2.76 & 2.71 & 3.17 & 3.40 & 2.85 & 2.15 & 3.56 & 3.69 & 5.08 & 2.12 & 2.71 & 3.60 & 4.04 & 3.03 & 4.73 & 2.95 & 2.39 \\
\hline $\mathbf{K}_{2} \mathbf{O}$ & 0.39 & 0.82 & 0.35 & 0.29 & 0.26 & 0.43 & 0.43 & 0.30 & 0.19 & 0.45 & 0.47 & 0.93 & 0.21 & 0.23 & 0.37 & 0.48 & 0.28 & 0.70 & 0.33 & 0.30 \\
\hline Toplam & 99.41 & 96.01 & 99.91 & 100.09 & 99.59 & 99.70 & 99.86 & 98.91 & 100.69 & 99.66 & 99.94 & 100.27 & 100.64 & 98.84 & 100.41 & 100.29 & 99.99 & 100.25 & 99.89 & 99.62 \\
\hline $\mathbf{S i}$ & 9.10 & 9.56 & 9.25 & 9.05 & 9.05 & 9.33 & 9.33 & 9.09 & 8.77 & 9.34 & 9.48 & 10.03 & 8.72 & 9.11 & 9.39 & 9.50 & 9.15 & 9.86 & 9.11 & 8.97 \\
\hline $\mathbf{A l}(\mathbf{t})$ & 6.84 & 6.15 & 6.67 & 6.84 & 6.80 & 6.53 & 6.52 & 6.80 & 7.12 & 6.56 & 6.44 & 5.93 & 7.17 & 6.77 & 6.53 & 6.36 & 6.73 & 6.05 & 6.79 & 6.90 \\
\hline $\mathrm{Fe}^{+2}$ & 0.10 & 0.53 & 0.13 & 0.13 & 0.16 & 0.13 & 0.16 & 0.14 & 0.12 & 0.11 & 0.10 & 0.11 & 0.11 & 0.18 & 0.10 & 0.12 & 0.12 & 0.11 & 0.11 & 0.14 \\
\hline $\mathrm{Ca}$ & 2.90 & 2.62 & 2.81 & 2.98 & 3.03 & 2.81 & 2.73 & 2.93 & 3.26 & 2.69 & 2.57 & 1.94 & 3.30 & 2.93 & 2.63 & 2.57 & 2.91 & 2.19 & 2.93 & 3.10 \\
\hline $\mathrm{Na}$ & 0.99 & 0.82 & 1.03 & 0.98 & 0.97 & 1.13 & 1.21 & 1.03 & 0.76 & 1.27 & 1.30 & 1.78 & 0.75 & 0.97 & 1.27 & 1.42 & 1.08 & 1.66 & 1.05 & 0.85 \\
\hline $\mathbf{K}$ & 0.09 & 0.20 & 0.08 & 0.07 & 0.06 & 0.10 & 0.10 & 0.07 & 0.04 & 0.11 & 0.11 & 0.21 & 0.05 & 0.06 & 0.09 & 0.11 & 0.06 & 0.16 & 0.08 & 0.07 \\
\hline Toplam & 20.02 & 19.88 & 19.97 & 20.05 & 20.07 & 20.02 & 20.06 & 20.06 & 20.07 & 20.07 & 20.01 & 20.00 & 20.10 & 20.02 & 20.02 & 20.09 & 20.05 & 20.03 & 20.06 & 20.04 \\
\hline$\%$ An & 72.91 & 71.86 & 71.57 & 73.92 & 74.59 & 69.54 & 67.61 & 72.76 & 80.16 & 66.24 & 64.52 & 49.36 & 80.47 & 74.00 & 66.06 & 62.61 & 71.78 & 54.58 & 72.25 & 77.04 \\
\hline$\% \mathbf{A b}$ & 24.77 & 22.61 & 26.34 & 24.37 & 23.90 & 27.95 & 29.90 & 25.48 & 18.74 & 31.16 & 32.72 & 45.21 & 18.36 & 24.60 & 31.80 & 34.69 & 26.63 & 41.41 & 25.85 & 21.20 \\
\hline$\%$ Or & 2.32 & 5.54 & 2.08 & 1.71 & 1.51 & 2.50 & 2.49 & 1.76 & 1.10 & 2.60 & 2.76 & 5.43 & 1.18 & 1.40 & 2.14 & 2.70 & 1.59 & 4.01 & 1.90 & 1.76 \\
\hline
\end{tabular}


Ek Tablo 2'nin devamı

\begin{tabular}{|c|c|c|c|c|c|c|}
\hline Birim Ad & & & Bazalt & k dayk & & \\
\hline Örnek No I & $\mathrm{N}-5 \mathrm{c} 8$ & N-5 c8 & $\mathrm{N}-5$ c8 & $\mathrm{N}-5 \mathrm{c} 8$ & N-5 c10 I & $-5 \mathrm{c} 10$ \\
\hline & plaj-2 & plaj-2 & plaj-3 & plaj-3 & plaj-1 & plaj-1 \\
\hline & feno & feno & feno & feno & feno & feno \\
\hline & $\mathrm{m}$ & $\mathrm{k}$ & $\mathrm{m}$ & $\mathrm{k}$ & $\mathrm{m}$ & $\mathrm{k}$ \\
\hline $\mathrm{SiO}_{2}(\%)$ & 46.47 & 51.78 & 50.41 & 50.90 & 48.86 & 52.76 \\
\hline $\mathrm{Al}_{2} \mathbf{O}_{3}$ & 34.02 & 30.06 & 30.97 & 30.91 & 32.40 & 29.34 \\
\hline $\mathrm{FeO}^{*}$ & 0.78 & 0.65 & 0.70 & 0.69 & 0.68 & 0.64 \\
\hline $\mathrm{CaO}$ & 17.47 & 12.94 & 14.33 & 13.82 & 15.64 & 12.48 \\
\hline $\mathrm{Na}_{2} \mathrm{O}$ & 1.63 & 3.74 & 3.27 & 3.27 & 2.55 & 4.10 \\
\hline $\mathbf{K}_{2} \mathbf{O}$ & 0.13 & 0.50 & 0.36 & 0.37 & 0.26 & 0.54 \\
\hline Toplam & 100.50 & 99.67 & 100.03 & 99.96 & 100.39 & 99.86 \\
\hline $\mathbf{S i}$ & 8.54 & 9.47 & 9.22 & 9.30 & 8.94 & 9.61 \\
\hline $\mathbf{A l}(\mathbf{t})$ & 7.37 & 6.48 & 6.68 & 6.65 & 6.98 & 6.30 \\
\hline $\mathrm{Fe}^{+2}$ & 0.12 & 0.10 & 0.11 & 0.11 & 0.10 & 0.10 \\
\hline Ca & 3.44 & 2.53 & 2.81 & 2.70 & 3.07 & 2.44 \\
\hline $\mathbf{N a}$ & 0.58 & 1.33 & 1.16 & 1.16 & 0.90 & 1.45 \\
\hline $\mathbf{K}$ & 0.03 & 0.12 & 0.08 & 0.09 & 0.06 & 0.13 \\
\hline Toplam & 20.08 & 20.02 & 20.06 & 20.00 & 20.05 & 20.02 \\
\hline$\%$ An & 84.95 & 63.74 & 69.33 & 68.48 & 76.05 & 60.74 \\
\hline$\% \mathbf{A b}$ & 14.30 & 33.35 & 28.62 & 29.32 & 22.45 & 36.12 \\
\hline$\%$ Or & 0.75 & 2.92 & 2.05 & 2.21 & 1.50 & 3.14 \\
\hline
\end{tabular}


Ek Tablo 3. Kışlaköy (Erzurum-Narman) yöresi Eosen yaşlı volkanik kayaçlara ait olivin minerallerinin mikroprob analiz sonuçları.

\begin{tabular}{|c|c|c|c|c|c|c|c|c|c|c|c|c|c|c|c|c|c|c|c|c|}
\hline \multirow{5}{*}{$\begin{array}{l}\text { Birim Adı } \\
\text { Örnek No }\end{array}$} & \multicolumn{20}{|c|}{ Bazalt } \\
\hline & $\mathrm{N}-38 \mathrm{c} 1$ & $\mathrm{~N}-38 \mathrm{c} 1$ & $\mathrm{~N}-38 \mathrm{c} 2$ & $\mathrm{~N}-38 \mathrm{c} 2$ & & $\mathrm{~N}-38 \mathrm{c} 2$ & $\mathrm{~N}-38 \mathrm{c} 2$ & $\mathrm{~N}-38 \mathrm{c} 2$ & $\mathrm{~N}-38 \mathrm{c} 4$ & $4 \mathrm{~N}-38 \mathrm{c} 4$ & & $\mathrm{~N}-38$ c5 & $\mathrm{N}-38 \mathrm{c} 6$ & $\mathrm{~N}-38 \mathrm{c} 6$ & & & $\mathrm{~N}-38 \mathrm{c} 7$ & $\mathrm{~N}-38 \mathrm{c} 7$ & & $\mathrm{~J}-38 \mathrm{c} 8$ \\
\hline & ol1 & ol1 & ol1 & ol1 & ol2 & ol2 & ol3 & ol3 & ol1 & ol1 & ol2 & ol1 & ol1 & ol1 & ol2 & ol2 & ol1 & ol1 & ol1 & ol1 \\
\hline & feno & feno & feno & feno & feno & feno & feno & feno & feno & feno & feno & & feno & feno & feno & feno & feno & feno & feno & feno \\
\hline & $\mathrm{m}$ & $\mathrm{k}$ & $\mathrm{m}$ & $\mathrm{k}$ & $\mathrm{m}$ & $\mathrm{k}$ & $\mathrm{m}$ & $\mathrm{k}$ & $\mathrm{m}$ & $\mathrm{k}$ & $\mathrm{m}$ & $\mathrm{m}$ & $\mathrm{m}$ & $\mathrm{k}$ & $\mathrm{m}$ & $\mathrm{k}$ & $\mathrm{m}$ & $\mathrm{k}$ & $\mathrm{m}$ & $\mathrm{k}$ \\
\hline $\mathrm{SiO}_{2}(\%)$ & 39.65 & 37.84 & 40.06 & 38.45 & 40.22 & 38.74 & 40.19 & 39.85 & 40.09 & 37.42 & 39.77 & 39.87 & 41.16 & 38.80 & 40.98 & 39.47 & 39.05 & 38.13 & 39.96 & 37.94 \\
\hline $\mathrm{TiO}_{2}$ & 0.00 & 0.06 & 0.00 & 0.00 & 0.00 & 0.00 & 0.00 & 0.00 & 0.00 & 0.00 & 0.00 & 0.00 & 0.01 & 0.00 & 0.00 & 0.00 & 0.00 & 0.00 & 0.00 & 0.00 \\
\hline $\mathbf{A l}_{2} \mathbf{O}_{3}$ & 0.01 & 0.04 & 0.03 & 0.05 & 0.02 & 0.04 & 0.06 & 0.09 & 0.02 & 0.02 & 0.04 & 0.04 & 0.04 & 0.04 & 0.05 & 0.02 & 0.02 & 0.07 & 0.01 & 0.03 \\
\hline $\mathrm{Cr}_{2} \mathrm{O}_{3}$ & 0.00 & 0.00 & 0.01 & 0.01 & 0.00 & 0.08 & 0.00 & 0.00 & 0.01 & 0.00 & 0.01 & 0.00 & 0.04 & 0.00 & 0.04 & 0.00 & 0.00 & 0.00 & 0.00 & 0.00 \\
\hline $\mathrm{FeO}$ & 16.21 & 24.73 & 14.97 & 22.65 & 13.85 & 18.84 & 13.87 & 16.14 & 13.57 & 25.82 & 16.70 & 17.76 & 8.53 & 20.55 & 10.79 & 18.73 & 19.13 & 24.09 & 15.95 & 25.76 \\
\hline MnO & 0.24 & 0.48 & 0.26 & 0.41 & 0.24 & 0.36 & 0.26 & 0.26 & 0.25 & 0.54 & 0.25 & 0.31 & 0.09 & 0.42 & 0.14 & 0.34 & 0.32 & 0.46 & 0.30 & 0.55 \\
\hline MgO & 43.11 & 36.52 & 44.10 & 38.70 & 44.93 & 40.80 & 44.84 & 43.53 & 45.34 & 35.74 & 42.87 & 42.33 & 49.34 & 39.83 & 47.65 & 41.27 & 41.51 & 38.02 & 43.96 & 35.85 \\
\hline $\mathrm{NiO}$ & 0.22 & 0.21 & 0.25 & 0.16 & 0.26 & 0.21 & 0.19 & 0.22 & 0.29 & 0.13 & 0.27 & 0.18 & 0.44 & 0.26 & 0.31 & 0.15 & 0.25 & 0.14 & 0.20 & 0.16 \\
\hline $\mathrm{CaO}$ & 0.33 & 0.24 & 0.21 & 0.28 & 0.23 & 0.30 & 0.27 & 0.19 & 0.28 & 0.24 & 0.23 & 0.22 & 0.10 & 0.23 & 0.12 & 0.25 & 0.23 & 0.25 & 0.25 & 0.25 \\
\hline Toplam & 99.78 & 100.12 & 99.90 & 100.71 & 99.75 & 99.36 & 99.69 & 100.30 & 99.86 & 99.91 & 100.14 & 100.69 & 99.75 & 100.13 & 100.07 & 100.23 & 100.50 & 101.17 & 100.63 & 100.54 \\
\hline $\mathrm{Si}$ & 1.00 & 1.00 & 1.01 & 1.00 & 1.01 & 1.00 & 1.01 & 1.00 & 1.00 & 0.99 & 1.01 & 1.01 & 1.01 & 1.00 & 1.01 & 1.01 & 1.00 & 0.99 & 1.00 & 1.00 \\
\hline $\mathbf{T i}$ & 0.00 & 0.00 & 0.00 & 0.00 & 0.00 & 0.00 & 0.00 & 0.00 & 0.00 & 0.00 & 0.00 & 0.00 & 0.00 & 0.00 & 0.00 & 0.00 & 0.00 & 0.00 & 0.00 & 0.00 \\
\hline Al & 0.00 & 0.00 & 0.00 & 0.00 & 0.00 & 0.00 & 0.00 & 0.00 & 0.00 & 0.00 & 0.00 & 0.00 & 0.00 & 0.00 & 0.00 & 0.00 & 0.00 & 0.00 & 0.00 & 0.00 \\
\hline $\mathrm{Cr}$ & 0.00 & 0.00 & 0.00 & 0.00 & 0.00 & 0.00 & 0.00 & 0.00 & 0.00 & 0.00 & 0.00 & 0.00 & 0.00 & 0.00 & 0.00 & 0.00 & 0.00 & 0.00 & 0.00 & 0.00 \\
\hline Fe(ii) & 0.34 & 0.54 & 0.31 & 0.49 & 0.29 & 0.41 & 0.29 & 0.34 & 0.28 & 0.57 & 0.35 & 0.37 & 0.17 & 0.44 & 0.22 & 0.40 & 0.41 & 0.52 & 0.33 & 0.57 \\
\hline Mn & 0.01 & 0.01 & 0.01 & 0.01 & 0.01 & 0.01 & 0.01 & 0.01 & 0.01 & 0.01 & 0.01 & 0.01 & 0.00 & 0.01 & 0.00 & 0.01 & 0.01 & 0.01 & 0.01 & 0.01 \\
\hline Mg & 1.63 & 1.43 & 1.65 & 1.49 & 1.68 & 1.57 & 1.68 & 1.63 & 1.69 & 1.42 & 1.62 & 1.59 & 1.80 & 1.53 & 1.75 & 1.57 & 1.58 & 1.47 & 1.64 & 1.41 \\
\hline $\mathrm{Ni}$ & 0.00 & 0.00 & 0.01 & 0.00 & 0.01 & 0.00 & 0.00 & 0.00 & 0.01 & 0.00 & 0.01 & 0.00 & 0.01 & 0.01 & 0.01 & 0.00 & 0.01 & 0.00 & 0.00 & 0.00 \\
\hline Ca & 0.01 & 0.01 & 0.01 & 0.01 & 0.01 & 0.01 & 0.01 & 0.01 & 0.01 & 0.01 & 0.01 & 0.01 & 0.00 & 0.01 & 0.00 & 0.01 & 0.01 & 0.01 & 0.01 & 0.01 \\
\hline TOTAL & 3.00 & 3.00 & 2.99 & 3.00 & 2.99 & 3.00 & 2.99 & 3.00 & 3.00 & 3.01 & 2.99 & 2.99 & 2.99 & 3.00 & 2.99 & 2.99 & 3.00 & 3.01 & 3.00 & 3.00 \\
\hline Mg \# & 0.83 & 0.72 & 0.84 & 0.75 & 0.85 & 0.79 & 0.85 & 0.83 & 0.86 & 0.71 & 0.82 & 0.81 & 0.91 & 0.78 & 0.89 & 0.80 & 0.79 & 0.74 & 0.83 & 0.71 \\
\hline Fo & 82.37 & 72.08 & 83.77 & 74.95 & 85.03 & 79.11 & 84.97 & 82.55 & 85.40 & 70.74 & 81.85 & 80.68 & 91.08 & 77.20 & 88.60 & 79.41 & 79.18 & 73.40 & 82.83 & 70.84 \\
\hline $\mathbf{F a}$ & 17.37 & 27.38 & 15.95 & 24.60 & 14.70 & 20.49 & 14.74 & 17.17 & 14.34 & 28.66 & 17.88 & 18.98 & 8.83 & 22.34 & 11.26 & 20.22 & 20.46 & 26.09 & 16.86 & 28.54 \\
\hline
\end{tabular}


Ek Tablo 3'ün devamı

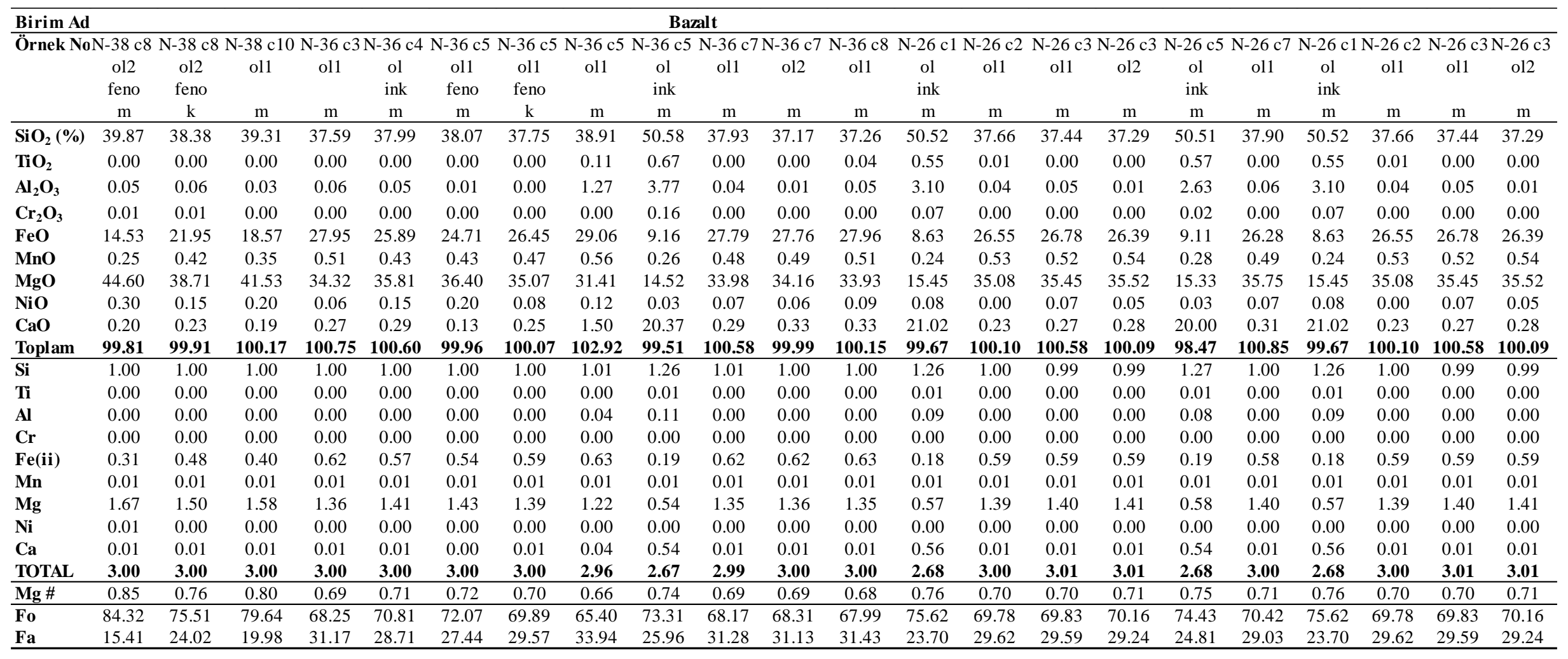


Ek Tablo 3'ün devamı

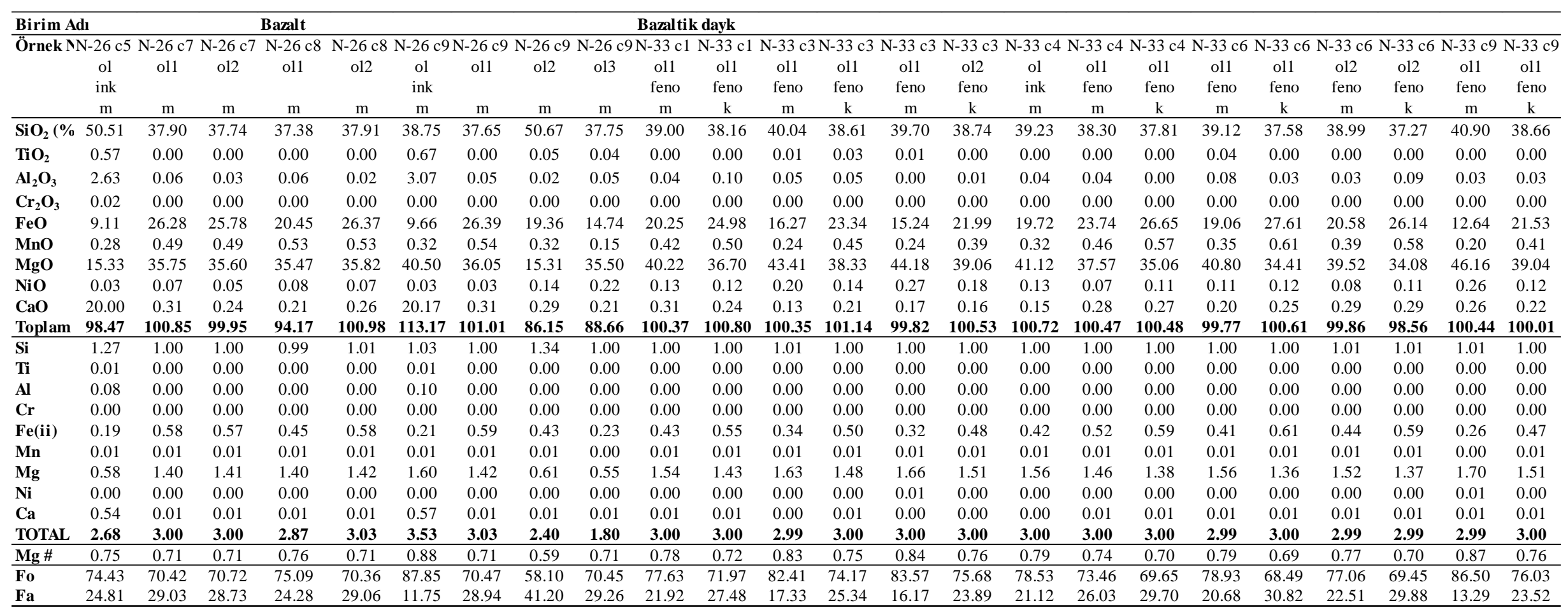


Ek Tablo 4. Kışlaköy (Erzurum-Narman) yöresi Eosen yaşlı volkanik kayaçlara ait Fe-Ti oksit minerallerinin mikroprob analiz sonuçları

\begin{tabular}{|c|c|c|c|c|c|c|c|c|c|c|c|c|c|c|c|c|c|}
\hline \multirow{2}{*}{$\begin{array}{l}\text { Birim Adı } \\
\text { Örnek No }\end{array}$} & \multicolumn{17}{|c|}{ Bazalt } \\
\hline & $\begin{array}{c}\mathrm{N}-36 \text { c8 } \\
\text { opak-1 }\end{array}$ & $\begin{array}{c}\mathrm{N}-36 \mathrm{c} 8 \\
\text { opak-2 }\end{array}$ & $\begin{array}{c}\mathrm{N}-36 \mathrm{c} 8 \\
\text { opak-3 }\end{array}$ & $\begin{array}{c}\text { N-36 c10 } \\
\text { opak-4 }\end{array}$ & $\begin{array}{c}\text { N-20 c1 } \\
\text { opak-1 }\end{array}$ & $\begin{array}{c}\text { N-20 c4 } \\
\text { opak-1 } \\
\text { kpir-1 içinde }\end{array}$ & $\begin{array}{c}\text { N-20 c7 } \\
\text { opak-2 }\end{array}$ & $\begin{array}{c}\mathrm{N}-20 \mathrm{c} 7 \\
\text { opak-3 }\end{array}$ & $\begin{array}{c}\mathrm{N}-20 \mathrm{c} 7 \\
\text { opak-4 }\end{array}$ & $\begin{array}{c}\mathrm{N}-20 \mathrm{c} 8 \\
\text { opak-5 }\end{array}$ & $\begin{array}{c}\text { N-26 } \\
\text { opak-1 }\end{array}$ & $\begin{array}{c}\text { N-26 c4 } \\
\text { opak-2 }\end{array}$ & $\begin{array}{c}\mathrm{N}-26 \mathrm{c} 4 \\
\text { opak-1 } \\
\text { kpir-1 içinde } \\
\end{array}$ & $\begin{array}{c}\text { N-26 c6 } \\
\text { opak-3 }\end{array}$ & $\begin{array}{c}\text { N-26 c7 } \\
\text { opak-1 } \\
\text { kpir-2 içinde }\end{array}$ & $\begin{array}{c}\mathrm{N}-26 \mathrm{c} 9 \\
\text { opak-1 } \\
\text { kpir-1 içinde } \\
\end{array}$ & $\begin{array}{c}\text { N-26 c9 } \\
\text { opak-1 } \\
\text { ol-1 içinde }\end{array}$ \\
\hline $\mathrm{SiO}_{2}$ & 0.19 & 0.17 & 0.26 & 0.24 & 0.08 & 0.14 & 0.02 & 0.02 & 0.10 & 0.05 & 0.15 & 0.14 & 0.18 & 0.09 & 0.12 & 0.41 & 0.08 \\
\hline $\mathrm{TiO}_{2}$ & 18.64 & 18.66 & 18.17 & 16.95 & 1.22 & 3.12 & 1.32 & 46.53 & 1.19 & 1.15 & 11.41 & 12.67 & 9.38 & 14.20 & 9.30 & 6.28 & 9.36 \\
\hline $\mathbf{A l}_{2} \mathbf{O}_{3}$ & 1.79 & 1.91 & 1.74 & 1.82 & 2.16 & 3.34 & 2.02 & 0.90 & 1.86 & 2.04 & 3.95 & 4.09 & 5.21 & 3.12 & 5.70 & 8.49 & 5.40 \\
\hline $\mathrm{Cr}_{2} \mathrm{O}_{3}$ & 0.02 & 0.03 & 0.03 & 0.04 & 0.33 & 0.93 & 0.28 & 0.03 & 0.09 & 0.44 & 0.84 & 0.96 & 0.74 & 1.27 & 0.58 & 0.79 & 0.78 \\
\hline FeO & 73.76 & 74.29 & 74.56 & 75.89 & 86.36 & 81.35 & 84.32 & 43.76 & 85.62 & 85.34 & 75.46 & 73.96 & 75.44 & 73.93 & 74.73 & 72.71 & 74.29 \\
\hline MnO & 0.54 & 0.61 & 0.71 & 0.51 & 0.83 & 0.96 & 0.70 & 0.10 & 0.61 & 0.69 & 0.43 & 0.40 & 0.35 & 0.52 & 0.38 & 0.51 & 0.40 \\
\hline MgO & 0.69 & 0.65 & 0.51 & 0.52 & 1.03 & 1.14 & 3.13 & 3.58 & 2.60 & 3.22 & 1.94 & 2.48 & 2.52 & 1.50 & 3.39 & 4.15 & 3.39 \\
\hline $\mathrm{CaO}$ & 0.09 & 0.06 & 0.11 & 0.14 & 0.07 & 0.06 & 0.06 & 0.04 & 0.10 & 0.02 & 0.02 & 0.04 & 0.07 & 0.08 & 0.11 & 0.14 & 0.02 \\
\hline Toplam & 95.77 & 96.47 & 96.15 & 96.22 & 92.18 & 91.13 & 91.98 & 94.97 & 92.26 & 93.02 & 94.20 & 94.78 & 93.90 & 94.75 & 94.41 & 93.52 & 93.78 \\
\hline $\mathrm{Si}$ & 0.06 & 0.05 & 0.08 & 0.07 & 0.02 & 0.04 & 0.01 & 0.01 & 0.03 & 0.01 & 0.04 & 0.04 & 0.05 & 0.03 & 0.03 & 0.12 & 0.02 \\
\hline $\mathrm{Ti}$ & 4.23 & 4.20 & 4.11 & 3.82 & 0.28 & 0.72 & 0.30 & 10.75 & 0.27 & 0.26 & 2.55 & 2.83 & 2.10 & 3.17 & 2.08 & 1.40 & 2.09 \\
\hline Al & 0.64 & 0.68 & 0.62 & 0.64 & 0.78 & 1.22 & 0.72 & 0.33 & 0.66 & 0.72 & 1.38 & 1.43 & 1.82 & 1.09 & 2.00 & 2.97 & 1.89 \\
\hline $\mathrm{Cr}$ & 0.00 & 0.01 & 0.01 & 0.01 & 0.08 & 0.23 & 0.07 & 0.01 & 0.02 & 0.10 & 0.20 & 0.23 & 0.17 & 0.30 & 0.14 & 0.18 & 0.18 \\
\hline $\mathbf{V}$ & 0.00 & 0.00 & 0.00 & 0.00 & 0.00 & 0.00 & 0.00 & 0.00 & 0.00 & 0.00 & 0.00 & 0.00 & 0.00 & 0.00 & 0.00 & 0.00 & 0.00 \\
\hline Fe(iii) & 6.79 & 6.81 & 7.00 & 7.55 & 14.53 & 13.02 & 14.60 & 0.00 & 14.71 & 14.63 & 8.17 & 8.69 & 8.68 & 7.91 & 9.42 & 10.12 & 9.00 \\
\hline Fe(ii) & 11.81 & 11.79 & 11.74 & 11.49 & 7.60 & 7.97 & 6.70 & 0.00 & 6.94 & 6.66 & 10.59 & 9.70 & 10.07 & 10.47 & 9.16 & 7.96 & 9.47 \\
\hline Mn & 0.14 & 0.16 & 0.18 & 0.13 & 0.22 & 0.25 & 0.18 & 0.02 & 0.16 & 0.17 & 0.11 & 0.10 & 0.09 & 0.13 & 0.10 & 0.13 & 0.10 \\
\hline Mg & 0.31 & 0.29 & 0.23 & 0.23 & 0.47 & 0.53 & 1.41 & 1.64 & 1.17 & 1.43 & 0.86 & 1.10 & 1.12 & 0.67 & 1.50 & 1.84 & 1.50 \\
\hline $\mathrm{Ca}$ & 0.03 & 0.02 & 0.04 & 0.05 & 0.02 & 0.02 & 0.02 & 0.01 & 0.03 & 0.01 & 0.01 & 0.01 & 0.02 & 0.03 & 0.03 & 0.05 & 0.01 \\
\hline Toplam & 24 & 24 & 24 & 24 & 24 & 24 & 24 & 24 & 24 & 24 & 24 & 24 & 24 & 24 & 24 & 25 & 24 \\
\hline
\end{tabular}

$\mathrm{Fe}+2$ ve Fe+3 ayrımı stokiometrik olarak hesaplanmıştır. Formül 32 oksijen üzerinden hesaplanmıştır. 
Ek Tablo 4'ün devamı

\begin{tabular}{|c|c|c|c|c|c|c|c|c|c|c|c|c|}
\hline Birim Adı & & & & & & Bazalti & k dayk & & & & & \\
\hline Örnek No & $\begin{array}{c}\mathrm{N}-33 \mathrm{c} 2 \\
\text { opak-1 }\end{array}$ & $\begin{array}{c}\mathrm{N}-33 \mathrm{c} 2 \\
\text { opak-2 }\end{array}$ & $\begin{array}{c}\mathrm{N}-33 \mathrm{c} 2 \\
\text { opak-3 }\end{array}$ & $\begin{array}{c}\mathrm{N}-33 \mathrm{c} 2 \\
\text { opak-4 }\end{array}$ & $\begin{array}{l}\mathrm{N}-5 \mathrm{c} 1 \\
\text { opak-1 }\end{array}$ & $\begin{array}{c}\mathrm{N}-5 \mathrm{c} 2 \\
\text { opak-1 } \\
\text { kpir-1 içinde }\end{array}$ & $\begin{array}{c}\mathrm{N}-5 \text { c4 } \\
\text { opak-1 } \\
\text { kpir içinde }\end{array}$ & $\begin{array}{l}\text { N-5 c4 } \\
\text { opak-2 }\end{array}$ & $\begin{array}{c}\text { N-5 c5 } \\
\text { opak- }\end{array}$ & $\begin{array}{l}\text { N-5 c5 } \\
\text { opak-3 }\end{array}$ & $\begin{array}{l}\text { N-5 c6 } \\
\text { opak-4 }\end{array}$ & $\begin{array}{c}\mathrm{N}-5 \text { c9 } \\
\text { opak-1 } \\
\text { kpir-3 içinde }\end{array}$ \\
\hline $\mathrm{SiO}_{2}$ & 0.06 & 0.09 & 0.05 & 0.07 & 0.12 & 0.11 & 0.06 & 0.15 & 0.07 & 0.17 & 0.09 & 0.10 \\
\hline $\mathrm{TiO}_{2}$ & 11.01 & 12.69 & 10.73 & 14.01 & 15.99 & 9.57 & 9.82 & 17.41 & 12.20 & 16.18 & 16.29 & 12.57 \\
\hline $\mathbf{A l}_{2} \mathbf{O}_{3}$ & 2.33 & 1.73 & 2.33 & 2.29 & 2.74 & 3.39 & 2.70 & 2.17 & 2.05 & 2.54 & 2.49 & 2.98 \\
\hline $\mathrm{Cr}_{2} \mathrm{O}_{3}$ & 0.03 & 0.05 & 0.05 & 0.02 & 0.09 & 0.99 & 1.90 & 0.10 & 0.62 & 0.17 & 0.11 & 0.57 \\
\hline $\mathrm{FeO}$ & 79.92 & 78.77 & 80.74 & 76.29 & 72.86 & 74.79 & 74.50 & 71.45 & 75.20 & 72.52 & 73.44 & 73.27 \\
\hline MnO & 0.45 & 0.55 & 0.34 & 0.54 & 0.58 & 0.59 & 0.47 & 1.31 & 0.46 & 0.58 & 0.61 & 0.52 \\
\hline MgO & 1.08 & 0.93 & 0.82 & 1.85 & 1.98 & 3.14 & 4.03 & 0.84 & 3.58 & 2.09 & 1.89 & 3.79 \\
\hline $\mathrm{CaO}$ & 0.02 & 0.05 & 0.08 & 0.02 & 0.00 & 0.17 & 0.11 & 0.05 & 0.06 & 0.02 & 0.04 & 0.05 \\
\hline Toplam & 94.92 & 94.96 & 95.21 & 95.21 & 94.36 & 92.83 & 93.61 & 93.49 & 94.41 & 94.32 & 95.10 & 93.99 \\
\hline Si & 0.02 & 0.03 & 0.01 & 0.02 & 0.04 & 0.03 & 0.02 & 0.05 & 0.02 & 0.05 & 0.03 & 0.03 \\
\hline Ti & 2.49 & 2.88 & 2.42 & 3.15 & 3.62 & 2.16 & 2.19 & 4.03 & 2.72 & 3.66 & 3.67 & 2.80 \\
\hline Al & 0.83 & 0.61 & 0.82 & 0.80 & 0.97 & 1.20 & 0.94 & 0.79 & 0.72 & 0.90 & 0.88 & 1.04 \\
\hline $\mathrm{Cr}$ & 0.01 & 0.01 & 0.01 & 0.01 & 0.02 & 0.23 & 0.45 & 0.03 & 0.15 & 0.04 & 0.03 & 0.13 \\
\hline V & 0.00 & 0.00 & 0.00 & 0.00 & 0.00 & 0.00 & 0.00 & 0.00 & 0.00 & 0.00 & 0.00 & 0.00 \\
\hline Fe(iii) & 10.16 & 9.56 & 10.29 & 8.85 & 7.70 & 10.18 & 10.19 & 7.04 & 9.64 & 7.63 & 7.71 & 9.16 \\
\hline Fe(ii) & 9.90 & 10.33 & 9.96 & 10.20 & 10.62 & 8.58 & 8.28 & 11.33 & 9.03 & 10.62 & 10.69 & 9.01 \\
\hline Mn & 0.11 & 0.14 & 0.09 & 0.14 & 0.15 & 0.15 & 0.12 & 0.34 & 0.12 & 0.15 & 0.15 & 0.13 \\
\hline Mg & 0.48 & 0.42 & 0.37 & 0.82 & 0.89 & 1.41 & 1.78 & 0.39 & 1.58 & 0.94 & 0.85 & 1.68 \\
\hline Ca & 0.01 & 0.02 & 0.03 & 0.01 & 0.00 & 0.05 & 0.04 & 0.02 & 0.02 & 0.01 & 0.01 & 0.02 \\
\hline Toplam & 24 & 24 & 24 & 24 & 24 & 24 & 24 & 24 & 24 & 24 & 24 & 24 \\
\hline
\end{tabular}

